\title{
Simulação perfeita de processos de nascimento e morte espaciais
}

\author{
Marcos Antonio da Cunha Santos
}

Orientador:

Prof. Dr. Pablo Augusto Ferrari

Tese apresentada ao Instituto de Matemática e Estatística da Universidade de São Paulo, como parte dos requisitos para obtenção do grau de Doutor em Estatística. Área de concentração: Probabilidade.

\author{
USP - São Paulo \\ Outubro de 2004
}

Durante a realização deste trabalho o autor contou com o auxílio financeiro da CAPES. 
Este exemplar corresponde à redação final da tese de doutorado devidamente corrigida, defendida por Marcos Antonio da Cunha Santos e aprovada pela banca examinadora.

São Paulo, 26 de novembro de 2004.

Banca Examinadora:

- Prof. Dr. Pablo Augusto Ferrari - IME-USP (Presidente)

- Prof.Dr. Yoshiharu Kohayakawa - IME-USP

- Prof. Dr. Mario José de Oliveira - IF-USP

- Prof. Dr. Domingos Humberto Urbano Marchetti - IF-USP

- Profa. Dra. Nancy Lopes Garcia - UNICAMP 


\section{Agradecimentos}

- Meu agradecimento ao Prof. Pablo Augusto Ferrari, pela orientação, incentivo e discussões;

- a todos os meus colegas do IME-USP, em especial a Adriano Siqueira, Geraldine Góes Bosco, Fernando Pigeard, Nevena Maric e Thomas Ritchie pela amizade, solidariedade e clima de discussão científica;

- aos professores do IME-USP de modo geral, em especial a Fabio Prates Machado, Elisabeti Kira e Vladimir Belitsky pela disponibilidade em diversas ocasiões;

- ao Prof. Antonio Galves, pelo apoio e incentivo durante o doutorado no $I M E$;

- a Renato Assunção e Francisco Soares, do departamento de Estatística da $U F M G$, pelo incentivo. 


\section{Resumo}

Apresentamos um método que permite enumerar subconjuntos de contornos de Peierls (também denominados animals) no modelo de Ising ferromagnético em baixas temperaturas em uma rede quadrada. Um amostrador exato para os contornos de Peierls é apresentado. Apresentamos também um algoritmo dinâmico, baseado no MCMC, para amostrar tais objetos. Como aplicação, consideramos a medida de Gibbs expressa em termos dos contornos para simular pela primeira vez o modelo de Ising em baixas temperaturas, de acordo com o "Backward Forward Algorithm", proposto recentemente por Ferrari, Fernández and Garcia [3]. Este algoritmo permite obter amostras perfeitas em janelas finitas de medidas em volume infinito e é válido para medidas absolutamente contínuas em relação a um processo de Poisson. Um modo alternativo de simular este processo no contexto do BFA também é apresentado. 


\section{Abstract}

We present a method to enumerate subsets of Peierls contours (also called animals) in the Ising ferromagnetic model at low temperature on the square lattice. An exact sampler for Peierls contours is presented. We present also a dynamic MCMC based algorithm to sampler these objects. As an application, we consider the Gibb's measure expressed in terms of Peierls contours in order to simulate, for the first time, the Ising model at low temperature according to the perfect simulation scheme "Backward Forward Algorithm", proposed recently by Ferrari, Fernández and Garcia [3]. This algorithm provides perfect samples of finite windows of the infinite-volume measures and is valid for measures that are absolutely continuous with respect to some Poisson processes. An alternative way to simulate the target process in the BFA context is also presented. 


\section{Índice}

1 O Método dos Contornos 2

1.1 Introdução . . . . . . . . . . . . . . . . . . . . . 2

1.1.1 O modelo de Ising e o método dos contornos . . . . . . . . . . 2

1.1.2 Processos de nascimento e morte espaciais . . . . . . . . . . 5

1.1.3 Simulação Perfeita de Processos Espaciais . . . . . . . . . . . 6

1.1.4 O modelo de Ising e a simulação via método dos contornos . . 7

2 Enumeração dos contornos de Peierls 10

2.1 Sistema de contornos . . . . . . . . . . . . . . . . . . 10

2.2 Enumeração de contornos em $\mathbb{Z}^{2} \ldots \ldots$. . . . . . . . . . . . . 12

2.2.1 Enumeração de algumas classes de objetos . . . . . . . . . . . 12

2.2.2 Enumeração de contornos de Peierls . . . . . . . . . . . . . . 15

2.3 Amostragem . . . . . . . . . . . . . . . . . . . . 20

2.3 .1 Introdução . . . . . . . . . . . . . . . . . . . 20

2.3.2 Um amostrador exato para os contornos de Peierls . . . . . . 21

2.3.3 Amostra em função de $\beta$. . . . . . . . . . . . . . . . . . . 29

3 Método dinâmico para a geração de contornos de Peierls 32

3.1 MCMC . . . . . . . . . . . . . . . . . . . . . 32

3.2 MCMC para contornos de Peierls . . . . . . . . . . . . . . . . 34

3.2 .1 Alguns aspectos relacionados à convergência . . . . . . . . . . 39

3.2 .2 Geração de estados . . . . . . . . . . . . . . . . . . . . 40

3.3 Acoplamento . . . . . . . . . . . . . . . . . . . 42

4 Simulação perfeita de um processo espacial de nascimento e morte 46

4.1 O Backward Forward Algorithm . . . . . . . . . . . . . . . . . . . 46 
4.1 .1 Introdução . . . . . . . . . . . . . . . . . . . . 46

4.1.2 O BFA para o modelo de Ising ferromagnético . . . . . . . . . 47

4.1 .3 Simulação da rede com perdas . . . . . . . . . . . . . 50

4.1 .4 Simulação com tipos de cilindros . . . . . . . . . . . . . 52

4.1.5 Uma contrução gráfica para o processo infinito . . . . . . . . . 57

4.2 Resultados . . . . . . . . . . . . . . . . . . . 61

$\begin{array}{ll}\text { Bibliografia } & 71\end{array}$ 


\section{Lista de Figuras}

2.1 Exemplo de um contorno de Peierls que apresenta somente curvas válidas . 12

2.2 Em um vértice, os estados dos elos 1 e 2 formam a entrada $i_{1} i_{2}$ respecti-

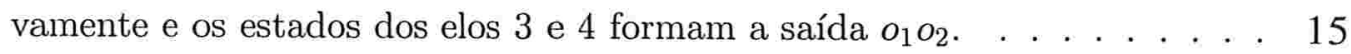

2.3 Um polígono parcialmente construído, escolhendo-se os estados dos elos da esquerda para a direita e do topo para a base, até o vértice assinalado. Os números mostram a configuração parcial $\{2201 \ldots\}$ da última coluna em construção. . . . . . . . . . . . . . . . . . . . . . . . . 17

2.4 Regras de transição para os contornos de Peierls de acordo com a Tabela 1. Os números representam os estados dos quatro elos na rede dual adjacentes a um vértice. Para maior clareza somente as curvas válidas formadas pelos elos estão desenhadas. Os estados dos elos horizontais à esquerda e vertical superior na figura formam a "entrada"; os estados dos elos vertical inferior e horizontal à direita formam a "saída". . . . . . . . . . . . . . . . . . . . . 19

2.5 Recodificação do estado de conectividade da figura. Em (a) uma configuração de coluna 2200...11 (lida do topo para a base) que corresponde a dois laços aninhados à esquerda; (b) a recodificação necessária quando a parte inferior do laço externo é conectado à parte inferior do outro. . . . . . 19

2.6 Exemplo da formação de um polígono conforme o algoritmo proposto. Em (a) a configuração $\{2001\}$ é escolhida para a última coluna à direita; as demais colunas são escolhidas sucessivamente da esquerda para a direita. Em (d) os elos verticais necessários para conectar o contorno são adicionados. 31

3.1 Exemplo de transição por pivotamento. . . . . . . . . . . . . . . . . . . . 34

3.2 Exemplo de transição por troca de configuração de coluna, com a troca $\{0021\} \rightarrow\{2010\}$ na terceira coluna. . . . . . . . . . . 36 
3.3 Exemplo de obtenção de um contorno verticalmente convexo a partir de um contorno com laços internos. Em (a) o contorno apresenta um laço aninhado "21" a partir da terceira coluna; o laço é removido em dois passos, trocando-se as configurações da terceira e da quarta coluna. Em (b) os pares remanescentes " 12 "são removidos por sucessivas trocas de configurações de colunas. . . . . . . . . . . . . . . . . . . . 38

3.4 Exemplo de geração de contornos de Peierls em retângulo com $12 \times 15$ células, via MCMC. Em (a) $\beta=0,5$ e 12000 iterações; (b) $\beta=0,3$ e 3000 iterações; (c) $\beta=0,1$ e 1000 iterações. Os contornos foram gerados com a restrição de tocarem os limites do retângulo. . . . . . . . . . . . 38

3.5 Os estados $i_{1}, i_{2}$ dos dois elos adjacentes ao vértice formam a "entrada"; os estados $o_{1}, o_{2}$ formam a "saída". . . . . . . . . . . . . . . . . 41

3.6 Exemplo de acoplamento de duas cadeias com transições dadas pelo algoritmo proposto, em um retângulo com $8 \times 8$ células e $\beta=0,1$. Em (a) os estados iniciais. (b) Estados após algumas dezenas de passos e (c) configurações com o processo interrompido após 6400 passos $(T<6400)$. . . . . " 4

4.1 Em (a) um conjunto de marcas tipo 1 associadas a um processo pontual de Poisson em duas dimensões. Em (b) a mesma configuração, vista de modo alternativo como a realização de um processo de Poisson no interior de $\Lambda$ para marcas tipo 1,2 e $3 \ldots \ldots . \ldots . \ldots 51$

4.2 Em (a) um conjunto de marcas tipo 1 associados a pontos de um processo de Poisson. . . . . . . . . . . . . . . . . . . . 56 56

4.3 Simulação para uma rede $50 \times 50, \beta=0.56$. A figura à esquerda é o processo livre; à direita após o refinamento. . . . . . . . . . . . . . 62

4.4 Magnetização $M$ para uma grade $100 \times 100$ em função de $\beta$. Cada ponto assinalado é a média de 1000 simulações obtidas com o algoritmo A2; a linha corresponde aos valores teóricos. . . . . . . . . . . . . . 63 


\section{Capítulo 1}

\section{O Método dos Contornos}

\subsection{Introdução}

Avanços recentes no estudo de processos espaciais de nascimento e morte tem motivado o interesse no desenvolvimento de algoritmos eficientes para simulação perfeita de processos deste tipo. Recentemente foram dadas condições suficientes para a existência desses processos usando uma construção gráfica espaço-temporal [1]. Um caso particular de um processo espacial de nascimento e morte é a rede com perdas. Este processo apresenta uma interessante conexão com o modelo de Ising para o caso ferromagnético a baixas temperaturas. Neste capítulo apresentaremos as idéias básicas envolvidas na simulação de processos desta natureza e os problemas relacionados que motivaram este trabalho.

\subsubsection{O modelo de Ising e o método dos contornos}

Seja o espaço $\Omega=\Omega_{0}^{\mathbb{Z}^{d}}$, onde $\Omega_{0}$ é um conjunto finito de possíveis estados associados a um objeto. Usaremos o termo rede $d$-dimensional ao grafo associado de modo usual ao conjunto $\mathbb{Z}^{d}$. No modelo de Ising ferromagnético, $\Omega_{0}=\{-1,+1\}$ e os objetos são denominados de spins.

Seja $\Lambda \subset \mathbb{Z}^{d}$ um conjunto finito e $\sigma \in\{-1,+1\}^{\Lambda}$. O modelo de Ising atribui para o volume $\Lambda$ e $\beta \geq 0$ a distribuição de probabilidade

$$
\mu_{\Lambda}^{\beta}(\sigma)=\frac{1}{Z_{\Lambda}^{\beta}} e^{-\beta H(\sigma, \Lambda)}
$$


onde

$$
H(\sigma, \Lambda)=-\sum_{i<j \in \Lambda} \alpha_{i j} \sigma(i) \sigma(j)+\sum_{i \in \Lambda} h_{i} \sigma(i)
$$

é o Hamiltoniano ou função energia, $Z_{\Lambda}$ é a constante de normalização, $h_{i}$ o valor do campo externo e $\alpha_{i j}$ o peso da interação entre os pares de spins $i, j$. No modelo de Ising considerado neste trabalho cada spin interage somente com os spins mais próximos: $\alpha_{i j}=1$ se $|i-j|=1$ e $\alpha_{i j}=0$ para os demais pares $i, j$. Consideraremos ainda que não há a presença de campo externo $\left(h_{i} \equiv 0\right)$.

A medida 1.1 pode ser expressa de uma outra maneira, como a medida de uma configuração de contornos. Uma definição de contornos para dimensão $d \geq 1$, pode ser vista em Fernandez, Ferrari e Garcia [2]. Neste trabalho consideraremos apenas o caso $d=2$. Neste caso os contornos são curvas fechadas, formadas por linhas verticais e horizontais de comprimento unitário que separam as regiões de spins "+"das regiões de spins "-". Estas linhas são denominadas elos. Se fixarmos a condição de fronteira $\sigma=+1$ (ou $\sigma=-1$ ) fora de $\Lambda$, pode ser demonstrado que a cada configuração de spins corresponde uma única configuração de contornos compatíveis. No Capítulo 2 discutiremos em mais detalhes uma definição para contornos compatíveis.

O método dos contornos consiste em associar, no modelo de Ising, probabilidades a conjuntos de contornos, ao invés de considerar os spins diretamente. Este método, algumas vezes descrito como "animal representation", foi utilizado por Peierls para demonstrar a existência de transição de fase no modelo de Ising em duas dimensões; desde então tem sido utilizado como uma técnica alternativa para obtenção de várias propriedades do modelo de Ising [33]. Os contornos são usualmente denominados contornos de Peierls. Um tratamento rigoroso sobre a relação da medida de uma configuração de spins em baixa temperatura no modelo de Ising e sua expressão em termos dos contornos foi apresentada por Dobrushin [26], a seguir apresentaremos em uma breve revisão os principais resultados de nosso interesse.

Sejam os conjuntos $\partial \Lambda=\left\{i \in \Lambda^{c}:|i-j|=1, j \in \Lambda\right\}$ e $\partial^{\text {int }} \Lambda=\{i \in \Lambda:|i-j|=$ $\left.1, j \in \Lambda^{c}\right\}$ fronteira interna de $\Lambda$, onde $\Lambda^{c}=\mathbb{Z}^{2} \backslash \Lambda$. O número de pontos do conjunto $\Lambda^{c}$ vizinhos ao sítio $i$ é:

$$
R_{i}(\Lambda)=\left|\left\{j \in \partial \Lambda:|i-j|=1, i \in \partial^{i n t} \Lambda\right\}\right|
$$


Para um volume finito $\Lambda$ com condição de fronteira positiva e ausência de campo externo,

$$
H^{+}(\sigma, \Lambda)=-\sum_{\{i, j\} \subseteq \Lambda:|i-j|=1} \sigma(i) \sigma(j)-\sum_{i \in \partial^{i n t} \Lambda} \sigma(i) R_{i}(\Lambda)
$$

Dada a rede $\mathbb{Z}^{2}$, denominaremos de elo ao intervalo fechado de comprimento unitário que conecta os pontos adjacentes da rede dual $\mathbb{Z}^{2}+\left(\frac{1}{2}, \frac{1}{2}\right)$. Para cada elo $e \in \mathbb{E}$ há dois vértices da rede original a uma distância $\frac{1}{2}$ de $e$, que são os vértices adjcentes ao elo e. Seja $\mathbb{E}$ o conjunto formado por todos os elos da rede dual e $\mathbb{E}(\Lambda)$ o conjunto de elos $e \in \mathbb{E}$ tal que pelo menos um ponto em $\Lambda$ é adjacente ao elo $e$. Dada uma configuração $\sigma$, a fronteira $B(\sigma)$ é o conjunto de todos os elos $e \in \mathbb{E}(\Lambda)$ tal que, se $i, j$ são pontos da rede original adjacente ao elo $e, \sigma(i) \neq \sigma(j)$. A expressão 1.4 pode ser escrita como

$$
H^{+}(\sigma, \Lambda)=\sum_{e \in \mathbb{E}(\Lambda)}\left(1_{\{e \in B(\sigma)\}}-1_{\{e \in \mathbb{E}(\Lambda) \backslash B(\sigma)\}}\right)=2|B(\sigma)|-|\mathbb{E}(\Lambda)|
$$

Seja $\gamma$ um contorno individual e $|\gamma|$ o número de elos do contorno $\gamma$. A expressão 1.1 pode ser escrita como:

$$
\mu_{\Lambda,+}^{\beta}(\sigma)=\frac{1}{Z_{\Lambda,+}^{\beta}} e^{-2 \beta|B(\sigma)|+\beta|E(\Lambda)|}
$$

com o fator de normalização

$$
Z_{\Lambda,+}^{\beta}=e^{\beta|\mathbb{E}(\Lambda)|} \sum_{\Gamma_{\Lambda} \in C_{\Lambda,+}} \prod_{\gamma \in \Gamma_{\Lambda}} e^{-2 \beta|\gamma|}=e^{\beta|\mathbb{E}(\Lambda)|} Z_{\Lambda}^{\text {cont }}
$$

onde $Z_{\Lambda}^{\text {cont }}$ é a função partição para os contornos e $C_{\Lambda,+}$ é o conjunto formado por famílias de contornos compatíveis dois a dois em $\Lambda$.

A medida de Gibbs correspondente a condições externas positivas pode portanto ser traduzida a uma medida no espaço dos contornos. De acordo com 1.7 uma configuração finita $\eta$ de contornos em $\Lambda$ terá o seguinte peso:

$$
\mu_{\Lambda,+}^{\beta}(\eta)=\frac{e^{-2 \beta \sum_{\gamma \in \eta}|\gamma|}}{Z_{\Lambda}^{\text {cont }}}
$$

Esta expressão pode ser interpretada considerando-se que a cada contorno está associado o peso

$$
w^{(\beta)}(\gamma)=e^{-2 \beta|\gamma|}
$$


e

$$
w^{(\beta)}(\eta)=\frac{\prod_{\gamma \in \eta} w^{(\beta)}(\gamma)}{\Theta_{\Lambda,+}^{\beta}}
$$

com

$$
\Theta_{\Lambda,+}^{\beta}:=1+\sum_{\eta \in C_{\Lambda,+}} \prod_{\gamma \in \eta} w^{(\beta)}(\gamma)
$$

Uma vantagem na utilização do método dos contornos no modelo de Ising é que para os contornos existe apenas a restrição de que não podem apresentar interseções. Este é um caso mais simples do que a interação entre spins, quando expressa em termos dos spins individuais. Além disto, esta propriedade permite expressar o modelo de Ising, em temperaturas abaixo da temperatura crítica de percolação, como um processo espacial de nascimento e morte de contornos, como veremos.

\subsubsection{Processos de nascimento e morte espaciais}

Em um processo de nascimento e morte objetos que pertencem a um certo conjunto enumerável $\Gamma$ aparecem e desaparecem. Cada objeto $\gamma \in \Gamma$ tem uma taxa de nascimento $c(\gamma, \eta)$, onde $\eta$ descreve a configuração de objetos presentes no instante do possível nascimento de $\gamma$. A morte ocorre com taxa 1 independentemente de qualquer outra coisa. Neste trabalho nos concentraremos nesse caso mais simples.

Um caso particular de processos de nascimento e morte espaciais são as redes com perda (loss networks) introduzidas por Erlang no começo de século e estudadas por Kelly [32]. Fernández, Ferrari e Garcia [2] deram condições suficientes para a existência desses processos e para a ergodicidade dos mesmos. Ergodicidade nesse contexto significa convergência à única medida invariante para qualquer configuração inicial. Nesse caso o conjunto $\Gamma$ tem associada uma matriz de compatibilidade $m: \Gamma \times \Gamma \rightarrow\{0,1\}$. A taxa de nascimento de $\theta$ é uma constante dependendo de $\theta$ vezes a função indicadora de compatibilidade com os objetos presentes. $\mathrm{O}$ nascimento ocorre se o objeto for compatível com todos os presentes. Se não, o objeto é perdido (daqui o nome das redes).

A conexão com processos de nascimento e morte espaciais é que a rede com perda na qual o contorno $\theta$ tem taxa de nascimento $\exp (-\beta|\theta|)$ e relação de compatibilidade dada por

$$
m(\gamma, \theta)=1\{\gamma \cap \theta \neq \emptyset\}
$$


aceita a medida $\mu_{\Lambda,+}^{\beta}$ como invariante (e reversível). Assim, propriedades de redes com perda podem implicar propriedades no modelo de Ising. Em geral as propriedades das redes são obtidas para $\beta$ superior ao chamado $\beta$ de Peierls (baixa temperatura no modelo de Ising).

\subsubsection{Simulação Perfeita de Processos Espaciais}

Propp e Wilson [17] apresentaram uma técnica geral com o uso de cadeia de Markov que permite que amostras sejam geradas com exatamente a distribuição de equilíbrio da cadeia. Deste modo, ao contrário de métodos que garantem apenas a convergência de uma medida à medida de interesse - métodos assintóticos - nesta técnica é possível definir um tempo de parada no qual a amostra obtida possui exatamente a distribuição desejada. As técnicas com este objetivo tornaram-se conhecidas como simulação perfeita e desde então há o interesse no estudo e no aprimoramento das possibilidades neste campo como uma maneira alternativa de simular vários tipos de processos estocásticos.

Um esquema de simulação perfeita para um espaço de probabilidade $(X, \Omega, F, \mu)$ consiste em:

(i) Um processo $V=\left(V_{t}\right)_{t \geq 0}$,

(ii) $\operatorname{Um}\left\{G_{t}\right\}$-tempo-de-parada, $\tau=\tau(V)$, onde $G_{t}=\sigma\left(V_{s}, 0 \leq s \leq t\right)$, tal que

$$
P(\tau(V)<\infty)=1,
$$

(iii) Uma função aleatória $\Phi_{V}: R_{+} \rightarrow X$ tal que

$$
P\left(\Phi_{V}(t) \in A\right)=\mu(A) \quad, \quad \forall t \geq \tau .
$$

O Coupling from the Past [17] e o Fill's Interruptible Algorithm[4] tornaram-se os mais conhecidos no esquema de simulação perfeita. O CFTP consiste, em linhas gerais, na geração simultânea de várias cadeias de Markov e construídas com o método de "acoplamento desde o passado". As cadeias são iniciadas com todos os estados possíveis a partir de um instante $t_{-n}<0$ e geradas de modo acoplado até 
o instante $t_{0}=0$, onde $n$ é um inteiro positivo. O valor de $n$ é determinado pelo algoritmo de modo a garantir que todas as cadeias se encontrem um mesmo estado em $t=0$; o critério do tempo de parada garante que a amostra em $t_{o}$ seja obtida com exatamente a medida invariante do processo. Neste caso o processo $V_{t}$ consiste de variáveis independentes uniformemente distribuídas no intervalo $[0,1]$. A idéia é

- Exibir uma função $F$ tal que a cadeia de Markov construída indutivamente por $X_{n}=F\left(X_{n-1}, V_{n}\right)$ tenha $\mu$ como única medida invariante. Defina $F_{[k, k]}(x, \underline{V})=$ $F\left(x, V_{k}\right)$ e para $k^{\prime}>k$,

$$
F_{\left[k, k^{\prime}\right]}(x, \underline{V})=F\left(F_{\left[k, k^{\prime}-1\right]}(x, \underline{V}), V_{k^{\prime}}\right)
$$

Note que $F_{\left[k, k^{\prime}\right]}(x, \underline{V})$ depende somente em $\left(V_{k}, \ldots, V_{k^{\prime}}\right)$.

- Defina

$$
\tau=\min \left\{n: F_{[-n, 0]}(x, \underline{V}) \text { não depende de } x\right\}
$$

e

$$
\Phi_{\underline{V}}(\tau)=F_{[-\tau, 0]}(x, \underline{V})
$$

para todo $x \in \mathbf{X}$.

\subsubsection{O modelo de Ising e a simulação via método dos contornos}

Uma simulação da dinâmica do modelo de Ising para o caso ferromagnético pode ser realizada de modo usual pelo método MCMC (Monte Carlo Markov Chain). O MCMC permite gerar um processo estocástico através de uma cadeia de Markov que tem como medida invariante a medida do processo de interesse. No modelo de Ising a cadeia de Markov associada possui como espaço de estados configurações $d$-dimensionais de spins em uma região finita $\Lambda \subset \mathbb{Z}^{d}$.

Uma das principais características do MCMC é a sua natureza assintótica, pois o método utiliza a propriedade da convergência, sob certas condições, da distribuição inicial dos estados da cadeia para uma medida estacionária. De um modo geral este fato torna necessário um monitoramento da velocidade desta convergência. Outro aspecto importante que deve ser considerado em simulações com o MCMC é a necessidade de controlar a autocorrelação existente entre os estados gerados. 
Várias dinâmicas tem sido propostas para utilização do MCMC no modelo de Ising. A mais simples, conhecida como "single spin flip dynamics", consiste em efetuar as transições entre os estados da cadeia de Markov alterando-se um único spin a cada vez. Para o caso ferromagnético a baixas temperaturas, no entanto, pode ser verificado que a cadeia de Markov não converge rapidamente [28][35]. Dentre as dinâmicas alternativas, a proposta por Swendsen e Wang [18] tornou-se amplamente utilizada; neste caso conjuntos de spins conectados são alterados simultaneamente a cada passo da cadeia.

Com o "acoplamento desde o passado"proposto por Propp e Wilson é possível a simulação perfeita do modelo de Ising. Desde então várias outras técnicas de simulação perfeita tem sido propostas. Ferrari, Fernández e Garcia [3] apresentaram um algoritmo para a simulação perfeita de processos que tenham como medida invariante a de um processo de nascimento e morte e que seja absolutamente contínuo em relação a um processo pontual de Poisson - o Backward Forward Algorithm. A conexão com o método dos contornos e o modelo de Ising é que o BFA permite, em princípio, a simulação perfeita do modelo de Ising ferromagnético a baixas temperaturas, através de uma dinâmica para os contornos. Neste esquema uma realização do processo associado ao modelo de Ising $d$-dimensional é obtido a partir de um de processo marcado em dimensão $d+1$, onde as marcas do processo marginal são os contornos de Peierls. Para a simulação de um processo desta natureza é necessário, no entanto, resolver o problema de gerar os contornos de Peierls a partir de uma medida dada. Este problema não trivial despertou o nosso interesse e está relacionado a duas questões básicas:

1. enumeração: dado o conjunto $\Gamma$ de contornos de Peierls, determinar o número $n(i)$ de contornos que existem com exatamente $i$ elos, $i=4,6,8 \ldots$;

2. amostragem: gerar $\gamma \in \Gamma$ de acordo com o peso $w^{(\beta)}(\gamma)$.

O primeiro problema é de natureza combinatorial para o qual não existe expressão analítica conhecida. Uma possibilidade é o de buscar algoritmos eficientes para a enumeração destes objetos por métodos computacionais. Evidentemente dada a natureza exponencial do problema (o número de contornos cresce exponencialmente com o perímetro) o interesse é o de desenvolver um algoritmo eficiente 
para $i=4,6,8 \ldots i_{\max }$. Como veremos, para fins da simulação do modelo de Ising via método dos contornos, é possível restringir o problema da enumeração de contornos à enumeração em um subconjunto $\mathbb{G} \subset \Gamma$. Desta maneira o peso de uma configuração de contornos $\Gamma_{\Lambda}$ pode ser obtido a partir dos pesos dos contornos $\gamma \in \mathbb{G} \cap \Gamma_{\Lambda}$.

O segundo caso consiste na construção de um amostrador que idealmente gere contornos com medida uniforme dado o perímetro ou, equivalentemente, gere contornos com perímetro de acordo com uma medida dada. Uma vez resolvido o problema da enumeração, um amostrador exato pode ser obtido, em princípio, calculando-se os pesos dos contornos a partir do método de enumeração. No Capítulo 2 discutiremos as questões envolvidas na enumeração dos contornos de Peierls e apresentaremos um amostrador exato para tais objetos.

Uma outra maneira de amostrar contornos sem enumerá-los é construir uma cadeia de Markov $\mathcal{M}$ que tenha como medida invariante a distribuição uniforme sobre o conjunto de contornos de um dado perímetro. Neste caso é necessário, além de garantir a ergodicidade de $\mathcal{M}$, considerar a eficiência do algoritmo, em termos da velocidade de convergência para a medida estacionária. No Capítulo 3 discutiremos algumas possibilidades para um amostrador via cadeia de Markov. No Capítulo 4 discutiremos, como uma aplicação, a simulação do modelo de Ising ferromagnético a baixas temperaturas, no contexto do Backward Forward Algorithm, cuja implementação torna-se factível a partir da técnica de amostragem dos contornos. 


\section{Capítulo 2}

\section{Enumeração dos contornos de Peierls}

\subsection{Sistema de contornos}

Para a representação de configurações de spins no espaço dos contornos, é necessária a adoção de algumas convenções para garantir que a representação seja única. Isto porque, em uma rede quadrada bidimensional, os contornos de Peierls são trajetórias fechadas na rede dual que podem apresentar "loops". Nesta seção apresentaremos uma definição mais precisa para conjuntos de contornos que podem representar uma configuração no modelo de Ising.

Uma convenção usual para evitar loops é considerar que os contornos formam curvas quando quatro segmentos se encontram em um mesmo vértice. Contornos para o caso $n$-dimensional são definidos como união de plaquetes [1], em duas dimensões as plaquetes são também denominadas elos. Neste ponto é necessária uma definição cuidadosa; neste texto adotaremos a utilizada em Dobrushin [26], que descreveremos a seguir.

Seja $\Lambda \in \mathbb{Z}^{2}$ um conjunto finito. Os contornos para o modelo de Ising ferromagnético com condições de fronteira "+", isto é, $\sigma_{i}=+1$ para $i \in \mathbb{Z}^{2} \backslash \Lambda$, são formados por segmentos de comprimento unitário - denominado elos - que conectam pontos adjacentes da rede dual $\mathbb{Z}^{2}+\left(\frac{1}{2}, \frac{1}{2}\right)$. Para cada configuração $\sigma \in\{-1,+1\}^{\Lambda}$ do modelo de Ising, a fronteira $B(\sigma)$ é o conjunto formado por todos os elos da rede dual tal que, se $i, j$ são pontos da rede original adjacente ao elo $e, \sigma_{i} \neq \sigma_{j}$.

Seja $\mathbb{E}$ o conjunto de todos os elos da rede dual. Seja $e_{1}, e_{2} \in \mathbb{E}$ dois diferentes 
elos com um vértice comum de coordenadas $\left(x_{1}, x_{2}\right) \in \mathbb{Z}^{2}+\left(\frac{1}{2}, \frac{1}{2}\right)$. Diremos que os elos $e_{1}, e_{2}$ formam uma curva válida se:

1. um dos elos conecta os vértices $\left(x_{1}, x_{2}\right)$ e $\left(x_{1}+1, x_{2}\right)$ e o outro conecta os vértices $\left(x_{1}, x_{2}\right)$ e $\left(x_{1}, x_{2}+1\right)$ ou

2. um dos elos conecta os vértices $\left(x_{1}, x_{2}\right)$ e $\left(x_{1}-1, x_{2}\right)$ e o outro conecta os vértices $\left(x_{1}, x_{2}\right)$ e $\left(x_{1}, x_{2}-1\right)$.

Definição 2.1 (contornos) Um contorno é uma sequência $\left\{e_{i}\right\}_{i=1,2 \ldots k}$ de elos $m u$ tuamente distintos tais que os elos $e_{i}, e_{i+1}, i=1,2, \ldots k, k+1=1$ tem um vértice comum $e$, se um par de elos $e_{i}, e_{i+1}$ neste contorno tem vértice comum com outro par $e_{j}, e_{j+1}$, então este último forma uma curva válida.

Os contornos são portanto trajetórias fechadas formadas por elos da rede dual conectados e que não apresentam loops. O conjunto formado por todos os contornos em $\Lambda$ de acordo com a definição (2.1) será denotado por $\mathbb{G}_{\Lambda}$.

Definição 2.2 (contornos compatíveis) Os contornos $\gamma_{1}, \gamma_{2}$ são ditos compatíveis se não possuem elos em comum e se, em qualquer vértice comum a ambos, cada contorno neste vértice forma uma curva válida ${ }^{1}$.

Seja $H_{\Lambda}$ o conjunto de todos os conjuntos $\pi \subseteq \mathbb{G}_{\Lambda}$ tal que qualquer dupla de contornos diferentes em $\pi$ são compatíveis. Para qualquer volume finito $\Lambda$ e qualquer configuração $\sigma \in\{-1,+1\}^{\Lambda}$ existe um único sistema de contornos $\pi(\sigma) \in H_{\Lambda}$ tal que

$$
B(\sigma)=\cup_{\gamma \in \pi(\sigma)} \gamma
$$

Este resultado garante portanto uma decomposição de modo único de uma configuração de contornos; uma demonstração deste fato pode ser vista em Dobrushin $[26]$.

\footnotetext{
${ }^{1}$ Não há uniformidade na literatura quanto ao uso do termo compatível. Alguns autores utilizam o termo no sentido de interação por exclusão: dois contornos são compatíveis se não compartilham um mesmo vértice. Em um texto recente Borgs[10] argumenta em favor da utilização da expressão contornos independentes ao invés de compatíveis neste caso, que considera mais adequado no contexto de grafos. Neste trabalho optamos por utilizar a expressão contornos compativeis conforme a definição dada e reservar o termo independentes para contornos que não se intersectam, conforme sugerido por Borgs.
} 
De acordo com (2.1), para a simulação de sistemas de spins em $\Lambda$ pelo método dos contornos é suficiente portanto a determinação dos pesos $w^{(\beta)}(\gamma), \gamma \in \mathbb{G}$, onde $\mathbb{G}$ é o conjunto de contornos conforme a Definição 2.1. Este é um importante ganho para a solução do problema de enumeração dos contornos em função do número de elos, uma vez que o peso de uma configuração pode ser obtido a partir da enumeração de uma classe mais restrita de objetos - o sistema de contornos dado por $\mathbb{G}$.

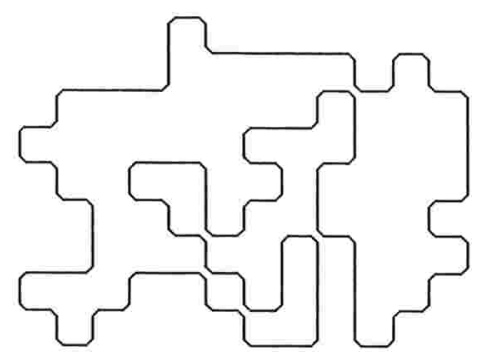

Figura 2.1: Exemplo de um contorno de Peierls que apresenta somente curvas válidas

\subsection{Enumeração de contornos em $\mathbb{Z}^{2}$}

\subsubsection{Enumeração de algumas classes de objetos}

Para a enumeração dos contornos em $\mathbb{G}$ não há um método conhecido que leve a expressões fechadas. Do ponto de vista da enumeração exata, um método geral para a busca de expressões fechadas para cálculo exato do número de certas classes de objetos geométricos, em função de parâmetros tais como perímetro ou área, é o método da função geratriz. Seja $\mathcal{P}$ uma família de polígonos. Uma função geratriz para a área, por exemplo, é a série de potências

$$
\sum_{n \geq 1} a_{n} t^{n}
$$

onde $a_{n}$ denota o número de elementos de $\mathcal{P}$ com área $n$. Neste método, o primeiro passo é conseguir uma decomposição apropriada dos objetos em $\mathcal{P}$, ou seja, uma definição recursiva que possa ser traduzida em equações e que definem de modo implícito a função geratriz. O segundo passo consiste na solução destas equações para obtenção de uma expressão fechada para a função geratriz. Este passo pode 
ser de grande complexidade. Várias classes de polígonos tem sido estudada na literatura neste esquema geral; em alguns casos não muito complexos esta técnica permite a enumeração e o estabelecimento de alguns resultados assintóticos, como por exemplo, no caso dos poliminós convexos [24][9]. Um poliminó é uma união de células quadradas unitárias no plano cujos vértices são pontos da rede; um poliminó é convexo se sua interseção com qualquer linha vertical ou horizontal é vazia ou um segmento de reta. Uma revisão detalhada de resultados obtidos por meio de técnicas combinatórias e função geratriz, para várias classes e subclasses de polígonos pode ser vista em [12]. No entanto há grandes dificuldades neste tipo de abordagem quando os polígonos são um pouco mais complexos; mesmo para os poliminós as soluções já obtidas são restritas para algumas subclasses (polígonos convexos, dirigidos, horizontalmente convexos etc).

Refletindo os novos recursos de hardware que são disponibilizados a cada ano e os avanços nos métodos computacionais, para problemas deste tipo tem crescido o interesse na busca de soluções por meio de algoritmos eficientes. De um modo geral, o problema de interesse é obter um algoritmo que calcule os coeficientes $a_{n}$ na expressão (2.2), o que é equivalente a efetuar uma enumeração dos objetos. Em linhas gerais, um algoritmo é considerado eficiente se o tempo de computação não cresce muito rapidamente em função do tamanho do input. Uma formalização desta idéia geralmente aceita é a definição de algoritmo polinomial. Um algoritmo polinomial deve fornecer um output em um tempo de computação que é limitado por alguma função fixa polinomial do tamanho do input. Para problemas que envolvem estruturas combinatórias em grafos, o tamanho da entrada é tipicamente da ordem do número $N$ de vértices. $\mathrm{Na}$ impossibilidade de obtenção de um algoritmo polinomial para certas classes de objetos geométricos, o interesse volta-se para algoritmos que, mesmo de natureza exponencial, apresentem baixas taxas de crescimento no tempo de computação em função de parâmetros como perímetro ou área destes objetos.

Além da questão da eficiência de um algoritmo para enumeração em termos de tempo de processamento, há naturalmente o problema relacionado da memória requerida para a sua implementação. Este problema é frequentemente uma das grandes dificuldades a serem contornadas quando o número de estruturas crescem exponencialmente. Citando alguns valores apenas como referência, uma implementação desenvolvida por Don Knuth para a contagem do número de poliminós com até 
47 células requereu 1 Gbyte de memória [15]; em 2001 uma contagem de passeios aleatórios auto evitantes (SAW's) com até 51 passos exigiu 10 Gbytes de memória e a movimentação de 5 Tbytes de dados [5].

\section{SAP's}

Para problemas de enumeração de objetos compactos em uma rede bidimensional, a técnica conhecida como matriz de transferência tornou-se uma técnica bastante flexível em termos de sua adaptação a diferentes objetos e tem sido utilizada para problemas de enumeração em diferentes contextos. Na mecânica estatística, esta técnica foi descrita no início da década de 80 por Derrida [7] e Klein [25]; já na década de 80 uma enumeração de circuitos hamiltonianos em rede quadrada foi realizada por Schmalz e outros [34]. Um caminho hamiltoniano em um grafo é um caminho que visita todos os vértices do grafo uma única vez; um circuito hamiltoniano é um caminho hamiltoniano que retorna ao ponto de partida. A enumeração destes objetos ainda é um interesse atual, como por exemplo, na modelagem de polímeros [6]. Como exemplo de aplicação envolvendo outro tipo de objeto, Jensen [20] efetuou recentemente a contagem de "site animals" com até 46 células com uma adaptação desta técnica; um "site animal" é um conjunto finito de sítios de uma rede conectados pelos elos vizinhos mais próximos.

Um problema que apresenta uma interessante proximidade ao da contagem dos contornos de Peierls, como veremos, é a enumeração de SAP's ("self-avoiding polygons") em duas dimensões. Um SAP pode ser definido como um passeio em uma rede que retorna ao ponto de partida sem nenhuma outra auto-interseção; ou alternativamente, um sub-grafo de uma rede cujos vértices são de grau zero ou dois. Em 1980 Enting, utilizando matriz de transferência e um interessante método para controle do estado de conectividade dos polígonos em retângulos, estabeleceu o número exato de SAP's em função do número de elos, para até 38 elos [16] e em um trabalho posterior, 46 elos [23]. O mesmo método com algumas modificações foi utilizado em 1999 por Jensen e Guttmann [22] para a obtenção do número exato de SAPs com até 90 elos. Este limite foi aumentado para 110 elos em 2003, com basicamente o uso do mesmo método e técnica de computação paralela [21]. 


\subsubsection{Enumeração de contornos de Peierls}

Para enumeração dos contornos de Peierls, utilizamos a decomposição em contornos conforme a definição 2.1 e o algoritmo matriz de transferência. A seguir descreveremos o método e as adaptações que utilizamos neste trabalho.

Seja $\Lambda=[0, n] \times[0, m] \subset \mathbb{Z}^{2}$ e $e_{1}, e_{2} \in E(\Lambda)$ elos que conectam o vértice $\left(x_{1}, x_{2}\right)$ ao vértice vizinho $\left(x_{1}-1, x_{2}\right)$ e $\left(x_{1}, x_{2}+1\right)$, respectivamente. A cada elo $e \in$ $E(\Lambda)$ atribuímos um estado $\tau(e)$. Diremos que os estados $\tau\left(e_{1}\right), \tau\left(e_{2}\right)$ formam uma entrada. Sejam $e_{3}, e_{4} \in E(\Lambda)$ os elos que conectam $\left(x_{1}, x_{2}\right)$ ao vértice $\left(x_{1}, x_{2}-1\right)$ e $\left(x_{1}+1, x_{2}\right)$, respectivamente. Os estados $\tau\left(e_{3}\right), \tau\left(e_{4}\right)$ formam a saída que corresponde ao vértice $\left(x_{1}, x_{2}\right)$ (Figura 2.2). Um contorno é construído percorrendo-se os vértices de $\Lambda$ do topo para a base e da esquerda para a direita. Inicialmente todos os elos possuem estado "0". No primeiro vértice, os estados dos elos que compõem a "saída" são deduzidos a partir da "entrada" e assim sucessivamente, até a obtenção de um contorno válido. Em cada vértice, os estados atribuídos aos elos e regras "de transição" devem garantir que uma saída em um vértice $\left(x_{1}, x_{2}\right)$ possa ser deduzida somente a partir da entrada e da posição do vértice no retângulo. Percorrendo-se todos os vértices em uma ordem pré-estabelecida e escolhendo-se em cada vértice uma saída é produzida uma figura válida.

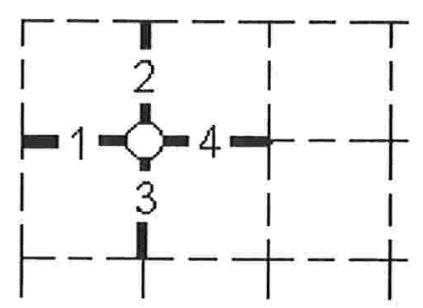

Figura 2.2: Em um vértice, os estados dos elos 1 e 2 formam a entrada $i_{1} i_{2}$ respectivamente e os estados dos elos 3 e 4 formam a saída $o_{1} o_{2}$.

A definição dos estados possíveis para um elo que compõe um objeto geométrico definido em $\mathbb{Z}^{2}$, como passeio aleatório, circuito hamiltoniano, poliminós, SAP e outros é um passo necessário para o uso deste procedimento e a definição a ser 
dada depende naturalmente do tipo de objeto. Para a contagem de animals, por exemplo, Jensen [20] considerou cinco estados possíveis para os elos; configurações de polígonos interagentes com "self-avoiding walks" em uma rede quadrada podem ser construídas atribuindo-se quatro estados distintos aos elos [8]. Nestes e em outros problemas, os estados devem ser tais que permitam a obtenção de figuras corretamente conectadas enquanto os vértices são percorridos um a um.

Para uma definição adequada dos estados dos elos e as regras de transição consideramos a relação entre a enumeração de contornos conforme a Definição 2.1 e a enumeração dos SAP's. Desta forma um procedimento pôde ser obtido por meio de uma adaptação do método originalmente proposto por Enting[16] para enumeração dos SAP's, considerando-se ainda algumas melhorias propostas por Jensen, Guttmann [22] e Jensen [21].

Para contornos $\gamma \in \mathbb{G}$ conforme a Definição 2.1, utilizamos para controle da conectividade, um conjunto de três estados, codificados de modo similar ao utilizado para os SAPs. Considere uma linha vertical que intercepta $\Lambda$ em $x=c \in \mathbb{R}$, $k-1<c<k, k=1,2, \ldots m$. Os estados possíveis para um elo que intercepta a linha são:

0 - se elo não é parte de um contorno;

1 - se elo é parte inferior de um laço fechado à esquerda da linha;

2 - se elo é parte superior de um laço fechado à esquerda da linha.

A Figura 2.3 mostra um exemplo de um contorno parcialmente construído via matriz de transferência, com a codificação dos elos ${ }^{2}$.

Consideraremos que os vértices definidos por um retângulo $n \times m$ células são percorridos sempre do topo para a base e da esquerda para a direita. Para definir as regras de transição para contornos de Peierls, a idéia básica é que estas regras devem ser tais que permitam somente a formação de contornos com curvas válidas, de acordo com a Definição 2.1. Para os SAP's, por exemplo, à entrada "11" (o primeiro dígito é o estado do elo vertical no par de elos do input) corresponde somente uma saída válida, que é a saída "00", de acordo com a tabulação original de Enting [16]. Para

\footnotetext{
${ }^{2}$ Jensen descreve em [22] e [21] a construção dos SAP's através da adição de sites ao longo de uma linha de fronteira que intercepta o retângulo. A descrição aqui apresentada é ligeiramente diferente e enfatiza as configurações de colunas como unidades básicas na construção dos contornos. Esta idéia será explorada na construção de um amostrador.
} 


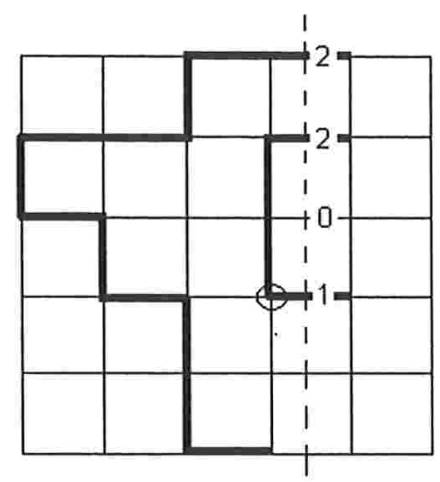

Figura 2.3: Um polígono parcialmente construído, escolhendo-se os estados dos elos da esquerda para a direita e do topo para a base, até o vértice assinalado. Os números mostram a configuração parcial $\{2201 \ldots\}$ da última coluna em construção.

um contorno de Peierls, no entanto, para esta entrada deve corresponder exatamente duas saídas possíveis: "00" e "11". Esta última deve ser acrescentada pois o par entrada/saída corresponde à formação de uma curva válida. De modo similar para as entradas " 22 " e "21" e assim por diante. Considerando-se cada entrada possível e que somente curvas válidas podem ser formadas é possível obter o conjunto de regras a serem utilizadas.

$\mathrm{Na}$ Tabela 1 apresentamos as regras completas para os contornos de Peierls. Neste ponto é interessante observar que, de modo diferente do que ocorre para os SAPs, a cada entrada da Tabela 1 corresponde exatamente um par de saídas possíveis. Isto ocorre porque para os contornos, um laço pode ser fechado em um vértice ou "prosseguir" formando curvas válidas (Figura 2.4). Esta última possibilidade equivale a uma auto-interseção das linhas, o que no caso dos SAP's não é possível. Em um contorno de Peierls uma auto-interseção das linhas pode ser válido, se considerarmos que os contornos sempre apresentam curvas próximos aos vértices. O fato de cada entrada apresentar exatamente duas saídas possíveis pode ser explorada em um algoritmo para a geração de contornos.

Além das regras expressas na Tabela 1, para a determinação dos estados dos elos em uma "saída" é necessário considerar ainda algumas restrições adicionais, de acordo com a posição do vértice no retângulo. Devido a estas restrições, dado uma entrada, uma das saídas tabeladas pode eventualmente não ser válida. Estas restrições dependem da entrada e são as mesmas para o caso dos SAPs: 
- entrada " 12 ": se a saída correspondente for "00" significa que o contorno foi fechado, o que é possível apenas se não houver restrições em relação à necessidade do contorno tocar os limites laterais do retângulo. Para que elos o contorno toque as laterais do retângulo, a saída " 00 " deve ser considerada inválida, se o vértice está em uma coluna interior no retângulo.

- entradas " 11 " e "22": neste caso uma saída "00" significa que um laço foi fechado (Fig 2.5). Isto exige uma recodificação na configuração parcial já obtida, já que o estado de conectividade da figura parcialmente formada é alterado. Este fato ocorre também para a os SAP's e o procedimento para a recodificação dos elos de uma mesma coluna é análogo. Uma descrição de como efetuar esta recodificação pode ser vista em [16] e [22].

- se um vértice está na base do retângulo, saídas com o primeiro dígito diferente de zero não são válidas, pois significam que um elo vertical conecta a fronteira $\partial \Lambda$.

\begin{tabular}{|c|c|c|}
\hline entrada & saída 1 & saída 2 \\
\hline 00 & 12 & 00 \\
\hline 01 & 10 & 01 \\
\hline 02 & 20 & 02 \\
\hline 10 & 10 & 01 \\
\hline 11 & 11 & $00 *$ \\
\hline 12 & 12 & 00 \\
\hline 20 & 20 & 02 \\
\hline 21 & 00 & 21 \\
\hline 22 & 22 & $00^{*}$ \\
\hline
\end{tabular}

(*) Configuração da coluna deve ser recodificada.

A contagem do número de contornos com $i$ elos pode ser efetuada somando-se o número de contornos em todas as "caixas" com $n \times m$ células que são relevantes para a contagem, ou seja, $\operatorname{com} 2(n+m)=N, n \leq m$. Para evitar que figuras sejam contadas mais de uma vez, somente os contornos que tocam as laterais, topo e base de um retângulo devem ser considerados. Este ponto não é crítico e não foi efetuado 
<smiles>[2H]C([2H])([2H])[2H]</smiles><smiles>[2H]C([2H])([2H])I</smiles>

0<smiles>[2H]C(I)(I)I</smiles><smiles>[2H]C1CCCC1</smiles>
0<smiles>[Z]C([2H])([2H])[13C]([2H])([2H])[2H]</smiles><smiles>[2H]C([2H])([2H])[2H]</smiles><smiles>[2H]C([2H])(I)I</smiles><smiles>IC(I)(I)I</smiles><smiles>[2H]C([2H])(I)I</smiles><smiles>[2H]C([2H])(I)I</smiles><smiles>[2H]C([2H])([2H])[2H]</smiles><smiles>[Z]C([2H])([2H])[2H]</smiles><smiles>[2H]C([2H])(I)I</smiles><smiles>[2H]C([2H])([2H])[2H]</smiles><smiles>[Z]C(I)(I)I</smiles><smiles>[Z]C([2H])([2H])I</smiles>

Figura 2.4: Regras de transição para os contornos de Peierls de acordo com a Tabela 1. Os números representam os estados dos quatro elos na rede dual adjacentes a um vértice. Para maior clareza somente as curvas válidas formadas pelos elos estão desenhadas. Os estados dos elos horizontais à esquerda e vertical superior na figura formam a "entrada"; os estados dos elos vertical inferior e horizontal à direita formam a "saída".

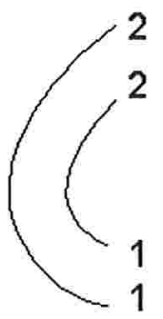

(a)

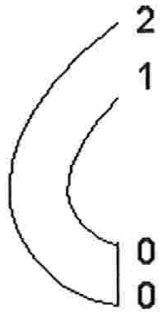

(b)

Figura 2.5: Recodificação do estado de conectividade da figura. Em (a) uma configuração de coluna 2200...11 (lida do topo para a base) que corresponde a dois laços aninhados à esquerda; (b) a recodificação necessária quando a parte inferior do laço externo é conectado à parte inferior do outro. 
originalmente por Enting[16], que utilizou apenas uma restrição parcial (os SAP's tocam as laterais do retângulo); o controle considerando-se apenas contornos que tocam o topo, base e laterais do retângulo foi uma das adaptações utilizadas por Jensen e Guttmann [22]. Neste trabalho utilizamos este controle atribuindo cada configuração de coluna dois dígitos adicionais, que indicam a situação do contorno parcialmente formado à esquerda de uma coluna: "00" se o contorno parcial não tocou topo ou base, "01" se tocou somente topo, "10" se tocou somente a base e "11" se tocou topo e base. A exigência do contorno tocar os limites laterais é satisfeita com a restrição de que não pode ocorrer uma configuração de zeros na primeira coluna nem contornos completados antes da última.

\subsection{Amostragem}

\subsubsection{Introdução}

Um ponto de interesse recorrente na literatura nos últimos anos é o de obter maneiras de amostrar tais objetos a partir de uma medida dada. Este problema é de interesse na mecânica estatística e probabilidade e tem se tornado também de interesse em outras áreas recentes de pesquisa, como por exemplo na modelagem de visão computacional, onde a tendência para o uso de campos Markovianos e a medida de Gibbs na modelagem de imagens torna atual a questão de amostrar objetos cada vez mais complexos [36]. Um problema clássico, de natureza combinatória, é a amostragem de passeios aleatórios auto-evitantes em redes ("self-avoiding walk SAW"), em função do número de passos. Em 1995 Alan Sokal [13] apresentou um estudo sobre a eficiência de vários algoritmos para amostragem de SAW's e novos desenvolvimentos.

Adotando uma definição similar à utilizada por Sokal [13], diremos que um algoritmo para a geração de contornos é estático se gera uma sequência de amostras estatisticamente independentes de uma distribuição $\pi$ desejada de probabilidade; um algoritmo é dinâmico se gera uma sequência de amostras correlacionadas a partir de algum processo estocástico, como por exemplo, um processo de Markov. Neste último caso amostras são geradas com a distribuição de equilíbrio da cadeia de Mar- 
kov.

Um amostrador para objetos não muito complexos é possível de ser obtido associado-se uma codificação aos objetos e considerando-se esta codificação como uma palavra escrita a partir de um alfabeto definido. Permutação na ordem total ou parcial de uma palavra inicial permite a obtenção de um novo objeto. Um passeio aleatório em duas dimensões com $n$ passos pode ser codificado, por exemplo, como uma sequência de letras $l_{1}, l_{2} \ldots l_{n}$ onde $l \in\{N, S, L, O\}$ define um dos quatro movimentos possíveis. Uma amostragem pode ser obtida através de um algoritmo que efetue alterações na sequência original para produzir uma nova codificação. Esta técnica é discutida em detalhes em [11], onde é aplicada para algumas subclasses de poliminós. É uma técnica aplicável se as transformações forem conhecidas e eficientes para obtenção de novas palavras válidas a partir de uma palavra inicial; no entanto obter as transformações pode ser um problema de difícil solução para objetos mais complexos.

\subsubsection{Um amostrador exato para os contornos de Peierls}

Nesta seção discutiremos um método estático para obtenção de contornos de Peierls $\gamma \in \mathbb{G}$ construído a partir da técnica da enumeração. Este método permite a geração de contornos com medida uniforme de probabilidade, dado o número de elos $|\gamma|$. Um método dinâmico pode ser obtido sem a necessidade da enumeração; no próximo capítulo apresentaremos um algoritmo dinâmico via cadeia de Markov para a geração de contornos.

De modo um pouco diferente ao descrito por Enting [16] e Jensen [22], neste trabalho utilizaremos com frequência o conceito de configuração de coluna. Dado o retângulo $n \times m$ células que corresponde à fronteira de $\Lambda=[0, n] \times[0, m] \subset \mathbb{Z}^{2}$, a configuração da coluna $k, 1 \leq k \leq m$, é a sequência $\left\{\sigma_{i}\right\}_{i=0,1, \ldots n}$ formada pelos estados dos $n+1$ elos que interceptam a linha vertical $x=c \in \mathbb{R}, k-1<c<k, k=$ $1,2, \ldots m$ e de um ou mais dígitos indicadores do estado de conectividade do contorno à esquerda da coluna. Os estados são ordenados do elo de maior coordenada $x_{2}$ ao elo em $x_{2}=0$. Diremos que no retângulo $n \times m$ uma configuração de coluna é válida para a $k$-ésima coluna se existe um contorno que pode ser construído pelo método 
proposto e que apresenta os mesmos estados de elos e dígitos indicadores na $k$-ésima coluna. Denominaremos por $C_{\Lambda}^{(k)}, k=1,2 \ldots m$, ao conjunto de configurações de colunas válidas para a $k$-ésima coluna em $\Lambda$ e $C_{\Lambda}=\cup_{k=1}^{m} C_{\Lambda}^{(k)}$.

Seja o grafo dirigido finito $G_{\Lambda}(V, A)$, onde $V$ é o conjunto de vértices e $A$ o conjunto de elos ou arcos. Para maior clareza usaremos o termo "arco" para grafos de modo geral e reservaremos o termo "elo" para os segmentos unitários que compõem os contornos. Considere que a cada vértice $v \in V$ está associado uma única configuração de coluna $c(v) \in C_{\Lambda}$. Diremos que duas configurações de colunas $c \in C_{\Lambda}^{(k)}$ e $c^{\prime} \in C_{\Lambda}^{(k+1)}$ são adjacentes se as configurações "se casam" de modo a que $c^{\prime}$ pode ser obtida a partir de $c$ e das regras de transição. $O$ par de vértices $v, v^{\prime} \in V$ está conectado no sentido $v \rightarrow v^{\prime}$ pelo arco $\left(v, v^{\prime}\right) \in A$ se as configurações de coluna $c(v)$ e $c\left(v^{\prime}\right)$ são adjacentes. Neste caso escreveremos $v \sim v^{\prime}$.

Seja $V^{(k)}=\left\{v \in V \mid c(v) \in C_{\Lambda}^{(k)}\right\}, k=1, \ldots m$. Cada vértice $v \in V^{(k)}$ representa uma configuração de coluna válida para a $k$-ésima coluna. Desta forma ao caminho $\left\{v_{1}, v_{2} \ldots v_{m}\right\}$ em $G_{\Lambda}$ corresponde a sequência de configurações de colunas $\left\{c\left(v_{1}\right), c\left(v_{2}\right) \ldots c\left(v_{m}\right)\right\}$ de um contorno válido em $\Lambda$. Seja o peso $w(v)$ igual ao número de caminhos que conectam o vértice $v \in V^{(j)}$ ao conjunto $V^{(1)}$ :

$$
w(v)=\sum_{v^{\prime} \in V^{(j-1)}, v^{\prime} \sim v} w\left(v^{\prime}\right), \quad 1<j \leq m
$$

com a convenção $w(v)=1$ se $v \in V^{(1)}$. O nosso objetivo é amostrar contornos em $\Lambda$ com medida uniforme, dado o número de elos do contorno. Para apresentar o método que utilizamos vamos considerar primeiro o caso menos restrito de amostrar um contorno uniformemente em $\Lambda$, não importando o número de elos. A estratégia para a geração do contorno é efetuar a escolha das configurações de coluna, escolhendo-se sucessivamente as configurações de acordo com os pesos de um conjunto de candidatos. Considerando $v_{o}$ vértice que correponde a uma configuração de coluna de zeros, uma caminho $\left\{v_{0}, v_{1} \ldots v_{m}\right\}$ em $G_{\Lambda}$ pode ser obtido da seguinte maneira: 
Algoritmo Geração de um contorno em $\Lambda=[0, n] \times[0, m] \subset \mathbb{Z}^{2}$ com medida uniforme

$k=m$;

$V^{(k)}=\left\{v \in V \mid c(v) \in C_{\Lambda}^{(k)}\right\}$

procedimento: cálculo dos pesos $w(v)$ para $v \in V^{(k)}$

escolha $v_{k} \in V^{(k)}$ de acordo com o peso $w\left(v_{k}\right)$

enquanto $k>0$ faça

$k=k-1$

$V^{(k)}=\left\{v \in V \mid v \sim v_{k+1}\right\}$

procedimento: cálculo dos pesos $w(v)$ para $v \in V^{(k)}$

escolha $v_{k} \in V^{(k)}$ de acordo com o peso $w\left(v_{k}\right)$

Proposição $2.3 \grave{A}$ sequencia de configurações $\left\{c\left(v_{0}\right), c\left(v_{1}\right), \ldots c\left(v_{m}\right)\right\}$ corresponde um contorno obtido com medida uniforme de probabilidade.

Prova: Seja $S_{\Lambda}$ o conjunto de todos os caminhos $\left\{v_{0}, v_{1}, \ldots v_{m}\right\}$ que correspondem a contornos válidos em $\Lambda$. A probabilidade de escolha de um caminho em $G_{\Lambda}$ de acordo com o algoritmo é

$$
\begin{gathered}
P\left(v_{0}, v_{1}, \ldots v_{m}\right)=P\left(v_{0} \mid v_{1}, v_{2}, \ldots v_{m}\right) P\left(v_{1}, v_{2} \ldots v_{m}\right)= \\
=P\left(v_{0} \mid v_{1}\right) P\left(v_{1} \mid v_{2}\right) \ldots P\left(v_{m}\right)= \\
=\frac{w\left(v_{0}\right)}{\sum_{\left\{v \in V^{(0)}: v \sim v_{1}\right\}} w(v)} \times \frac{w\left(v_{1}\right)}{\sum_{\left\{v \in V^{(1)}: v \sim v_{2}\right\}} w(v)} \ldots \times \frac{w\left(v_{m}\right)}{\sum_{\left\{v \in V^{(m)}\right\}} w(v)}= \\
=\frac{w\left(v_{0}\right)}{w\left(v_{1}\right)} \times \frac{w\left(v_{1}\right)}{w\left(v_{2}\right)} \ldots \times \frac{w\left(v_{m}\right)}{\sum_{\left\{v \in V^{(m)}\right\}} w(v)}=\frac{w\left(v_{0}\right)}{\sum_{\left\{v \in V^{(m)}\right\}} w(v)}=\frac{1}{\left|S_{\Lambda}\right|}
\end{gathered}
$$

Como a cada vértice está associado uma única configuração de coluna, a cada sequência de configurações corresponde um único contorno em $\Lambda$.

\section{Determinação dos pesos}

De acordo com (2.3), os pesos associados aos vértices podem ser calculados recursivamente, percorrendo-se as colunas da esquerda para a direita (convenção). O 
peso de cada vértice é igual à soma dos pesos dos vértices vizinhos. Um algoritmo para a determinação dos pesos de cada configuração de coluna pode ser construído do seguinte modo:

procedimento: Cálculo dos pesos $w(v), v \in V^{(k)}$

$k \in \mathbb{N}, k \leq m$

para $v \in V^{(1)}$ faça $w(v)=1$;

para $1<j \leq k$ faça:

para $v \in V^{(j)}$ faça:

$w(v)=\sum_{v^{\prime} \in V^{(j-1)}: v \sim v^{\prime}} w\left(v^{\prime}\right)$

Para gerar um contorno com exatamente $N$ elos, um procedimento similar ao descrito pode ser adotado. Seja o grafo $G^{\prime}$, onde a cada vértice está associado o peso $w(v, i), v \in V, i \in \mathbb{N}$. O peso $w(v, i)$ é o número de caminhos que conectam $v$ ao conjunto $V^{(1)}$, onde cada caminho corresponde a um contorno em $\Lambda$ parcialmente formado com exatamente $i$ elos. Dado um par de vértices $\left(v, v^{\prime}\right), v \in V^{(k)}, v^{\prime} \in V^{(k+1)}$, onde $v \rightarrow v^{\prime}$, diremos que $c(v)$ é a configuração predecessora e $c\left(v^{\prime}\right)$ é a configuração sucessora. Dada uma configuração sucessora $c(v)$, a escolha de uma configuração predecessora $c\left(v^{\prime}\right)$ deve ser feita considerando-se o peso $w\left(v^{\prime}, i\right)$ e o custo $\eta\left(v, v^{\prime}\right)$, igual ao número de elos verticais necessários para conectar $c(v), c\left(v^{\prime}\right)$ de modo válido.

\section{Estrutura de dados}

Nesta seção apresentaremos uma descrição mais detalhada da implementação que efetuamos para este algoritmo. Uma estrutura de dados aonde cada configuração de coluna é um objeto permite armazenar na memória cada nova geração à medida que os objetos são gerados. Esta estrutura é apropriada para a enumeração, mas para o amostrador proposto, um programa deve realizar também uma busca de configurações, dado número de elos. Se as configurações forem armazenadas na medida em que são geradas, esta busca pode se tornar um ponto crítico. Este problema pode ser contornado naturalmente de várias maneiras; em uma primeira 
versão de um amostrador implementamos uma estrutura simples para a execução desta tarefa.

As configurações válidas para a $k$-ésima coluna são alocadas em uma lista sequencial e identificadas através de um indexador primário ("hash table"). Neste ponto é relevante a natureza exponencial do problema, uma vez que para um retângulo $n \times m$, o número de configurações em cada coluna cresce exponencialmente em função da altura $n$ do retângulo. A memória requerida para esta tarefa é o principal desafio na enumeração dos caminhos, uma vez que é necessário manter na memória os pesos das configurações já calculadas no passo anterior, à medida que é percorrido o caminho da coluna inicial à coluna final do retângulo. É interessante observar, no entanto, que para $m$ fixo, o uso de memória cresce exponencialmente em função de $n$ e não do número de contornos. Isto já é um ganho significativo em relação a um algoritmo para enumeração direta.

Para a $k$-ésima coluna do retângulo $n \times m$ associamos o array para os pesos $A_{\Lambda}^{(k)}$, onde o elemento $A_{\Lambda}^{(k)}(i, r)$ é o número de contornos parcialmente formados à esquerda da coluna $k$, com exatamente $r$ elos e que apresentam configuração na $k$-esima coluna com índice primário $i$. O valor de $r$ é calculado contando-se os elos verticais e horizontais do contorno à esquerda da $k$-ésima coluna, considerando-se os elos horizontais da própria coluna, inclusive. Deste modo

$$
A_{\Lambda}^{(k+1)}(j, n)=\sum_{i: r+s=n} A_{\Lambda}^{(k)}(i, r)
$$

onde a soma é sobre todas as configurações que se casam de modo correto com a configuração de índice $j$ e custo $s$ para produzir um contorno parcial com $n$ elos até a $k$-ésima coluna.

Dado o número máximo de elos $n_{\max }$ a ser considerado para um contorno em $\Lambda$, naturalmente apenas as configurações com $n+s \leq n_{\max }$ são registradas. Além do mais, para o cálculo de $A^{(k+1)}$ é necessário conhecer somente $A^{(k)}$ calculado no passo anterior e as regras de transição. Portanto uma vez calculado $A^{(k+1)}$ a partir de $A^{(k)}$, este último pode ser descartado.

Com a convenção $C_{\Lambda}^{(0)}=\left\{\theta_{0}\right\}$, onde $\theta_{0}$ é uma configuração onde todos os elos estão no estado zero, as configurações válidas para a primeira coluna de um retângulo são as configurações sucessoras de $\theta_{0}$. Podemos resumir o procedimento para a 
determinação dos pesos das configurações da coluna $q, 1 \leq q \leq m$ como segue:

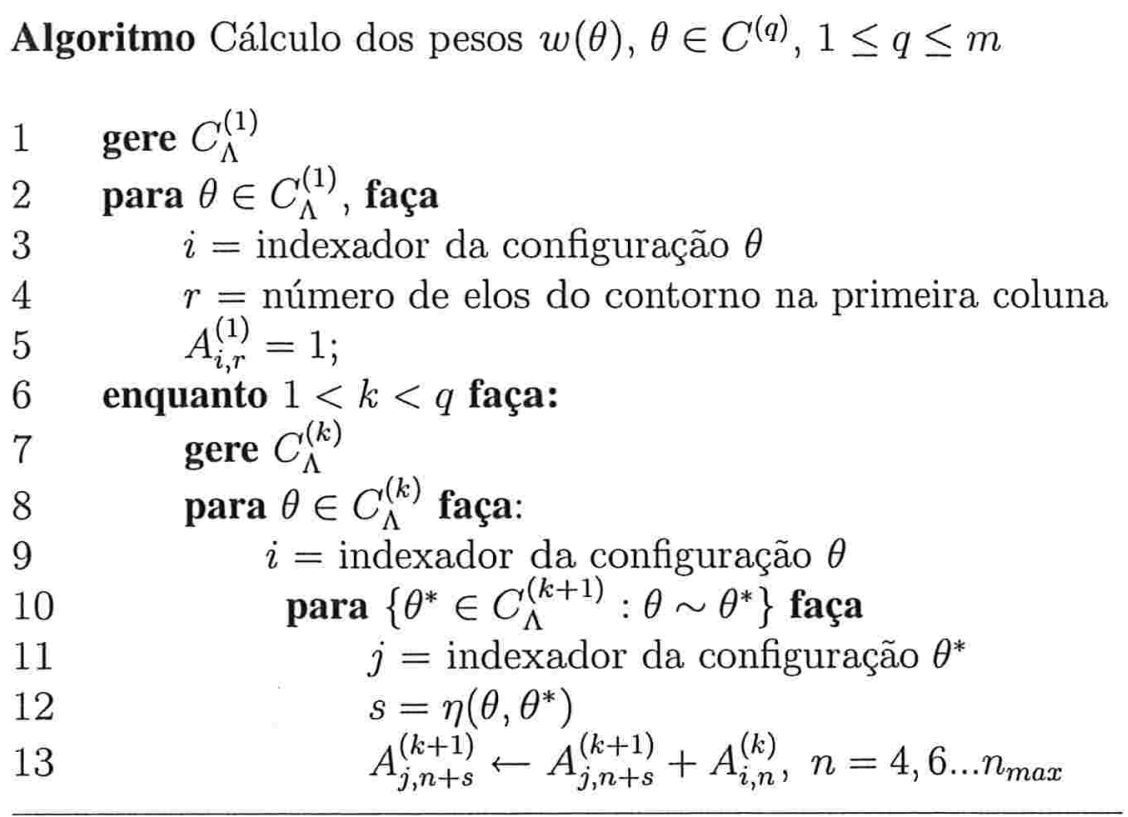

Na estrutura de dados utilizada há uma regra simples para a atualização das contagens, que pode ser explorada em uma otimização. A cada passo do programa, para os contornos com $n$ elos que apresentam uma configuração "fonte" indexada por $i$ compatível com uma configuração "alvo" indexada por $j$, temos a relação

$$
A_{\Lambda}^{(k+1)}(j, n+s) \leftarrow A_{\Lambda}^{(k+1)}(j, n+s)+A_{\Lambda}^{(k)}(i, n)
$$

onde $s$ é o número de elos que foi adicionado ao contorno pela configuração sucessora. A expressão (2.6) pode ser interpretada como o resultado da operação de somar à linha $i$ de $A^{(k+1)}$ a linha $j$ de $A^{(k)}$ transladada em $s$ unidades. Para reproduzir a transição $A_{\Lambda}^{(k)} \rightarrow A_{\Lambda}^{(k+1)}$ é suficiente registrar, portanto, para cada par de configurações fonte/alvo a sequência de inteiros $\{i, j, s\}$ que representam: indexador da configuração fonte, indexador da configuração alvo e o deslocamento $s$ que deve ser efetuado à linha $j$ para a soma com a linha $i$. Este procedimento pode ser utilizado como um fator de otimização, uma vez que permite evitar a repetição de cálculos já efetuados nos passos anteriores. 


\section{Determinação da vizinhança de uma configuração}

Uma vez estabelecido um procedimento para o cálculo dos pesos das configurações, para a construção de um amostrador é necessário resolver o problema não trivial de, dado $C^{(k)}$, gerar $C^{(k+1)}, 0 \leq k \leq m$ ou, em outras palavras, estabelecer um procedimento que permita, dada uma configuração de coluna precursora, determinar o conjunto de todas configurações sucessoras. Quando o número de configurações sucessoras não é um ponto crítico, dado uma configuração antecessora naturalmente uma solução é gerar todos as configurações possíveis e rejeitar as que não são sucessoras. Como o número de elementos que compõem cada geração cresce a altas taxas é necessário uma solução mais eficiente para este problema.

Uma solução para o problema de, dado uma configuração "pai", determinar todas as configurações "filhas", pode ser procurada em dois diferentes contextos. O primeiro consiste em considerar as configurações de coluna como palavras de um alfabeto; neste caso um conjunto de regras deve permitir ir de uma palavra precursora a uma palavra sucessora através de alterações na sequência das letras que compõem a palavra "pai". Um procedimento deste tipo foi utilizado na enumeração de SAP's [14].

Um segundo modo é deduzir um conjunto de regras a partir de construções gráficas, considerando a geometria da rede e as características geométricas dos objetos a serem gerados. Esta foi a maneira que utilizamos para os contornos de Peierls, explorando as regras deduzidas para uso da matriz de transferência. Naturalmente estes dois métodos são equivalentes e diferem apenas no contexto de sua formalização; no entanto o segundo nos pareceu permitir uma dedução mais direta das regras a serem utilizadas.

Um amostrador para contornos com $i$ elos com medida uniforme em um retângulo $n \times m$ pode ser implementado como: 


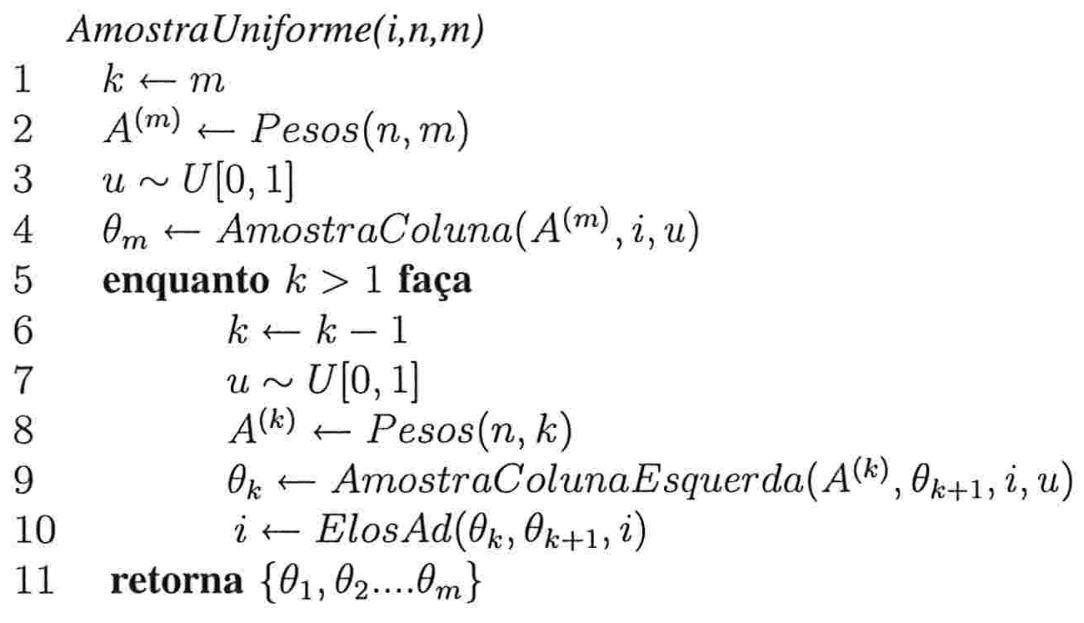

O procedimento $\operatorname{Elos} A d\left(\theta_{k}, \theta_{k+1}, i\right)$, na linha 10, atualiza o número de elos já ocupados pelo contorno parcialmente formado. Em cada passo este procedimento retorna o número de elos ocupados em $\theta_{k+1}$ somado ao custo $\eta\left(\theta_{k}, \theta_{k+1}\right)$ da junção das colunas. Para a coluna $k=m-1$ deve ser acrescentado o número de elos verticais necessários para o fechamento do contorno pela direita.

Proposição 2.4 AmostraUniforme $(i, n, m)$ produz uma sequência $\left\{\theta_{1}, \theta_{2} \ldots \theta_{m}\right\}$ de configurações de coluna que corresponde a um contorno $\gamma \in \mathbb{G}_{\Lambda, i}$ gerado de modo uniforme.

Prova: A função $\operatorname{Pesos}(n, k)$ retorna um array $A^{(k)}, 1 \leq k \leq m$, com os pesos

$$
\begin{gathered}
w(\theta, i)=1 \text {, se } \theta \in C^{(1)} \\
w(\theta, i)=\sum_{\theta^{\prime} \in C^{(k-1): \theta^{\prime} \sim \theta}} \sum_{s} w\left(\theta^{\prime}, s\right) 1_{\left\{s+\eta\left(\theta^{\prime}, \theta\right)=i\right\}} \text {, se } \theta \in C^{(k)}, 1<k \leq m
\end{gathered}
$$

onde $i \leq i_{\max }$ é o número de elos. Na linha 4, AmostraColuna $\left(A^{(m)}, i, u\right)$ escolhe um contorno com configuração $\theta_{m}$ na coluna $m$ entre todos os contornos com $i$ elos de acordo com o peso $w\left(\theta_{m}, i\right)$. Para as demais colunas, dado $\theta \in C^{(k+1)}, 1 \leq k<m$, AmostraColunaEsquerda $\left(A^{(k)}, \theta, i^{\prime}, u\right)$ retorna um par $\left(\theta^{\prime}, i^{\prime \prime}\right), \theta^{\prime} \in C^{(k)}$ de acordo com os pesos da expressão (2.7) tal que $\theta^{\prime}$ se casa $\operatorname{com} \theta$ para formar um contorno válido 
com $i$ elos e assim por diante, até a escolha da primeira coluna à esquerda. Uma adaptação da expressão (2.4) aos pesos em (2.7) é imediata.

O procedimento $\operatorname{Pesos}(n, k)$ é o ponto mais crítico dada a natureza exponencial do problema. Uma grande quantidade de tempo e memória são requeridos para os cálculos dos pesos. Uma alternativa é, dado as dimensões do retângulo, calcular previamente e armazenar na memória $A^{(1)}, A^{(2)} \ldots, A^{(m)}$. Desta forma temos uma versão mais simplificada para AmostraUniforme $(i, n, m)$ :

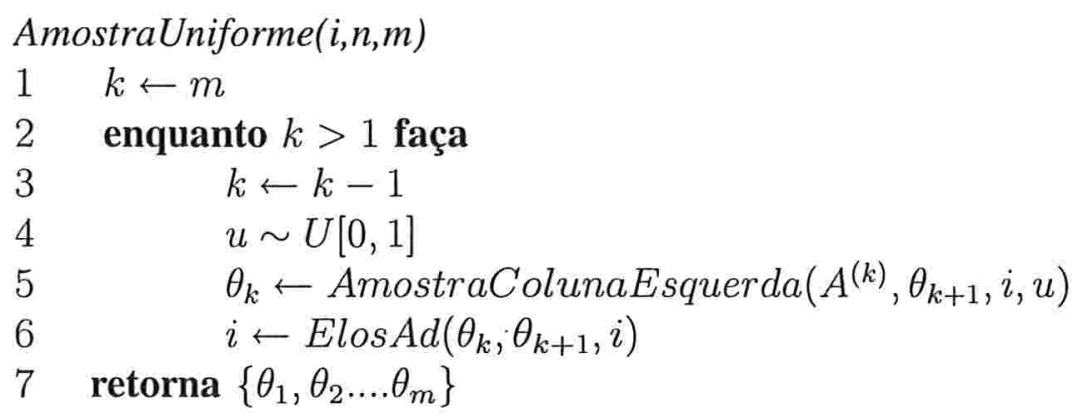

\subsubsection{Amostra em função de $\beta$}

Para uma amostragem de um contorno com $i$ elos em função de $\beta$ é necessário considerar todos os retângulos que podem conter um contorno válido com $i$ elos. Em um procedimento prévio, uma contagem do número de contornos com $i=4,6 \ldots i_{\text {max }}$ elos é efetuada em todas as "caixas" $j \times k$ relevantes. É imediato verificar que o máximo valor de $j$ a ser considerado corresponde à caixa com perímetro $i_{\max }$. Por simetria é necessário considerar somente os casos $j \leq m$.

Seja $\mathbb{G}_{j, k}$ o conjunto de contornos válidos em uma caixa com $j \times k$ células e $\mathbb{G}_{i, j, k}=\left\{\gamma \in \mathbb{G}_{j, k}:|\gamma|=i\right\}$. Neste caso

$$
w^{(\beta)}\left(\mathbb{G}_{i, j, k}\right)=\frac{\sum_{\gamma} e^{-2 \beta|\gamma|} 1_{\left\{|\gamma|=i, \gamma \in \mathbb{G}_{j k}\right\}}}{\sum_{\gamma} e^{-2 \beta|\gamma|}}=\frac{N(i, j, k) e^{-2 \beta i}}{\sum_{i} N(i) e^{-2 \beta i}}
$$

onde $N(i)$ é o número de contornos com $i$ elos e $N(i, j, k)$ é o número de contornos com $i$ elos em uma caixa com $j \times k$ células. Dado $\beta$, uma estratégia é amostrar 
inicialmente o número de elos e em seguida as dimensões da caixa. Isto pode ser feito a partir de uma lista $L$ que contém todas as contagens $N(i, j, k)>0, i \leq i_{\text {max }}$, calculados em um procedimento prévio, de acordo com a técnica de enumeração para os contornos. A partir da lista $L$ o vetor de inteiros $(i, n, m)$ é escolhido com probabilidade

$$
P(i, n, m \mid \beta)=\frac{N(i, n, m) e^{-2 \beta i}}{\sum_{i \leq i_{\max }} N(i) e^{-2 \beta i}}
$$

Um contorno $\gamma$ pode então ser gerado, dado $\beta$, como segue:

$$
\begin{array}{ll}
\text { AmostraContorno }(\beta) \\
1 & u \sim \text { Uniforme }[0,1] \\
2 & (i, n, m) \leftarrow \text { EscolheCaixa }(L, \beta, u) \\
3 & \gamma \leftarrow \text { AmostraUniforme }(i, n, m)
\end{array}
$$

Proposição 2.5 O procedimento AmostraContorno( $\beta$ ) retorna um contorno $\gamma$ com probabilidade

$$
w^{(\beta)}(\gamma)=\frac{e^{-2 \beta i}}{\sum_{i \leq i_{\max }} N(i) e^{-2 \beta i}}
$$

onde $i=|\gamma|$.

Prova: EscolheCaixa $(L, \beta, u)$ retorna o vetor de inteiros $(i, n, m)$ com probabilidade dada por 2.9 a partir dos pesos préviamente calculados; AmostraUniforme $(i, n, m)$ é um procedimento independente que retorna um contorno $\gamma$ em uma caixa $n \times m$ com probabildade $1 / N(i, n, m)$ 


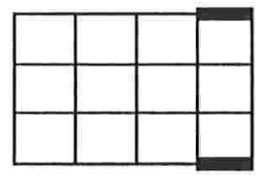

(a)

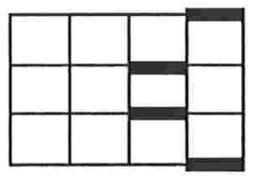

(b)

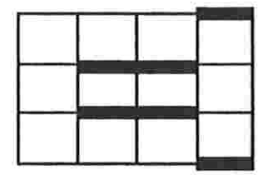

(c)

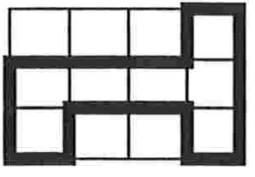

(d)

Figura 2.6: Exemplo da formação de um polígono conforme o algoritmo proposto. Em (a) a configuração $\{2001\}$ é escolhida para a última coluna à direita; as demais colunas são escolhidas sucessivamente da esquerda para a direita. Em (d) os elos verticais necessários para conectar o contorno são adicionados. 


\section{Capítulo 3}

\section{Método dinâmico para a geração de contornos de Peierls}

\subsection{MCMC}

O método Markov Chain Monte Carlo tem sido utilizado nas mais diversas aplicações e áreas, como processamento de imagens, física estatística, simulação de processos estocásticos, problemas de natureza combinatória e outros. Dado $\Omega \mathrm{um}$ conjunto finito de estruturas e $\pi$ uma medida de probabilidade em $\Omega$, o MCMC pode ser utilizado para amostrar elementos de $\Omega$ de acordo com a medida $\pi$. A idéia básica é obter uma cadeia de Markov com espaço de estados $\Omega$ e que tenha $\pi$ como medida estacionária. Iniciando a cadeia em um estado inicial arbitrário, após um certo número de iterações suficientemente grande o estado da cadeia é considerado uma amostra de um elemento de $\Omega$, gerado de acordo com uma medida que converge em distribuição para $\pi$.

Uma cadeia de Markov é dita ergódica se a distribuição de probabilidade sobre $\Omega$ converge assintóticamente para uma medida $\pi$ independente do estado inicial da cadeia. Para $T$ suficientemente grande, a propriedade de ergodicidade garante que a distribuição dos estados é arbitrariamente próxima da distribuição desejada. Como técnica de simulação, é desejável que a cadeia seja construída com transições através de perturbações simples ou pequenas modificações nas estruturas em $\Omega$. Uma cadeia é dita reversivel se

$$
\pi(x) p(x, y)=\pi(y) p(y, x)
$$

para todo $x, y \in \Omega$, onde $p(x, y)$ é a probabilidade de transição $y \rightarrow x$. No algoritmo 
hoje conhecido como "Metropolis-Hastings" [30], a condição 3.1 de reversibilidade é expressa como

$$
\pi(x) \alpha(x, y) q(x, y)=\pi(y) \alpha(y, x) q(y, x)
$$

e uma cadeia de Markov com medida estacionária $\pi$ pode ser construída adotando-se

$$
\alpha(x, y)=\min \left\{1, \frac{\pi(y) q(y, x)}{\pi(x) q(x, y)}\right\}
$$

Para cadeias de Markov com espaço de estados formado por polígonos e outros objetos geométricos em duas dimensões, um método que pode ser utilizado juntamente com o Metropolis-Hastings para construção de uma cadeia é o "pivot algorithm". Este algoritmo surgiu na literatura em 1969 [29] e foi analisado, sob o ponto de vista da sua eficiência e outros aspectos, por Madras e Sokal [31] em 1988. Desde então tem sido utilizado frequentemente em passeios aleatórios auto-evitantes, modelagem de polímeros em solução diluída, SAP's, polígonos, polígonos interagentes [8] e outros. Uma revisão detalhada do "pivot algorithm" em suas principais versões pode ser encontrada em [13] .

Nesta técnica, as transições entre os estados da cadeia são executadas por "pivotamento". O algoritmo pode ser resumido da seguinte forma:

1. escolha dois vértices do polígono no estado atual da cadeia;

2. aplique a uma das partes do polígono definidas pela linha que conecta os vértices escolhidos, uma operação de um grupo pré-definido de operações válidas (reflexão, rotação ou ambas);

3. verifique se o novo polígono obtido é um estado válido.

O resultado das operações escolhidas de um grupo de transformações válidas prédefinidas produz o candidato à transição (Figura 3.1). As modificações na estrutura do estado atual da cadeia não são modificações necessariamente do tipo local (informalmente, uma transformação é local se altera somente o estado de um vértice ou apenas uma vizinhança pequena de um vértice). O passo da rejeição/aceitação é necessário pois eventualmente as transformações podem produzir um contorno não válido. Isto ocorre, por exemplo, em uma cadeia de Markov para os SAW's, pois 

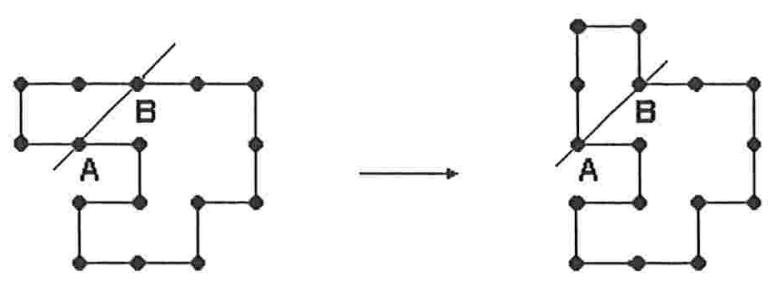

Figura 3.1: Exemplo de transição por pivotamento.

um candidato gerado pode apresentar auto-interseções. No caso do candidato ser inválido, é rejeitado e uma nova geração de um candidato é iniciada.

Esta técnica em princípio pode ser utilizada para um amostrador dinâmico de contornos de Peierls, mas é necessário garantir que todos os contornos podem ser gerados desta forma, a partir de um contorno inicial. Além do mais, para objetos mais complexos, como os contornos de Peierls, o passo da rejeição pode tornar o processo excessivamente lento. Na próxima seção apresentaremos uma maneira alternativa para a construção de uma cadeia de Markov onde o espaço de estados são os contornos de Peierls. A técnica para enumeração é explorada em conjunto com o MCMC para obter um amostrador dinâmico para os contornos.

\subsection{MCMC para contornos de Peierls}

Seja $\mathcal{N}(\gamma)$ o conjunto formado pelos contornos que compõem a vizinhança de $\gamma$. A estrutura de vizinhança é definida através das transformações que levam um estado a um estado vizinho. Seja $\mathbb{G}_{\Lambda} \subset \mathbb{G}$ o conjunto de contornos limitados pelo retângulo definido pela fronteira de $\Lambda=[0, n] \times[0, m]$ e que tocam as laterais, o topo e a base do retângulo. Considere uma cadeia de Markov $\mathcal{N}$ com espaço de estados $\mathbb{G}_{\Lambda}$ e medida estacionária

$$
\mu^{\beta}(\gamma)=\frac{e^{-\beta|\gamma|}}{Z_{\text {norm }}}, \gamma \in \mathbb{G}_{\Lambda}
$$

onde $|\gamma|$ é o número de elos do contorno e $Z_{\text {norm }}$ a constante de normalização.

A seguir apresentaremos um algoritmo que efetua as transições, a cada passo da cadeia, pela operação de troca da configuração de uma coluna do retângulo, uma 
coluna por vez. Os estados dos elos são definidos da mesma maneira que no método utilizado para a enumeração. Este procedimento apresenta a vantagem inicial de que o tempo de busca de um candidato para a transição é função somente da altura do retângulo e não do número de passos do contorno.

Para demonstrar a validade do algoritmo, é necessário demonstrar que a cadeia é irredutível. A irredutibilidade depende das alterações que são permitidas nas estruturas que compõem o espaço de estados, a cada passo. Antes de prosseguirmos, é importante verificar algumas características geométricas dos contornos e a maneira de como são gerados.

Usaremos a seguinte definição:

Definição 3.1 (v-convexo) Um polígono é verticalmente convexo se uma linha vertical da forma $x=k+\frac{1}{2}, k \in \mathbb{Z}$, ou não intercepta ou intercepta o polígono em exatamente dois pontos. De modo similar um poligomo pode ser horizontalmente convexo. Um polígono é convexo se é vertical e horizontalmente convexo.

Seja $\mathcal{N}(\gamma, j) \subseteq \mathcal{N}(\gamma)$ tal que, para $\gamma \in \mathbb{G}_{\Lambda}$ e $\gamma^{\prime} \in \mathcal{N}(\gamma)$, $\gamma$ e $\gamma^{\prime}$ apresentam o mesmo conjunto de elos horizontais ocupados em cada coluna $i \neq j$ (Figura 3.2). 


\section{Algoritmo}

1. Dado $\Lambda=[0, n] \times[0, m]$ escolha um contorno inicial $\gamma \in \mathbb{G}_{\Lambda}$. Comentário: $\mathrm{O}$ contorno $\gamma$ pode ser representado pela sequência de configurações de coluna $\left\{\theta_{1}, \theta_{2} \ldots \theta_{m}\right\}$, conforme a codificação adotada para os contornos de Peierls.

2. Escolha $j \in\{1,2 \ldots m\}$ de modo uniforme

3. Gere o conjunto $\mathcal{N}(\gamma, j)$ de contornos tal que, para $\gamma^{\prime} \in \mathcal{N}(\gamma, j)$, $\gamma$ pode ser obtido por meio de uma única operação de troca da configuração da $j$-ésima coluna.

4. Escolha uniformemente $\gamma^{\prime} \in \mathcal{N}(\gamma, j)$

5. Efetue a transição $\gamma \rightarrow \gamma^{\prime}$ com probabilidade

$$
\alpha\left(\gamma, \gamma^{\prime}\right)=\min \left\{1, \frac{e^{-\beta\left|\gamma^{\prime}\right|}}{e^{-\beta|\gamma|}}\right\}
$$

6. Repita 2.
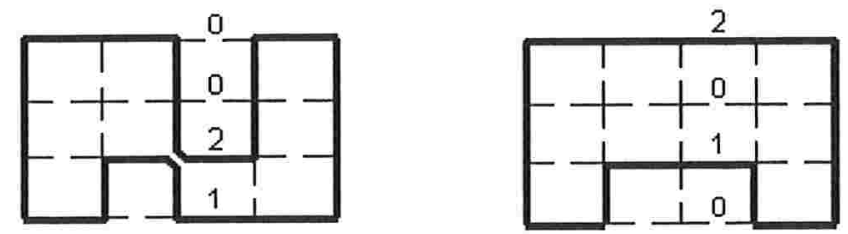

Figura 3.2: Exemplo de transição por troca de configuração de coluna, com a troca $\{0021\} \rightarrow$ $\{2010\}$ na terceira coluna.

Proposição 3.2 A cadeia $\mathcal{M}$ é irredutivel.

Prova: De acordo com a codificação dos elos nos contornos de Peierls, um contorno verticalmente convexo terá colunas da forma $\left\{\left(o_{1}\right) 2\left(o_{2}\right) 1\left(o_{3}\right)\right\}$, onde "o $i$ "é uma sequência vazia ou de zeros. Denominaremos de laço " 21 " ao conjunto de elos à esquerda de uma coluna que conecta um elo superior "2" da coluna a um elo inferior 
"1" da mesma coluna. Um laço é "12" quando conecta pela direita um elo superior "1" a um elo inferior "2" de uma mesma coluna. Assumiremos que os laços estão associados somente a contornos válidos.

Um contorno apresenta laços aninhados quando possui um laço "21" que é interno a outros laços "21". Um laço "21"que não possui laços internos pode ser removido por uma operação de troca de uma ou mais colunas, a partir da coluna que originou o laço. Isto porque a única maneira de um laço ser criado é quando, no sítio da rede dual correspondente, uma entrada "00" corresponde a uma saída "21". Mas para esta entrada uma saída "00"é também uma saída válida e é fácil verificar que a substituição de elos "21" por "00" na coluna que originou o laço deixa inalterado os estados dos elos na coluna seguinte. Repetindo-se esta operação é possível remover todo o laço "21"; repetindo-se para os outros laços é possível remover todos os laços aninhados de um contorno. O contorno resultante terá colunas da forma $\left\{\left(o_{1}\right) 2\left(o_{2}\right) 1 \ldots 2\left(o_{k-1}\right) 1\left(o_{k}\right)\right\}$, aonde um dígito " 2 " sempre é sucedido por uma sequência de zeros (eventualmente vazia) e um estado "1". Os elos "12" internos em uma coluna podem ser apagados de modo similar, substituindo-se os elos "12" por "00" na coluna aonde o laço é fechado. Desta forma é possível remover todos os elos internos de cada coluna, obtendo-se um contorno verticalmente convexo, através unicamente de operações de troca de colunas (Figura 3.3).

É imediato verificar que qualquer contorno verticalmente convexo pode ser levado, por sucessivas operações de troca de colunas, ao contorno $\gamma_{0}$ que é o contorno que coincide com os limites de $\Lambda$. Portanto todos os estados de $\mathcal{M}$ se intercomunicam através do estado $\gamma_{0}$ e portanto a cadeia é irredutível.

A cadeia $\mathcal{M}$ é também aperiódica, já que $p(\gamma \rightarrow \gamma)>0$, ou seja, há um loop em cada estado.

Proposição 3.3 A cadeia $\mathcal{M}$ apresenta medida estacionária dada por 3.4.

Prova: É suficiente demonstrar que a matriz de transição satisfaz a condição de reversibilidade 3.2. O núcleo da probabilidade de transição é simétrico, pois para $\gamma^{\prime} \in \mathcal{N}(\gamma, j), j \in\{1,2 \ldots m\}$, temos $q\left(\gamma, \gamma^{\prime}\right)=q\left(\gamma^{\prime}, \gamma\right)=1 /|\mathcal{N}(\gamma, j)|$. Para um núcleo simétrico a condição de reversibilidade é obtida diretamente de 3.4 e 3.5 . 


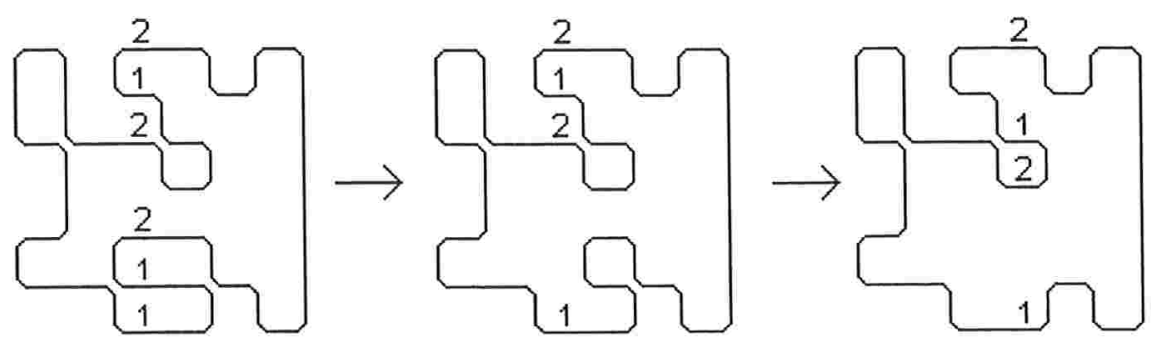

(a)
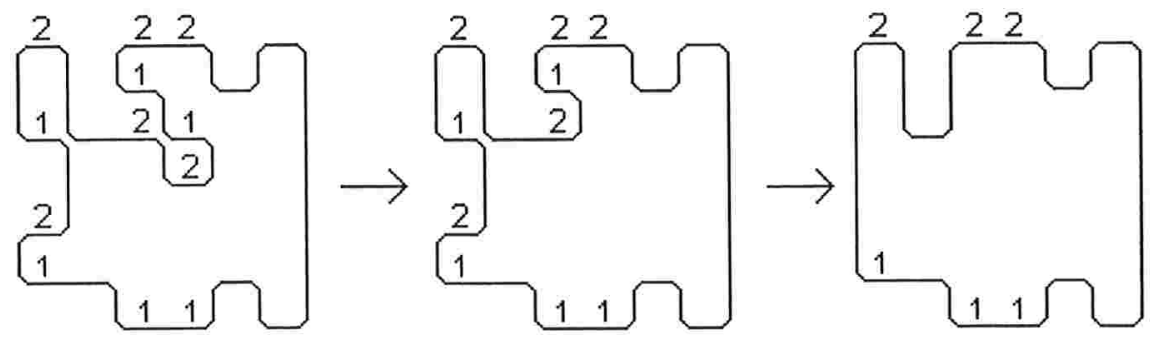

(b)

Figura 3.3: Exemplo de obtenção de um contorno verticalmente convexo a partir de um contorno com laços internos. Em (a) o contorno apresenta um laço aninhado " 21 "a partir da terceira coluna; o laço é removido em dois passos, trocando-se as configurações da terceira e da quarta coluna. Em (b) os pares remanescentes "12"são removidos por sucessivas trocas de configurações de colunas.

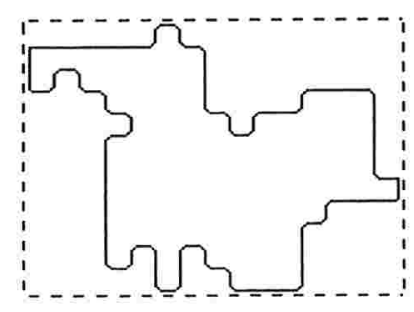

(a)

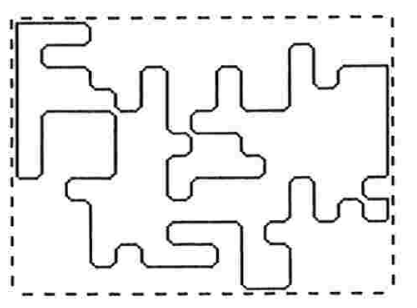

(b)

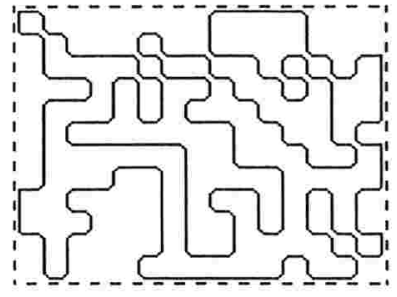

(c)

Figura 3.4: Exemplo de geração de contornos de Peierls em retângulo com $12 \times 15$ células, via MCMC. Em (a) $\beta=0,5$ e 12000 iterações; (b) $\beta=0,3$ e 3000 iterações; (c) $\beta=0,1$ e 1000 iterações. Os contornos foram gerados com a restrição de tocarem os limites do retângulo. 


\subsubsection{Alguns aspectos relacionados à convergência}

A cadeia $\mathcal{M}$ pode ser associada de modo usual a um passeio aleatório em um grafo não dirigido $G(V, E)$, com o conjunto de vértices $\Omega$ e o conjunto de $\operatorname{arcos}\{(i, j\} \in$ $\left.\Omega^{2}: p(i, j)>0\right\}$, com $\{p(i, j)\}$ definidos pelo algoritmo da seção 3.2. Considere um retângulo com $n \times m$ células, onde $n$ é a altura do retângulo. Um contorno não verticalmente convexo com $N$ elos que toca os limites laterais, a base e o topo retângulo, possui no máximo $N-2(m+n)$ elos internos para formar laços "21" ou "12". A remoção de um laço em um contorno reduz o total de elos em no mínimo duas unidades, já que para cada laço são removidos no mínimo um par de elos em uma mesma coluna. Portanto é possível remover todos os laços e obter um contorno verticalmente convexo em no máximo $N / 2-(m+n)$ operações de troca de colunas. Tomando-se $N$ igual ao número de elos de um retângulo, igual a $2 m n+m+n$, existe portanto um número $r<n m$ de transições que leva qualquer estado a um contorno verticalmente convexo. Para um contorno verticalmente convexo, é possível obter o contorno $\gamma_{0}$ percorrendo-se todas as colunas do retângulo em $m$ passos sucessivamente; portanto, dado os vértices $i, j$ em $G$, existe pelo menos um caminho $\operatorname{com} l<2(m n+n)$ arcos que conecta $i, j$ com uma visita ao estado $\gamma_{o}$. Além disto,

$$
P_{i, \gamma_{0}}>\left[(1 / m)\left(1 / 2^{n}\right)\right]^{r}=\epsilon
$$

onde $r=m(n+1)$, considerando que a cada transição, dado uma coluna antecessora com $n+1$ elos, há no máximo $2^{n}$ colunas candidatas que se casam com a coluna sucessora. Esta última propriedade é uma consequência direta das regras para a construção dos contornos de Peierls via matriz de transferência.

Além de estabelecer a viabilidade da obtenção de amostras de contornos de Peierls via MCMC da maneira proposta pelo algoritmo, é necessário verificar alguns aspectos relacionados à eficiência. Um problema básico em MCMC é a questão da escolha do tempo de $T$ para amostragem. Este é um ponto de extensa pesquisa no uso desta técnica; para o nosso problema específico o espaço de estados cresce exponencialmente com as dimensões da caixa, o que limita a eficiência na geração de contornos com $n$ grande.

Os movimentos de transição em cadeia de Markov em estruturas complexas, de modo geral, são efetuados de modo a produzir pequenas mudanças na estrutura 
dos objetos - ditas mudanças "locais". Isto pode causar uma velocidade lenta de convergência ao equilíbrio. Alterações grandes nas estruturas podem, por outro lado, produzir grandes oscilações na cadeia. O método proposto, com transições através de troca de colunas inteiras a cada passo, tende a produzir uma taxa de rejeição alta para $n$ grande, uma vez que a troca de uma coluna pode produzir candidatos com grande diferença no número de elos em relação ao estado atual da cadeia. Este fato tende a aumentar a taxa de rejeição nas transições. Este problema pode ser evitado alterando-se o algoritmo de modo a que, ao invés de trocas colunas inteiras, as transições sejam efetuadas por troca parcial de colunas, o que permite transições mais "suaves"e com maior taxa de aceitação.

\subsubsection{Geração de estados}

Para a cadeia proposta, resta resolver o problema de, dado o par $(j, \gamma)$, determinar um contorno $\gamma^{\prime} \in \mathcal{N}(\gamma, j)$ candidato à transição, de modo eficiente. Uma possibilidade imediata é a de gerar todas as configurações de colunas compatíveis com a $j$-ésima coluna e escolher uma coluna candidata para a transição de modo uniforme. Este processo pode se tornar muito lento já que é necessário gerar previamente todas as configurações de colunas possíveis e o número de configurações cresce exponencialmente com $n$.

Uma outra possibilidade é a utilização do método de aceitação/rejeição, explorando a maneira de como os contornos são gerados. Para cada vértice no retângulo definido por $\Lambda$, temos as relações de entrada/saída para os estados dos quatro elos adjacentes. Aqui podemos explorar o fato de que para cada entrada há exatamente duas saídas possíveis. Dada uma configuração de coluna antecessora, gerar uma configuração sucessora com $n+1$ elos equivale a escolher um caminho com $n+1$ vértices em uma árvore binária, a partir da origem. Associando uma probabilidade $1 / 2$ a cada escolha possível na árvore, um caminho de $n+1$ nós pode ser escolhido de modo uniforme via aceitação/rejeição. Uma vez escolhido uma coluna candidata, o passo da rejeição decorre das seguintes restrições, de acordo com a tabela na página 18:

1. Uma configuração de colunas aonde todos os elos são zeros deve ser rejeitada. Desta forma é evitada a formação de contornos "ilhas" separados em um mesmo 
retângulo.

2. As configurações geradas na última coluna devem ser "fecháveis", isto é, os laços devem ser conectados de modo a formar um contorno válido.

3. Uma configuração candidata deve substituir a original mantendo o contorno tocando a fronteira do retângulo;

4. Uma coluna gerada deve ser compatível com as colunas à esquerda e à direita.

Evidentemente a aceitação pode ser verificada ao mesmo tempo em que um configuração é gerada, a rejeição implica em gerar uma nova configuração desde o início. Este ponto parece comprometer em muito a eficiência na geração de colunas candidatas; no entanto deve ser considerado que o conjunto de restrições produz poucas saídas inválidas em relação ao número de elos da configuração. Para gerar uma coluna candidata, pode ser efetuado o seguinte: dado um par de elos com entrada, a cada saída possível (Tabela 1, pág. 18) é atribuído rótulo 0 ou 1. Desta maneira, dada uma coluna antecessora, uma coluna sucessora equivale a uma sequência codificada de escolhas $\left\{d_{i}\right\}_{i=0, \ldots n}, d_{i} \in\{0,1\}$ para as saídas possíveis.

Para detalhamento maior deste procedimento, considere que em cada vértice $k$ os estados dos elos adjacentes de entrada $\left(i_{2}, i_{2}\right)$ correspondem à saída $\left(o_{1}, O_{2}\right)$ (Figura 3.5). O procedimento GeraColuna $\left(c^{(j)}\right)$ gera uma configuração de elos $c^{(j+1)}=\left\{e_{0}, e_{1} \ldots e_{n}\right\}, e_{i} \in\{0,1,2\}$, para a coluna $j+1$ candidata à transição a partir da coluna $j$ :

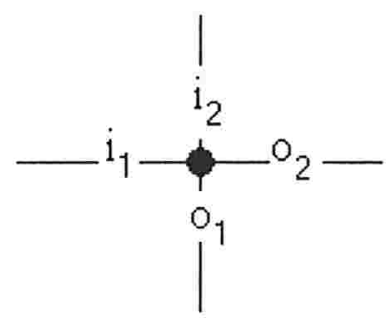

Figura 3.5: Os estados $i_{1}, i_{2}$ dos dois elos adjacentes ao vértice formam a "entrada"; os estados $o_{1}, o_{2}$ formam a "saída". 


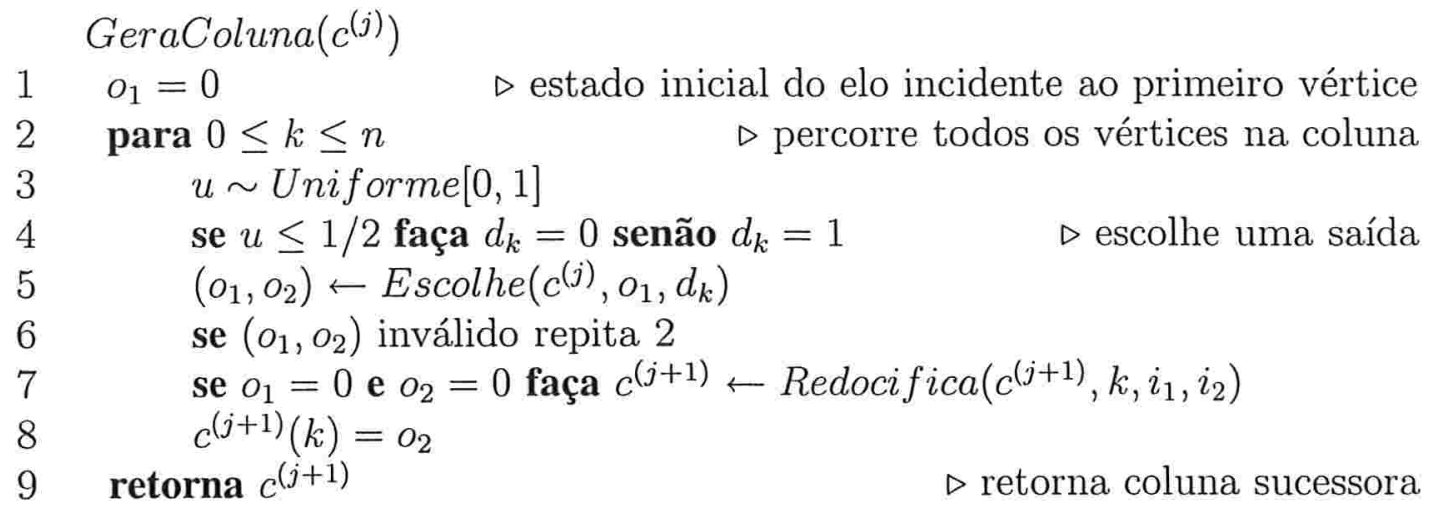

Na linha 4 o par de elos de saída é escolhido com probabilidade $1 / 2$. Na linha seguinte $E \operatorname{scolhe}\left(c^{(j)}, o_{1}, d_{k}\right)$ retorna o par de elos que formam a saída de acordo com a $j$-ésima coluna, o estado $o_{1}$ da saída anterior e o valor do rótulo $d_{k}$. Na linha 6 a coluna parcialmente gerada é rejeitada se a saída for inválida e neste caso uma nova configuração de coluna é realizada. $\mathrm{Na}$ linha 7 , se $\left(o_{1}, o_{2}\right)=(0,0)$ significa que um laço foi fechado; neste caso Recodifica $\left(c^{(j+1)}, k, i_{1}, i_{2}\right)$ efetua uma nova codificação para todos elos da coluna parcialmente gerada. Esta recodificação é necessária para considerar o novo estado dos elos provocado pelo eventual fechamento de um laço; o procedimento de recodificação é idêntico ao originalmente proposto por Enting[16] para os SAP's.

Uma vez gerada uma coluna candidata compatível com a coluna à esquerda, deve ser verificada a compatibilidade de $c^{(j+1)}$ com a coluna à direita, se houver. Neste caso não é difícil construir um procedimento que testa se a coluna à direita pode ser produzida a partir de $c^{(j+1)}$.

\subsection{Acoplamento}

A dinâmica proposta pelo algoritmo da seção (3.2) permite explorar as possibilidades de construir um acoplamento de duas cadeias de Markov cujo espaço de estados são contornos. Seja uma cadeia $\mathcal{N}$ com espaço de estados finito com $t$ discreto ou contínuo. Um acoplamento é processo estocástico $\left(X_{t}, Y_{t}\right)_{t \geq 0}$ onde os processos marginais $\left(X_{t}\right)_{t \geq 0}$ e $\left(Y_{t}\right)_{t \geq 0}$ são cópias de $\mathcal{M}$. Considere o acoplamento 
$\left(X_{t}^{(i)}, Y_{t}^{(j)}\right)_{t \geq 0}$ onde $X_{t}^{(i)}$ e $Y_{t}^{(j)}$ são cópias iniciadas nos estados $i, j$, respectivamente. Se existe $T^{i j}$ tal que

$$
X_{t}^{(i)}=Y_{t}^{(j)}, T^{i j} \leq t<\infty
$$

então $T^{i j}$ é denominado tempo de acoplamento e temos a desigualdade

$$
\left\|P^{(i)}\left(X_{t} \in .\right)-P^{(j)}\left(X_{t} \in .\right)\right\| \leq P\left(T^{i j}>t\right), 0 \leq t<\infty
$$

onde $\|$.$\| é a distância em variação total e P^{(i)}($.$) é a probabilidade do evento desig-$ nado por (.) para uma cadeia iniciada no estado $i$. Para espaço de estados discreto e supondo que $Y_{0}$ tenha como distribuição inicial a distribuição de equilíbrio, temos

$$
\sum_{x}\left|p^{t}(x)-\pi(x)\right| \leq P\left(X_{t} \neq Y_{t}\right)
$$

Um ponto de interesse nas simulações de processos estocásticos via cadeias de Markov é a questão de quantos passos são necessários para que a cadeia iniciada em um estado arbitrário se encontre "próxima"do estado de equilíbrio. Este tempo é usualmente denominado tempo de mistura (mixing time). Um algoritmo de simulação via cadeias de Markov deve exibir preferencialmente um tempo pequeno de mistura.

Um bom acoplamento permite uma rápida mistura. A questão é, dada uma cadeia, como construir um acoplamento eficiente em situações onde o espaço de estados é complexo.

Para uma cadeia com espaço de estados descrita nas seções anteriores, propomos um acoplamento de fácil implementação. A idéia é efetuar as transições maximizando as probabilidades de acoplamento em uma coluna.

Sem perda de generalidade e para maior clareza, consideremos o caso contínuo, com variáveis $X \in[a, b]$ e $X^{\prime} \in[c, d]$, com funções densidade uniforme $f_{1}, f_{2}$ respectivamente, $f_{1}>f_{2}$ e $a<c<b<d$. Para obter um acoplamento maximal de $X$ e $X^{\prime}$, um ponto é escolhido uniformemente sob $f_{1}$ e a coordenada $x$ do ponto é assumida como uma realização de $X$. Se o ponto está sob $f_{2}$, então $X^{\prime}=X=x$; se o ponto não está sob $f_{2}$, um novo ponto deve ser escolhido sob $f_{2}$ em $[b, d]$. A coordenada $x$ deste segundo ponto é então assumida como uma realização de $X^{\prime}$. Desta forma $P\left(X=X^{\prime}\right)$ é maximizada. Este procedimento é uma adaptação do utilizado 
para acoplamento maximal com funções densidades contínuas não uniformes; uma descrição detalhada de acoplamento maximal pode ser vista em [19].

Seja $C^{(j)}(\gamma)$ e $C^{(j)}\left(\gamma^{\prime}\right)$ o conjunto de configurações compatíveis com a j-ésima coluna de $\gamma$ e $\gamma^{\prime}$ respectivamente para produzir uma figura válida. A técnica descrita para um acoplamento maximal pode ser adaptada para o nosso problema, se considerarmos o caso discreto onde $f_{1}=1 /\left|C^{(j)}(\gamma)\right|$ e $f_{2}=1 /\left|C^{(j)}\left(\gamma^{\prime}\right)\right|$. O seguinte algoritmo corresponde um acoplamento maximal na geração das configurações de colunas para duas cadeias de Markov com transições por troca de coluna; a Figura 3.6 ilustra uma realização de duas cadeias geradas conforme proposto pelo algoritmo.

Algoritmo - Gera configurações de colunas candidatas à transição de modo acoplado

$\theta_{j}^{A}=$ configuração da $j$-ésima coluna na cadeia A

$\theta_{j}^{B}=$ configuração da $j$-ésima coluna na cadeia B

início

1 escolha $j \in\{1,2 \ldots m\}$ de modo uniforme;

2 gere $C^{(j)}(\gamma)$ e $C^{(j)}\left(\gamma^{\prime}\right)$

3 se $\left|C^{(j)}(\gamma)\right|<\left|C^{(j)}\left(\gamma^{\prime}\right)\right|$ troque os labels $\left(\gamma, \gamma^{\prime}\right)$

4 escolha $\theta_{j}^{A} \in C^{(j)}(\gamma)$ de modo uniforme

$5 u \sim$ Uniforme $[0,1]$

$6 \quad$ se $\theta_{j}^{A} \in C^{(j)}(\gamma) \cap C^{(j)}\left(\gamma^{\prime}\right)$ e $u \leq \frac{\left|C^{(j)}\left(\gamma^{\prime}\right)\right|}{\left|C^{(j)}(\gamma)\right|}$ faça $\theta_{j}^{B}=\theta_{j}^{A}$

7 senão

$8 \quad$ escolha $\theta_{j}^{B}$ de $C^{(j)}\left(\gamma^{\prime}\right) \backslash C^{(j)}(\gamma)$ de modo uniforme

9 repete 1 

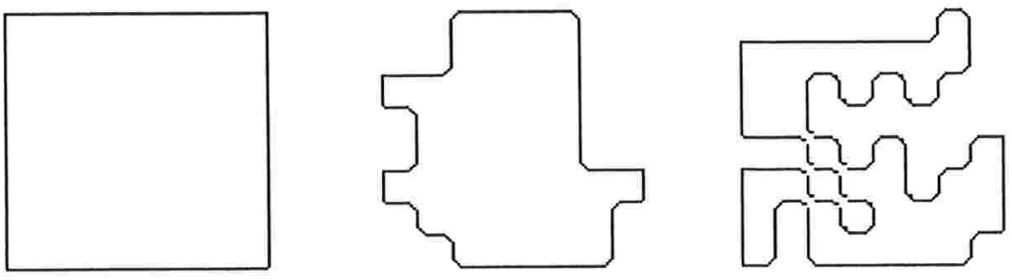

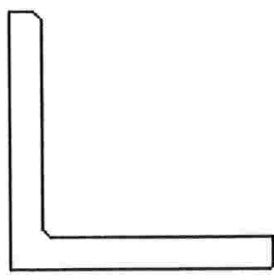

a

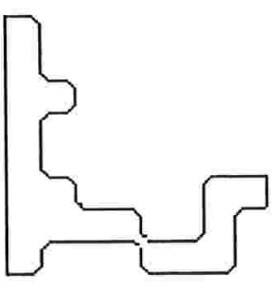

b

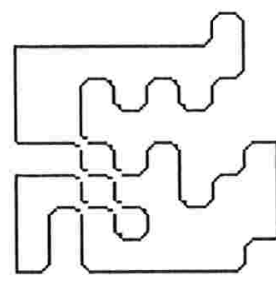

$\mathrm{C}$

Figura 3.6: Exemplo de acoplamento de duas cadeias com transições dadas pelo algoritmo proposto, em um retângulo com $8 \times 8$ células e $\beta=0,1$. Em (a) os estados iniciais. (b) Estados após algumas dezenas de passos e (c) configurações com o processo interrompido após 6400 passos $(T<6400)$. 


\section{Capítullo 4}

\section{Simulação perfeita de um processo espacial de nascimento e morte}

\subsection{O Backward Forward Algorithm}

\subsubsection{Introdução}

O algoritmo proposto recentemente por Fernandez, Ferrari e Garcia [3] permite uma simulação perfeita de processos espaciais que são absolutamente contínuos em relação a um processo pontual de Poisson. O algoritmo permite simular, entre outros, contornos de Peierls do modelo de Ising em baixas temperaturas e obter amostras perfeitas em uma janela finita $\Lambda \in \mathbb{Z}^{d}$ a partir de um processo marcado de nascimento e morte em $\mathbb{Z}^{d} \times \mathbb{R}$. Uma demonstração formal desta possibilidade é dada em [3]. No entanto, conforme já assinalamos, uma limitação neste caso é a necessidade de gerar os contornos de Peierls de modo uniforme, dado $\beta$ e o número de elos.

Nos próximos parágrafos descreveremos em linhas gerais o BFA e em seguida uma implementação, com as adaptações que realizamos, para o caso ferromagnético bidimensional, desenvolvida a partir das idéias apresentadas nos capítulos anteriores para a amostragem dos contornos. 


\subsubsection{O BFA para o modelo de Ising ferromagnético}

Um processo pontual $\psi$ é dito marcado se a cada ponto $\xi_{i}$ do processo está associado uma marca $m_{i} \in \mathbb{M}$, onde $\mathbb{M}$ é o espaço de marcas. As marcas podem ser variáveis contínuas, indicadoras de tipos ou estruturas mais complexas.

Uma configuração de spins do modelo de Ising ferromagnético em baixas temperaturas para $\Lambda \subset \mathbb{Z}^{2}$ pode ser associada de modo natural a um processo marcado. A dinâmica da evolução temporal do modelo, aonde spins mudam de estado em função do tempo, pode ser interpretada como a evolução temporal de contornos que "nascem"e "morrem"; esta é a conexão com processos de nascimento e morte. O BFA permite uma interessante construção gráfica em $\Lambda \times[0, t]$ de um processo marcado em $\mathbb{Z}^{2} \times \mathbb{R}$, de tal modo que os contornos associados ao processo marginal em $\Lambda \times\{0\}$ tenha como medida invariante a do modelo de Ising.

Para cada contorno $\gamma \in \mathbb{G}$ podemos associar uma origem em $\mathbb{Z}^{2}$. Seja $\mathrm{G}^{\prime}=$ $\mathbb{Z}^{2} \times \mathbb{G}$, onde a cada elemento de $\mathrm{G}^{\prime}$ estão associados uma coordenada espacial em $\mathbb{Z}^{2}$ e uma forma para o contorno. Diremos que dois contornos são equivalentes se coincidem após uma translação à origem; o conjunto formado por contornos que contém todos os elos no interior de $\Lambda \subset \mathbb{Z}^{2}$ será denominado por $\mathrm{G}_{\Lambda}^{\prime}$. Conforme descrito no capítulo 2, configurações de spins em $\Lambda \in \mathbb{Z}^{2}$ podem ser consideradas de modo equivalente como configurações de contornos compatíveis em $\Lambda$.

Definição 4.1 (contornos compatíveis) Os contornos $\Gamma, \Gamma^{\prime} \in \mathrm{G}^{\prime}$ são ditos compatíveis se não apresentam elos em comum e, se houver um vértice em comum, cada contorno apresenta somente curvas válidas neste vértice.

Escreveremos $\Gamma \sim \Gamma^{\prime}$ se $\Gamma, \Gamma^{\prime}$ compatíveis.

Um processo pontual marcado pode ser visto como um processo pontual ordinário em $\mathbb{Z}^{2} \times \mathbb{R} \times \mathbb{M}$, aonde a cada ponto do processo espacial $\left(\xi_{i}, T_{i}\right), \xi_{i} \in \mathbb{Z}^{2}, T_{i} \in \mathbb{R}$ está associada uma marca $m_{i} \in \mathbb{M}$. Considere um processo construído do seguinte modo: a cada $\left(\xi_{i}, T_{i}\right)$ de um processo de Poisson em $\mathbb{Z}^{2} \times \mathbb{R}$ está associado um contorno $\Gamma_{i} \in \mathrm{G}^{\prime}$, um intervalo de tempo $\left[T_{i}, T_{i}+S_{i}\right]$, onde todas estas variáveis são independentes, $S_{i} \sim \exp (1)$ e $Z_{i} \in\{0,1\}$. O processo assim construído é um 
processo marcado de nascimento e morte, com taxa de nascimento $\lambda$ e taxa de morte constante igual a 1 [3]. Para o modelo de Ising, $Z_{i}$ é uma variável indicadora aleatória que especifica se um contorno com instante de nascimento $t$ é compatível com os contornos já nascidos.

O processo $\mathbf{C}=\left\{\left(\xi_{i}, T_{i}, \Gamma_{i}, S_{i}, Z_{i}\right), i \in \mathbb{N}\right\}$ pode ser descrito de modo equivalente considerando-se que ao ponto $\left(\xi_{i}, T_{i}\right)$ está associado o cilindro

$$
C_{i}=\left(\Gamma_{i} \times\left[T_{i}, T_{i}+S_{i}\right], Z_{i}\right)
$$

que é especificado por uma base $\Gamma_{i} \in \mathbb{Z}^{2} \times \mathbb{G}$, um tempo de nascimento $T_{i}$, um tempo de vida $S_{i}$ e um indicador $Z_{i}$. De acordo com a notação utilizada em [3], os objetos e variáveis que compõem o cilindro genérico $C=(\Gamma \times[t, t+s]$, z) são designados como

$$
\operatorname{Basis}(\mathrm{C})=\Gamma, \operatorname{Birth}(\mathrm{C})=t, \operatorname{Life}(\mathrm{C})=[t, t+s] \text { e } \operatorname{Flag}(\mathrm{C})=z
$$

Definição 4.2 (cilindros incompatíveis) Os cilindros $C, C^{\prime}$ são incompatíveis se e somente se Basis $(C) \not \operatorname{Basis}\left(C^{\prime}\right)$ e Life $(C) \cap \operatorname{Life}\left(C^{\prime}\right) \neq \emptyset$.

Escreveremos $C \sim C^{\prime}$ para designar que os cilindros são compatíveis e $C \nsim C^{\prime}$, caso contrário.

O conjunto ancestrais de $\mathrm{C}$ é o conjunto de cilindros que nasceram antes de $\mathrm{C}$ e que são incompatíveis com C:

$$
\mathbf{A}_{1}^{C}=\left\{C^{\prime} \in \mathbf{C}: \operatorname{Birth}\left(C^{\prime}\right)<\operatorname{Birth}(C), C \nsim C^{\prime}\right\}
$$

O conjunto $A_{1}^{C}$ pode ser visto como um cluster de cilindros em $\mathbb{Z}^{2} \times \mathbb{R}$ que contém $\mathrm{C}$ e os cilindros que nasceram em momento anterior ao nascimento de $\mathrm{C}$. Recursivamente para $n \geq 2$ a n-ésima geração de ancestrais de $C$ é

$$
\mathbf{A}_{n}^{C}=\left\{C^{\prime \prime}: C^{\prime \prime} \in \mathbf{A}_{1}^{C^{\prime}} \text { para algum } C^{\prime} \in A_{n-1}^{C}\right\}
$$

O clã do cilindro C é a união de seus ancestrais:

$$
\mathbf{A}^{C}=\cup_{n \geq 1} \mathbf{A}_{n}^{C}
$$

A propriedade do processo de que um cilindro possui um clã finito com probabilidade um é fundamental e permite a construção gráfica proposta pelo algoritmo; para 
o modelo ferromagnético esta propriedade ocorre para $\beta>\beta_{c}$; uma demonstração formal pode ser vista em [3].

O BFA consiste basicamente em dois passos: o primeiro consiste em gerar, a partir de um conjunto inicial de cilindros em uma região finita $\Lambda \times\{0\}$, os seus ancestrais. Este passo é realizado gerando-se para cada cilindro em $T=0$ os ancestrais, em direção ao passado (passo backward). Os cilindros são gerados sem interação (processo livre); assim aglomerados formados por cilindros incompatíveis são obtidos. O segundo passo consiste em determinar, a partir do mais antigo ancestral, quais cilindros devem permanecer e quais devem ser apagados, de acordo com o critério de compatibilidade para os cilindros (passo forward). A interseção do conjunto de cilindros mantidos com $\Lambda \times\{0\}$ é uma amostra perfeita com medida invariante do processo infinito em $\mathbb{Z}^{2}$.

Para o modelo de Ising, a cada contorno $\gamma \in \mathbb{G}$ é associado um processo marginal pontual de Poisson com intensidade $w(\gamma)=e^{-2 \beta|\gamma|}$. O processo $\left\{\left(\Gamma_{i}, T_{i}\right), i \in I\right\}$ é um processo de Poisson em $\mathrm{G}^{\prime} \times \mathbb{R}$ com taxa $\nu \times l$, onde $l$ é a medida de Lebesgue em $\mathbb{R}, \nu=\sum_{\gamma \in \mathbb{G}} w(\gamma)=\sum_{i} N(i) e^{-2 \beta i}$, onde $N(i)$ é o número de contornos $\gamma \in \mathbb{G}$ com $i$ elos.

O algoritmo pode ser resumido como segue:

(1) Gere um processo pontual de Poisson $\left\{\xi_{1}, \xi_{2} \ldots \xi_{N}\right\}$ em $\Lambda \in \mathbb{Z}^{2}$ com média

$$
\sum_{i} N(i) e^{-2 \beta i}|\Lambda|
$$

onde $|$.$| denota número de pontos do conjunto.$

(2) A cada ponto $\xi_{i}$ associe um cilindro $C_{i}$, aonde a base é um contorno $\gamma_{i} \in \mathbb{G}$, escolhido de acordo com o peso $w^{(\beta)}\left(\gamma_{i}\right)$ e o tempo de vida dado por $S_{i} \sim \exp (1)$.

(3) Para cada cilindro da configuração inicial obtida nos passos 1 e 2, construa o clã de ancestrais do processo marcado em $\mathbb{Z}^{2} \times \mathbb{R}$. Nesta etapa os cilindros são considerados não interagentes (processo livre). 
(4) Uma vez gerado todos os ancestrais, efetue o refinamento ("cleaning procedure"), eliminando os cilindros de acordo com os critérios de incompatibilidade, a partir do mais antigo ancestral de cada clã com cilindros na configuração inicial.

A configuração de contornos que corresponde à interseção do conjunto de cilindros mantidos com $\Lambda \times\{0\}$ é uma amostra perfeita de uma configuração do modelo de Ising [3].

Para uma implementação do algoritmo, um ponto a ser considerado é a maneira de efetuar o passo (3), de modo a obter uma simulação exata para os clãs ancestrais. Em seguida discutiremos este ponto em mais detalhes.

\subsubsection{Simulação da rede com perdas}

A geração de um clã de cilindros em $\Lambda \times \mathbb{R}$ a partir de uma região finita $\Lambda$ não é uma questão trivial, pois para garantir que um clã seja completamente gerado é necessário considerar os cilindros que pertencem ao clã e que eventualmente podem ter coordenadas do centro que é associado ao processo pontual de Poisson fora de $\Lambda$. Para contornar este problema utilizamos um método para a geração do processo marcado nos mesmos moldes do método proposto em [3], mas considerando um conjunto maior de marcas, com cilindros discriminados em tipos ou cores. Este conjunto expandido de marcas permite a construção de um clã, dado uma configuração inicial em $T=0$, a partir da geração de processos pontuais apenas no volume ou áreas ocupadas por cada cilindro em $\mathbb{Z}^{2} \times \mathbb{R}$.

Dado um cilindro genérico $C$, seja $n, m$ as dimensões do menor retângulo que contém o contorno $\operatorname{Basis}(\mathrm{C})$ e $k_{i} \in\{-1,1\}, i=1,2,3$. Considere um processo pontual em $\mathbb{Z}^{2} \times \mathbb{R}$. A cada ponto $\left(x_{i}, y_{i}, t_{i}\right), x_{i}, y_{i} \in \mathbb{Z}, t_{i} \in \mathbb{R}$ do processo associamos as variáveis $k_{1}, k_{2}, k_{3}$, que definem o volume:

$$
\left[x_{i}, x_{i}+k_{1} m\right] \times\left[y_{i}, y_{i}+k_{2} n\right] \times\left[T_{i}, T_{i}+k_{3} S_{i}\right]
$$

onde $k=1+\sum_{i=1}^{3} 2^{i-2}\left(k_{i}+1\right), \gamma \in \mathbb{G}, S_{i}, T_{i} \in \mathbb{R}$. Desta forma um tipo $k \in\{1,2 \ldots 8\}$ 
é associado a cada cilindro, de acordo com a orientação espacial do cilindro em relação ao ponto $\left(x_{i}, y_{i}, t_{i}\right)$.

A idéia aqui é considerar que, em uma realização de um processo em $\mathbb{Z}^{2} \times \mathbb{R} \times \mathbb{M}$, as marcas que apresentam interseção com uma região finita $\Omega=\Lambda \times\left[t_{1}, t_{2}\right]$ podem ser geradas, de modo alternativo, através de um processo em $\mathbb{Z}^{2} \times \mathbb{R} \times \mathbb{M}^{\prime}$ no interior de $\Omega$, onde $\mathbb{M}^{\prime}$ é um conjunto expandido de marcas. Naturalmente esta possibilidade depende do tipo de marcas e natureza do processo. Como ilustração, considere o caso bidimensional de um processo $\left\{\left(\xi_{i}, M_{i}\right)\right\}_{i=1,2 . . n}$, onde os pontos $\xi_{i}$ juntos constituem um processo pontual de Poissson em $\mathbb{R}^{2}$ e $M_{i}$ são as marcas correspondentes a cada $\xi_{i}$. Considere o espaço de marcas $\mathbb{M}=\{[0, m] \times[0, n] ; m, n \in \mathbb{I}\}$. A marca $M_{i} \in \mathbb{M}$ é associada ao ponto $\left(x_{i}, y_{i}\right)$ transladando-se $M_{i}$ da origem ao ponto $\xi_{i}$ de modo a coincidir com a região $\left[x_{i}, x_{i}+m\right] \times\left[y_{i}, y_{i}+n\right]$. Considere agora um conjunto expandido de marcas, obtido associando-se os elementos de $\mathbb{M}$ de diferentes maneiras ao ponto $\xi_{i}$, de acordo com o vértice que é associado ao ponto. Neste caso há quatro maneiras de associar uma marca $M_{i} \in \mathbb{M}$ ao ponto $\xi_{i}$ ou, de modo equivalente, há quatro tipos de marcas a serem consideradas. A vantagem desta construção é que uma configuração de marcas que intercectam uma janela $\Lambda \subset \mathbb{R}^{2}$, em uma realização de um processo de marcas de um único tipo, pode ser obtida de modo equivalente considerando-se diferentes processos somente no interior de $\Lambda$, aonde as marcas são do tipo 1,2,3 e 4 (Fig. 4.1).

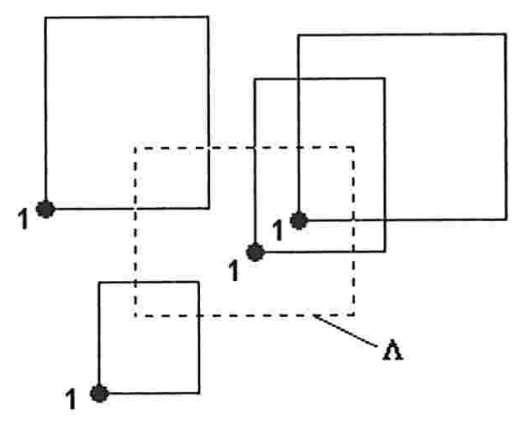

(a)

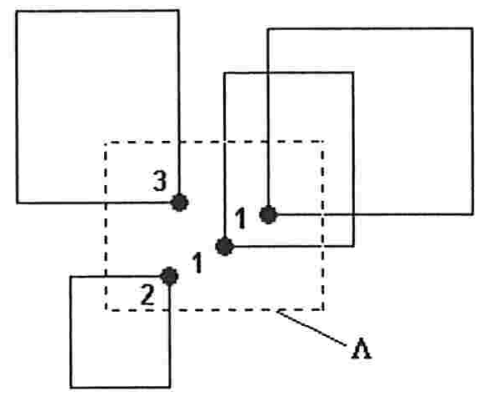

(b)

Figura 4.1: Em (a) um conjunto de marcas tipo 1 associadas a um processo pontual de Poisson em duas dimensões. Em (b) a mesma configuração, vista de modo alternativo como a realização de um processo de Poisson no interior de $\Lambda$ para marcas tipo 1,2 e 3. 
De modo similar, gerar uma configuração de cilindros incompatíveis com um cilindro genérico $C$ a partir de um processo pontual de Poisson $\phi_{\lambda}$ equivale, portanto, a gerar um processo pontual de Poisson $\phi_{\lambda}^{(k)}$ no interior de $C$ para cada $k \in \mathbb{L}$, onde $\mathbb{L}$ é o conjunto de cores. A cor ou tipo de marca pode ser relacionada ao vértice de um cilindro genérico que será associado ao ponto do processo. Neste caso o procedimento é equivalente a gerar um único processo no interior do cilindro $\mathrm{C}$ com intensidade $2^{d} \lambda$ e escolher, de modo uniforme, um tipo para cada ponto. Deste modo toda uma geração do clã ancestral pode ser obtida, a partir de um cilindro inicial, gerando-se apenas pontos no interior de cada cilindro da geração anterior. Denominando de cilindro "pai" o cilindro no interior do qual pontos de um processo pontual de Poisson são gerados e de cilindro "filho" os cilindros associados aos pontos no interior do cilindro pai, é fácil ver que a regra abaixo garante que configurações de cilindros incompatíveis sejam geradas com as taxas corretas, evitando-se que diferentes tipos de marcas produzam uma mesma configuração equivalente:

Regra: um cilindro tipo $k$ nao pode ter nenhum vértice correspondente a um cilindro tipo $i<k$ no interior do cilindro "pai".

\subsubsection{Simulação com tipos de cilindros}

Nesta seção apresentaremos uma implementação considerando processos com tipos de cilindros, conforme descrito na seção anterior. O algoritmo que utilizamos pode ser descrito como:

(1) Gere um processo pontual de Poisson $\left\{\xi_{1}, \xi_{2} \ldots \xi_{N}\right\}$ em $\Lambda \in \mathbb{Z}^{2}$ com intensidade $\lambda_{0}=\sum_{i} N(i) e^{-2 \beta i}$

(2) A cada ponto $\xi_{i}$ associe um cilindro $C_{i}$, aonde a base é um contorno $\gamma_{i} \in \mathbb{G}$, escolhido de acordo com o peso $w^{(\beta)}\left(\gamma_{i}\right)$ e o tempo de vida dado por $S_{i} \sim \exp (1)$.

(3) Para cada cilindro da geração atual construa o processo $\phi_{\lambda}$ pontual de Poisson no volume definido pela base do cilindro e o tempo de vida, 
$\operatorname{com} \lambda=8 \lambda_{0}$

(4) Para cada ponto de $\phi_{\lambda}$ associe um cilindro tipo $k$, onde $k \in\{1,2, \ldots 8\}$ escolhido de modo uniforme, a base do cilindro de acordo com os pesos calculados previamente e tempo de vida $\exp (1)$, formando assim uma nova geração de cilindros.

(5) Repita 3 para a nova geração de cilindros até formar todos os clãs de ancestrais.

(6) Efetue o refinamento, eliminando os cilindros de acordo com os critérios de incompatibilidade, a partir do mais antigo ancestral.

Para uma descrição mais detalhada da implementação efetuada, utilizaremos a seguinte notação e variáveis adicionais, além das utilizadas na formulação original em [3]:

- $\mathbb{G}_{n m} \in \mathbb{G}$ é o conjunto de contornos tal que, se $\gamma \in \mathbb{G}_{n m}$, então o retângulo $n \times m$ células é o menor retângulo que contém $\gamma$. À "caixa" $\Theta_{n m}=[0, n] \times[0, m]$ está associado portanto o peso $w^{(\beta)}\left(\mathbb{G}_{n m}\right)=\sum_{\gamma \in \mathbb{G}_{n m}} w^{(\beta)}(\gamma)$.

- $\operatorname{Basis} Y(C)=n, \operatorname{Basis} X(C)=m$

- Label $(C)$ para o tipo do cilindro.

- Origem $(C)$ são coordenadas em $\mathbb{Z}^{2} \times \mathbb{R}$ do cilindro em relação à origem de $\Lambda$. 


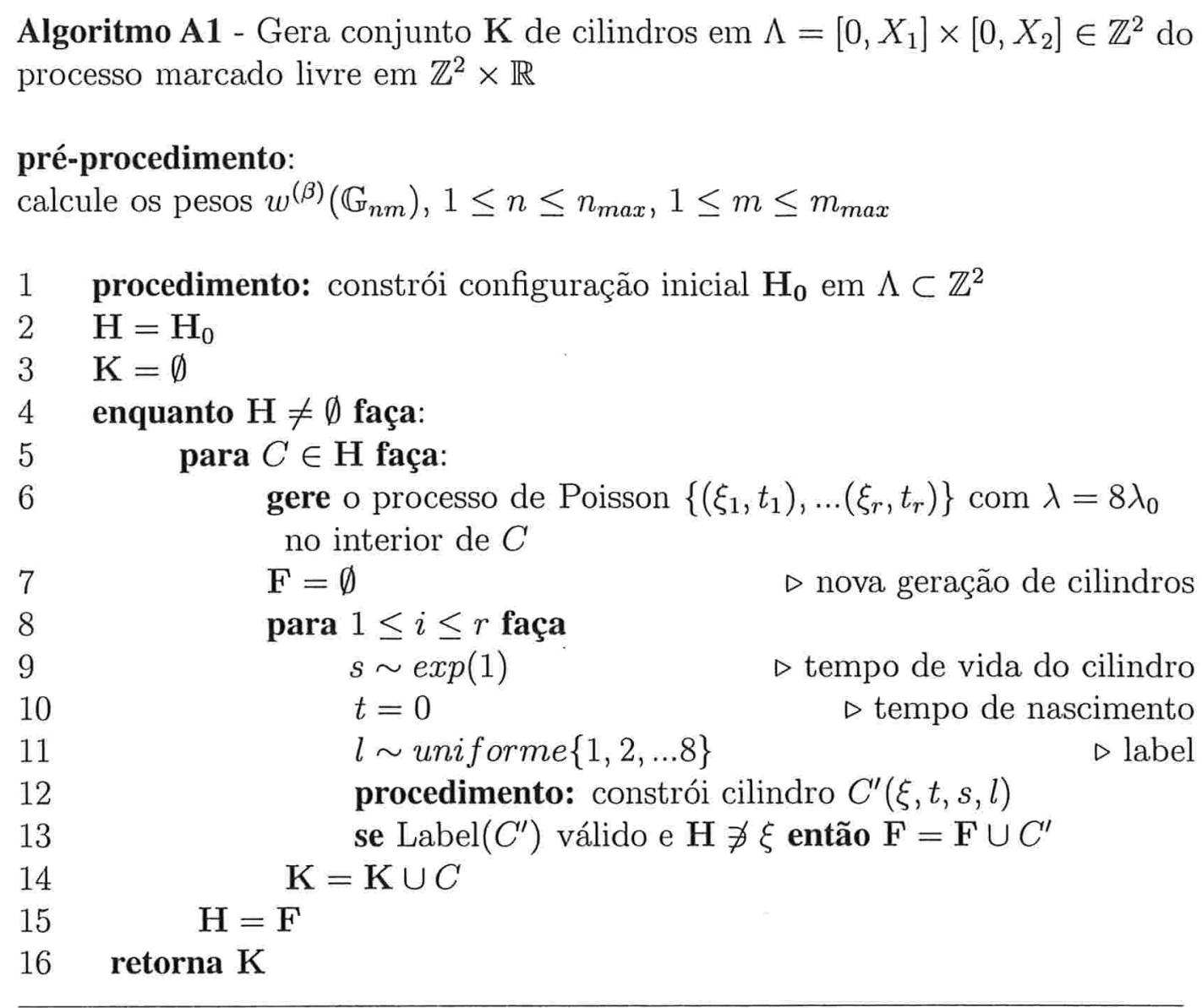

Procedimento: configuração inicial de cilindros $\mathrm{H}_{0}$ em $\Lambda \subset \mathbb{Z}^{2}$;

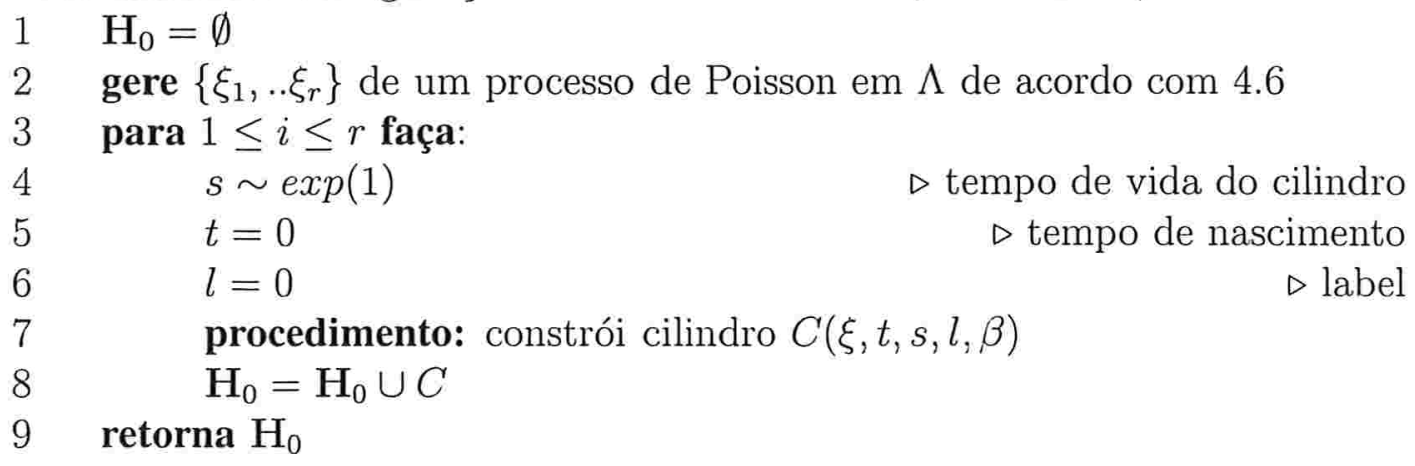


Procedimento: constrói cilindro $C(\xi, t, s, l, \beta)$

1 escolha um conjunto $\mathbb{G}_{n m}$ de acordo com os pesos $w^{\beta}\left(\mathbb{G}_{n m}\right)$

$2 \operatorname{Basis}(\mathrm{C})=\gamma \in \mathbb{G}_{n m}$ de acordo com o peso $w^{\beta}(\gamma)$

$3 \quad \operatorname{BasisX}(\mathrm{C})=m$

$4 \quad \operatorname{Basis} \mathrm{Y}(\mathrm{C})=n$

$5 \quad \operatorname{Label}(C)=l$

$6 \operatorname{Birth}(\mathrm{C})$, Origem(C) e Life(C) de acordo com $\xi$ e $l$

$7 \quad \operatorname{Flag}(\mathrm{C})=1$

\section{Refinamento do processo livre}

O procedimento para o refinamento é basicamente o apresentado por Ferrari, Fernandez e Garcia [3], com pequenas alterações. Na versão que desenvolvemos, a cada cilindro é atribuído um indicador para tentativa de nascimento válida; uma tentativa de nascimento é válida se existe compatibilidade entre o cilindro e todos os já nascidos. Deste modo, em uma implementação do algoritmo, os cilindros que devem ser eliminados devido à interação não o são de fato, apenas recebem um indicador para tentativa de nascimento não válida. No final somente os cilindros da configuração inicial com indicador apropriado são considerados.

Algorimo - Refinamento do processo marcado em $\mathbb{Z}^{2} \times \mathbb{R}$

K conjunto de cilindros do processo livre.

1 ordene $\mathrm{K}=\left\{C_{1}, \ldots C_{r}\right\}$ em função do tempo de nascimento

2 para $1 \leq i \leq r$ faça:

$3 \quad$ para $i<j \leq r$ faça:

$4 \quad$ se $\operatorname{Flag}\left(C_{i}\right)=1$ e $C_{i} \nsim C_{j}$ então $\operatorname{Flag}\left(C_{j}\right)=0$

$5 \quad$ retorna $\{C \in \mathrm{K}: \mathrm{Flag}(C)=1 ; \tau(C)=0\}$

Na linha 1 o conjunto de cilindros em $\mathrm{K}$ é ordenado de acordo com: $C \prec C^{\prime}$ se e somente se $\operatorname{Brith}(C) \prec \operatorname{Birth}\left(C^{\prime}\right)$. 


\section{Correção para geração dos cilindros do processo livre}

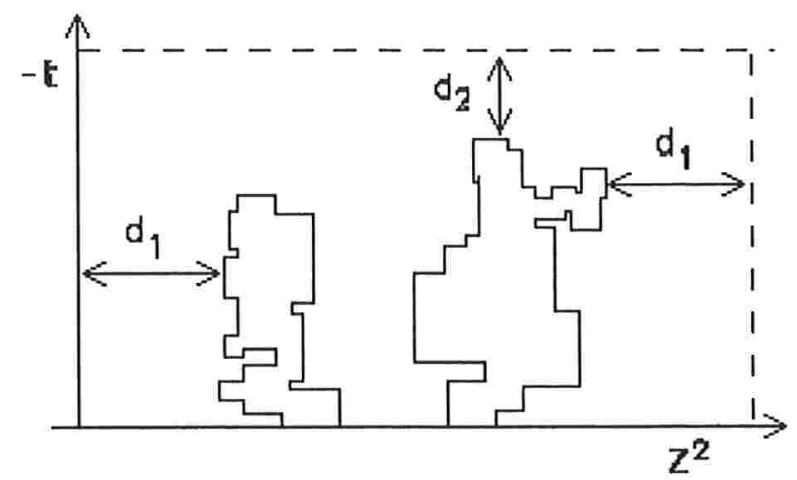

Figura 4.2: Em (a) um conjunto de marcas tipo 1 associados a pontos de um processo de Poisson.

No método de construção proposto para o processo infinito, alguns cilindros não são considerados na construção do processo, que são os que eventualmente apresentam interseção não nula com um clã gerado conforme o algoritmo mas não possui vértices no interior de nenhum cilindro. Para levar em consideração esta possibilidade, seja a região $\left[x_{\min }, x_{\max }\right] \times\left[y_{\min }, y_{\max }\right] \times\left[0, t_{\max }\right]$ o menor volume que contém os cilindros do processo livre em $\mathbb{Z}^{2} \times \mathbb{R}$ gerados pelo método proposto. Valores iniciais para as distâncias $d_{1}, d_{2} \in \mathbb{R}$ podem ser escolhidas de modo que a probabilidade de ocorrência de cilindros que interceptam algum cluster mas que não estejam inteiramente contidos em $\Lambda^{\prime}=\left[x_{\min }-d_{1}, x_{\max }+d_{1}\right] \times\left[y_{\min }-d_{1}, y_{\max }+\right.$ $\left.d_{1}\right] \times\left[0, t_{\max }+d_{2}\right]$ seja arbitrariamente pequena. Uma vez definido $\Lambda^{\prime}$ :

(1) Gere um processo marcado $\Phi$ em $\Lambda^{\prime}$ de acordo com 4.6 .

(2) Aceite os cilindros em (1) que não tenham vértices no interior de $\mathbf{K}$. Este passo elimina cilindros aonde o processo marcado já foi gerado.

(3) Para cada cilindro $C_{i} \in \Phi, i=1,2 \ldots$ que permanece após o passo (2) faça $\mathrm{K}=\mathrm{K} \cup C_{i}$. 
O volume $\Lambda^{\prime}$ deve ser escolhido antes da geração de amostras, de modo que a probabilidade de um cilindro $C \in \mathbf{K}$ não esteja inteiramente contido em $\Lambda^{\prime}$ seja pequena; ajustes nas escolhas iniciais podem ser realizadas.

Esta limitação na construção exata dos aglomerados de cilindros pode no entanto ser removida completamente, em uma construção gráfica alternativa, aonde a idéia de cilindros multitipos é generalizada e processos pontuais gerados apenas em $\mathbb{Z}^{2}$, nas bases de cada cilindro.

\subsubsection{Uma contrução gráfica para o processo infinito}

No procedimento descrito na seção 4.1.3, um espaço de marcas aumentado é obtido associando-se as marcas de um espaço inicial $\mathbb{M}$ aos pontos do processo pontual de Poisson de diferentes modos. Uma generalização desta idéia é considerar que, para um contorno $\theta \in \mathbb{G}$, há $\nu(\theta)$ modos de associá-lo a um ponto genérico $\xi$ de um processo pontual, onde $\nu$ é o volume. A associação ocorre quando a um centro aleatório $x \in \theta$ é atribuído as coordenadas de $\xi$.

No procedimento a seguir, o uso de marcas com centros aleatórios é utilizada para contemplar todas as possibilidades de configurações de cilindros incompatíveis. Um processo pontual de Poisson é gerado apenas em regiões fintas de $\mathbb{Z}^{2}$, que correspondem às bases dos cilindros. Uma vez gerado um contorno para $T=t$, um cilindro com Life $(C)=\left[T-e_{1}, T+e_{2}\right]$ é formado gerando-se $e_{1}, e_{2}$ com distribuição $\exp (1)$.

O processo pode ser simplificado considerando-se marcas em $\mathbb{Z}^{2}$ como regiões $m \times$ $n$ células e peso $w^{(\beta)}\left(\mathbb{G}_{n m}\right)$. Dado um retângulo, um contorno pode ser amostrado conforme o procedimento descrito no capítulo 3.

Para o processo $\phi_{\lambda}$ de Poisson em $\Lambda \in \mathbb{Z}^{2}$, a intensidade é

$$
\lambda=\sum_{\gamma \in \mathbb{G}} N(|\gamma|) e^{-2 \beta|\gamma|}=\sum_{n, m \in \mathbb{I}} \sum_{\gamma \in G} N(|\gamma|) e^{-2 \beta|\gamma|} 1_{\left\{\gamma \in \mathbb{G}_{n m}\right\}}=\sum_{n, m \in \mathbb{I}} w^{(\beta)}\left(\mathbb{G}_{n m}\right)
$$

onde $w^{(\beta)}\left(\mathbb{G}_{n m}\right)=\sum_{\gamma \in \mathbb{G}_{n m}} w^{(\beta)}(\gamma)$ é o peso da caixa $\Theta_{n m}=[0, n] \times[0, m]$

Este processo pode ser gerado em $\Lambda$ de modo equivalente: considere um processo 
pontual de Poisson em $\Lambda$ para cada $\Theta_{n m}, m, n \in \mathbb{I}$, com intensidade $w^{(\beta)}\left(\mathbb{G}_{n m}\right) \nu\left(\Theta_{n m}\right)$. Para cada ponto do processo gere uma marca $\Theta$ de acordo com $w^{(\beta)}(\Theta)$; a marca é aceita com probabilidade $1 / \nu(\Lambda \cap \Theta)$.

A seguir uma descrição mais detalhada do algoritmo.

Algoritmo - Gera conjunto de cilindros $\mathbf{K}$ em $[0, X] \times[0, Y] \times \mathbb{R}$

$\Lambda(C)=[x, x+\operatorname{Basis} X(C)] \times[y, y+\operatorname{Basis} Y(C)], x, y \in \mathbb{Z}$ coordenadas da Origem $(\mathrm{C})$.

$\eta=\sum_{n, m} w^{(\beta)}\left(\mathbb{G}_{n m}\right) \nu\left(\Theta_{n m}\right)$

$C_{0}=$ cilindro inicial: $\operatorname{BasisX}\left(C_{0}\right)=X, \operatorname{Basis} Y\left(C_{0}\right)=Y, \operatorname{Birth}\left(C_{0}\right)=0, \operatorname{Flag}\left(C_{0}\right)=1$ e demais atributos vazios ou nulos.

início:

(1) $\mathbf{K}=\emptyset, \mathbf{H}=C_{0}$

(2) Escolha $C \in \mathrm{H}$ e faça $T=\operatorname{Birth}(\mathrm{C})$

(3) Gere um processo pontual de Poisson $\phi_{\eta}=\left\{\xi_{1}, \xi_{2} \ldots \xi_{r}\right\}$ em $\Lambda(C)$

(4) Para $\xi \in \phi_{\eta}$

(5) Escolha $\Theta_{n m}$ de acordo com o peso $w^{\beta}\left(\mathbb{G}_{n m}\right)$

(6) Escolha o centro $x \in \Theta_{n m}$, de modo uniforme. Ao par $\left\{\Theta_{n m}, x\right\}$ corresponde a marca $\theta_{n m}^{x}$, com a forma dada por $\Theta_{n m}$ e centro $x$

(7) Aceite a marca $\theta_{n m}^{x}$ com probabilidade $1 / \nu\left(\Lambda(C) \cap \theta_{n m}^{x}\right)$ 
(8) Se a marca é aceita, faça

(9) $e_{1} \sim \exp (1), e_{2} \sim \exp (1)$

(10) Escolha $\gamma \in \mathbb{G}_{n m}$ de acordo com o peso $w^{(\beta)}(\gamma)$

(11) Construa o cilindro $C^{\prime} \operatorname{com} \operatorname{Life}\left(C^{\prime}\right)=\left[T-e_{1}, T+e_{2}\right]$, $\operatorname{Basis}\left(C^{\prime}\right)=\gamma, \operatorname{Birth}\left(C^{\prime}\right)=T-e_{1}, \operatorname{Flag}\left(C^{\prime}\right)=1$ e demais atributos de acordo com $m, n, \xi, x$

(12) Se não há interseção de $\Lambda\left(C^{\prime}\right) \times \operatorname{Life}\left(C^{\prime}\right)$ com uma região aonde um processo $\phi_{\eta}$ já tenha sido gerado, isto é, região $\Lambda\left(C^{\prime \prime}\right) \times\left\{\operatorname{Birth}\left(C^{\prime \prime}\right)\right\}$ para algum $C^{\prime \prime} \in \mathbf{K}$, faça $\mathbf{F}=\mathbf{F} \cup C^{\prime}$. $\mathrm{O}$ conjunto $\mathbf{F}$ é formado pelos "filhos" dos cilindros de $\mathbf{H}$

(13) Faça $\mathbf{K}=\mathbf{K} \cup C, \mathbf{H}=\mathbf{H} \backslash\{C\}$

(14) Se $H \neq \emptyset$ repita 2

(15) Se $\mathbf{F}=\emptyset$ faça $\mathbf{K}=\mathbf{K} \backslash\left\{C_{0}\right\}$ e fim. Senão faça $\mathbf{H}=\mathbf{F}$ e repita 2

A seguir apresentamos a versão deste algoritmo conforme implementado neste trabalho: 


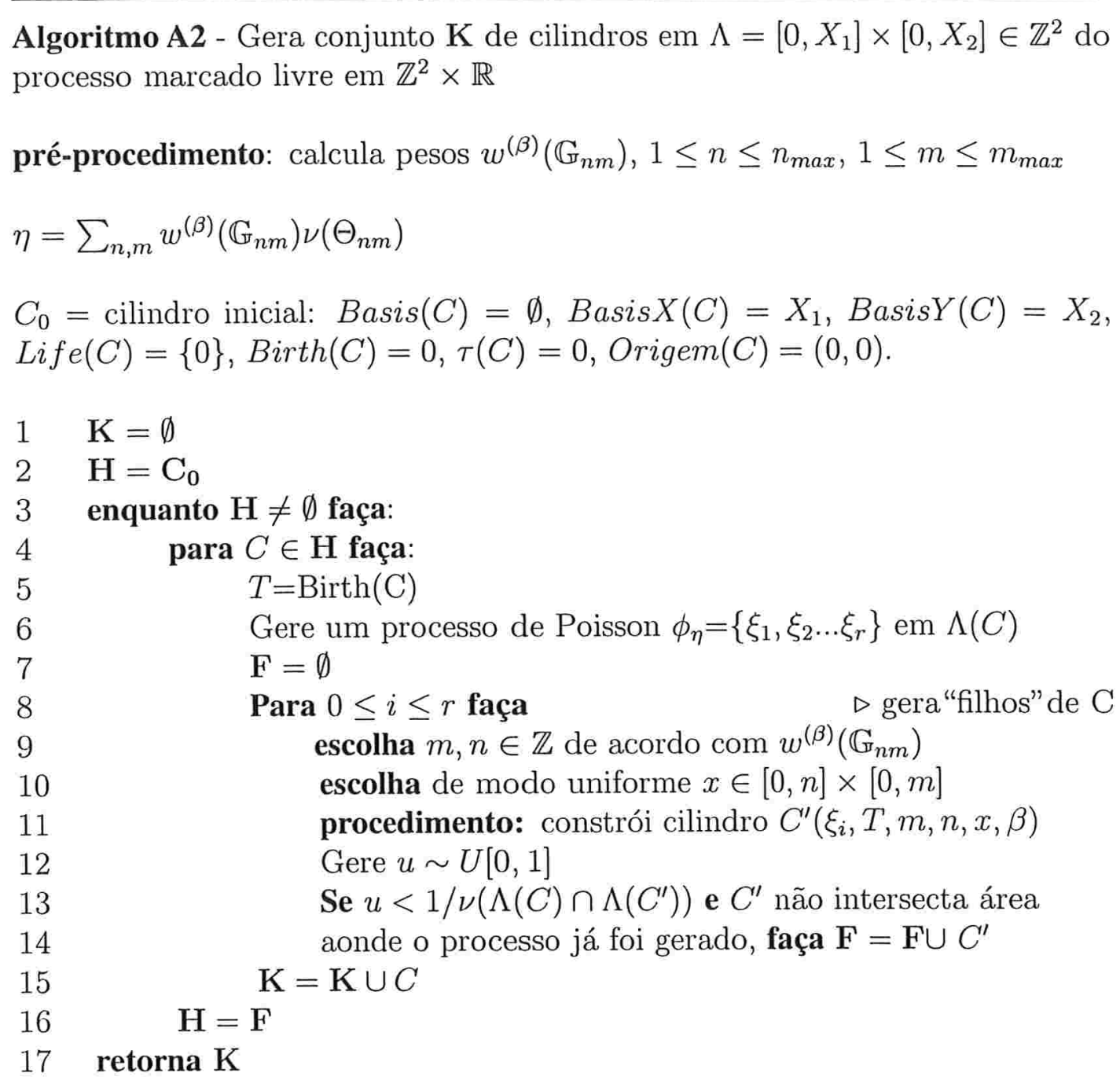


Procedimento: constrói cilindro $C(\xi, T, m, n, x, \beta)$

$1 \quad$ Escolha $=\gamma \in \mathbb{G}_{n m}$ de acordo com o peso $w^{\beta}(\gamma)$

$2 \operatorname{Basis}(\mathrm{C})=\gamma$

$3 \quad \operatorname{BasisX}(\mathrm{C})=m$

$4 \quad \operatorname{Basis} Y(\mathrm{C})=n$

$5 \quad e_{1} \sim \exp (1)$

$6 \quad e_{2} \sim \exp (1)$

$7 \quad \operatorname{Birth}(\mathrm{C})=T-e_{1}$

$8 \quad \operatorname{Life}(C)=\left[T-e_{1}, T+e_{2}\right]$

9 Origem $(C)$ de acordo com $\xi$ e as coordenadas de $x$

$10 \quad \mathrm{Flag}(\mathrm{C})=1$

Após a obtenção do conjunto $\mathbf{K}$ de cilindros do processo livre, o passo do refinamento é executado de modo idêntico ao descrito na seção 4.1.4.

\subsection{Resultados}

Na Tabela 1 do apêndice estão o número $N(i)$ de contornos $\gamma \in \mathbb{G}$ em função do número $i$ de elos; na Tabela 2 os pesos dos conjuntos $\mathbb{G}_{n m}$, obtidos com o procedimento para contagem descrito no Capítulo 2.

A Figura 4.3 é uma amostra de uma rede $50 \times 50, \operatorname{com} \beta=0.56$. A amostra foi obtida em uma simulação via BFA do modelo de Ising em $2 \mathrm{D}$, com a determinação prévia dos pesos dos contornos conforme descrito.

O valor de $\beta$ para uma simulação é limitada pelo comportamento crítico do processo de nascimento e morte de contornos, pois devemos ter $\beta>\beta_{P}$, onde $\beta_{P}$ é o valor crítico para a probabilidade de percolação. Do ponto de vista computacional há ainda a limitação devida ao cálculo prévio dos pesos dos contornos. Esta última ocorre uma vez que uma enumeração eficiente é limitada por um perímetro máximo, de acordo com a disponibilidade de memória e tempo de computação. No processo de nascimento e morte, para valores $\beta$ muito altos a probabilidade de contornos grandes é baixa; no entanto para simulações com $\beta$ próximo a $\beta_{P}$ a probabilidade de nascimento de grandes contornos pode ser significativa.

Uma determinação do $\beta$ máximo pode ser obtida considerando-se como limite 
superior em duas dimensões para o número de contornos $N(i)$ com $i$ elos o número de passeios aleatórios possíveis com $i$ passos:

$$
\sum_{\gamma \in \mathbb{G}} N(|\gamma|) e^{-2 \beta|\gamma|}<\sum_{i=4,6 \ldots} 4 \cdot 3^{i} e^{-2 \beta i}
$$

Esta última série converge para $\beta>\beta_{P}=(1 / 2) \operatorname{Ln} 3 \approx 0.55$. O valor $\beta_{P}$ é a "percolação de Peierls"[33].

De acordo com os dados no Apêndice 1, é possível calcular alguns valores como referência para simulação. Para $\beta=0.56$, a taxa do processo de Poisson em $\Lambda \subset \mathbb{Z}^{2}$ associado a um contorno com 54 elos é $1.26 \times 10^{-8} \nu(\Lambda)$; para $\beta=0.6$, a taxa é $<10^{-8} \nu(\Lambda)$ para contornos com perímetro $>40$. Desta forma, uma simulação para $\beta>0.6$ em uma área com $100 \times 100$ células, por exemplo, é possível com boa aproximação com a utilização de contornos com até 50 elos.

A Figura 4.4 mostra a magnetização por sítio para uma grade $100 \times 100$, obtida para vários valores de $\beta>0.55$. Cada ponto assinalado é a média de 1000 simulações obtidas com o algoritmo A2 e enumeração de contornos com até 58 elos; a linha corresponde aos valores exatos de acordo com a solução proposta por Onsager [27] para o modelo de Ising em duas dimensões em baixas temperaturas.
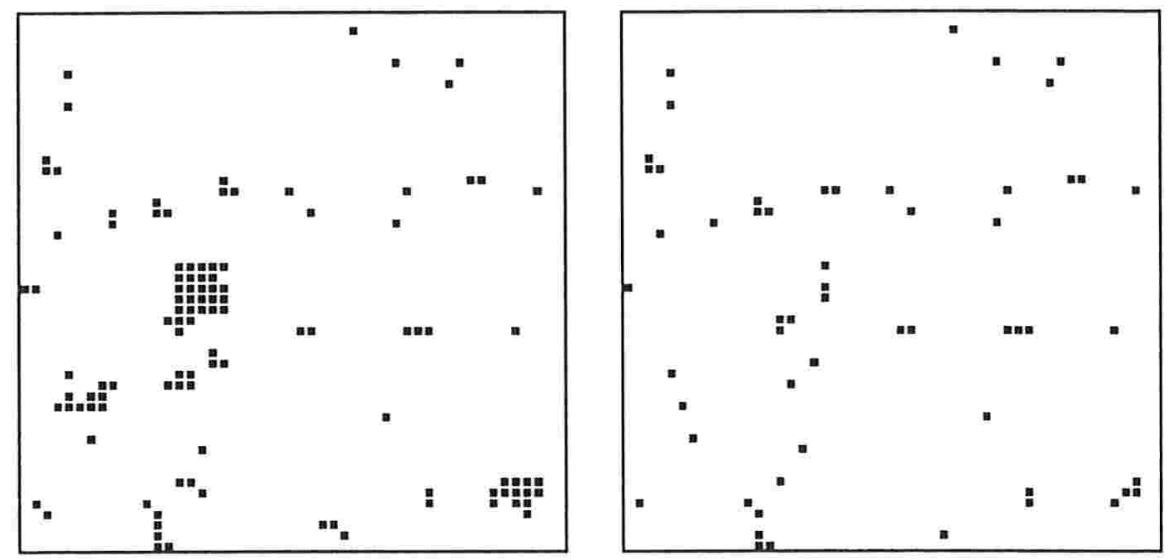

Figura 4.3: Simulação para uma rede $50 \times 50, \beta=0.56$. A figura à esquerda é o processo livre; à direita após o refinamento. 


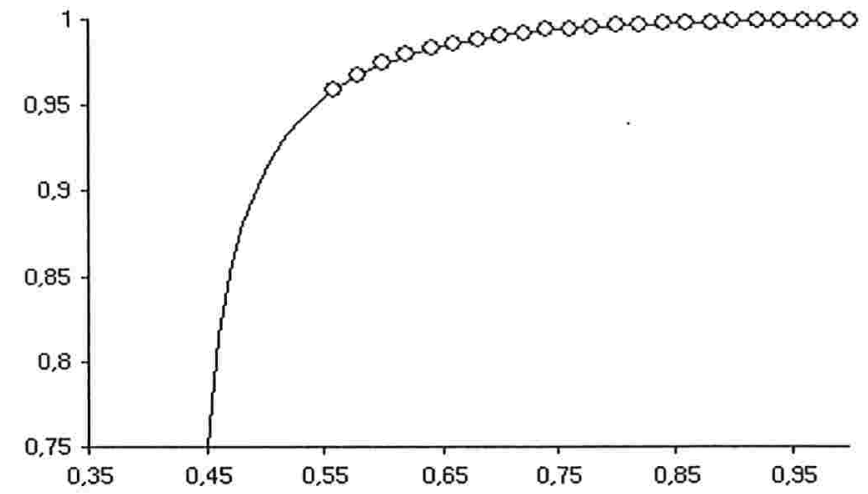

Figura 4.4: Magnetização $M$ para uma grade $100 \times 100$ em função de $\beta$. Cada ponto assinalado é a média de 1000 simulações obtidas com o algoritmo A2; a linha corresponde aos valores teóricos. 


\section{Apêndice}

Tabela 1 - Número de contornos $\gamma \in \mathbb{G}$ em função do número de elos $i$.

\begin{tabular}{|l|r||l|r|}
\hline \multicolumn{4}{|l|}{ Tabela 1 } \\
\hline \hline $\mathrm{i}$ & $N(i)$ & $\mathrm{i}$ & $N(i)$ \\
\hline \hline 4 & 1 & 32 & $3,91532 \mathrm{E}+09$ \\
6 & 2 & 34 & $2,37797 \mathrm{E}+10$ \\
8 & 8 & 36 & $1.45676 \mathrm{E}+11$ \\
10 & 32 & 38 & $8.99294 \mathrm{E}+11$ \\
12 & 145 & 40 & $5.58999 \mathrm{E}+12$ \\
14 & 698 & 42 & $3.49641 \mathrm{E}+13$ \\
16 & 3542 & 44 & $2.19930 \mathrm{E}+14$ \\
18 & 18674 & 46 & $1.39054 \mathrm{E}+15$ \\
20 & 101525 & 48 & $8.83331 \mathrm{E}+15$ \\
22 & 565816 & 50 & $5.63563 \mathrm{E}+16$ \\
24 & 3218844 & 52 & $3.60987 \mathrm{E}+17$ \\
26 & $1,86302 \mathrm{E}+07$ & 54 & $2.32082 \mathrm{E}+18$ \\
28 & $1,09428 \mathrm{E}+08$ & 56 & $1.49719 \mathrm{E}+19$ \\
30 & $6,50949 \mathrm{E}+08$ & 58 & $9.68923 \mathrm{E}+19$ \\
\hline
\end{tabular}

Tabelas 2,3,4 e 5 - Número de contornos $\gamma \in \mathbb{G}$ que tocam as laterais, base e topo de um retângulo com $n \times m$. 


\begin{tabular}{|rr|r|r|r|r|r|r|r|r|r|}
\hline \multicolumn{2}{|l|}{ Tabela 2} \\
\hline $\mathrm{n}$ & $\mathrm{m}$ & $\mathrm{s}=4$ & $\mathrm{~s}=6$ & $\mathrm{~s}=8$ & $\mathrm{~s}=10$ & $\mathrm{~s}=12$ & $\mathrm{~s}=14$ & $\mathrm{~s}=16$ & $\mathrm{~s}=18$ & $\mathrm{~s}=20$ \\
\hline 1 & 1 & 1 & 0 & 0 & 0 & 0 & 0 & 0 & 0 & 0 \\
1 & 2 & 0 & 1 & 0 & 0 & 0 & 0 & 0 & 0 & 0 \\
1 & 3 & 0 & 0 & 1 & 0 & 0 & 0 & 0 & 0 & 0 \\
1 & 4 & 0 & 0 & 0 & 1 & 0 & 0 & 0 & 0 & 0 \\
1 & 5 & 0 & 0 & 0 & 0 & 1 & 0 & 0 & 0 & 0 \\
1 & 6 & 0 & 0 & 0 & 0 & 0 & 1 & 0 & 0 & 0 \\
1 & 7 & 0 & 0 & 0 & 0 & 0 & 0 & 1 & 0 & 0 \\
1 & 8 & 0 & 0 & 0 & 0 & 0 & 0 & 0 & 1 & 0 \\
1 & 9 & 0 & 0 & 0 & 0 & 0 & 0 & 0 & 0 & 1 \\
2 & 2 & 0 & 0 & 6 & 0 & 0 & 0 & 0 & 0 & 0 \\
2 & 3 & 0 & 0 & 0 & 15 & 4 & 0 & 0 & 0 & 0 \\
2 & 4 & 0 & 0 & 0 & 0 & 28 & 24 & 1 & 0 & 0 \\
2 & 5 & 0 & 0 & 0 & 0 & 0 & 45 & 80 & 17 & 0 \\
2 & 6 & 0 & 0 & 0 & 0 & 0 & 0 & 66 & 200 & 103 \\
2 & 7 & 0 & 0 & 0 & 0 & 0 & 0 & 0 & 91 & 420 \\
2 & 8 & 0 & 0 & 0 & 0 & 0 & 0 & 0 & 0 & 120 \\
3 & 3 & 0 & 0 & 0 & 0 & 79 & 52 & 22 & 0 & 0 \\
3 & 4 & 0 & 0 & 0 & 0 & 0 & 253 & 364 & 263 & 92 \\
3 & 5 & 0 & 0 & 0 & 0 & 0 & 0 & 621 & 1652 & 1835 \\
3 & 6 & 0 & 0 & 0 & 0 & 0 & 0 & 0 & 1291 & 5606 \\
3 & 7 & 0 & 0 & 0 & 0 & 0 & 0 & 0 & 0 & 2395 \\
4 & 4 & 0 & 0 & 0 & 0 & 0 & 0 & 1254 & 2832 & 3820 \\
4 & 5 & 0 & 0 & 0 & 0 & 0 & 0 & 0 & 4406 & 15364 \\
4 & 6 & 0 & 0 & 0 & 0 & 0 & 0 & 0 & 0 & 12409 \\
5 & 5 & 0 & 0 & 0 & 0 & 0 & 0 & 0 & 0 & 21015 \\
\hline
\end{tabular}




\begin{tabular}{|c|c|c|c|c|c|c|c|c|}
\hline \multicolumn{9}{|c|}{ Tabela 3} \\
\hline $\mathrm{n}$ & $\mathrm{m}$ & $\mathrm{s}=22$ & $s=24$ & $s=26$ & $s=28$ & $s=30$ & $s=32$ & $\mathrm{~s}=34$ \\
\hline 1 & 10 & 1 & 0 & 0 & 0 & 0 & 0 & 0 \\
\hline 1 & 11 & 0 & 1 & 0 & 0 & 0 & 0 & 0 \\
\hline 1 & 12 & 0 & 0 & 1 & 0 & 0 & 0 & 0 \\
\hline 1 & 13 & 0 & 0 & 0 & 1 & 0 & 0 & 0 \\
\hline 1 & 14 & 0 & 0 & 0 & 0 & 1 & 0 & 0 \\
\hline 1 & 15 & 0 & 0 & 0 & 0 & 0 & 1 & 0 \\
\hline 1 & 16 & 0 & 0 & 0 & 0 & 0 & 0 & 1 \\
\hline 2 & 6 & 6 & 0 & 0 & 0 & 0 & 0 & 0 \\
\hline 2 & 7 & 399 & 74 & 1 & 0 & 0 & 0 & 0 \\
\hline 2 & 8 & 784 & 1190 & 456 & 32 & 0 & 0 & 0 \\
\hline 2 & 9 & 153 & 1344 & 2982 & 1944 & 332 & 8 & 0 \\
\hline 2 & 10 & 0 & 190 & 2160 & 6594 & 6540 & 2064 & 160 \\
\hline 2 & 11 & 0 & 0 & 231 & 3300 & 13266 & 18612 & 9394 \\
\hline 2 & 12 & 0 & 0 & 0 & 276 & 4840 & 24783 & 46728 \\
\hline 2 & 13 & 0 & 0 & 0 & 0 & 325 & 6864 & 43615 \\
\hline 2 & 14 & 0 & 0 & 0 & 0 & 0 & 378 & 9464 \\
\hline 2 & 15 & 0 & 0 & 0 & 0 & 0 & 0 & 435 \\
\hline 3 & 4 & 9 & 0 & 0 & 0 & 0 & 0 & 0 \\
\hline 3 & 5 & 1224 & 431 & 56 & 4 & 0 & 0 & 0 \\
\hline 3 & 6 & 9382 & 9128 & 5723 & 1962 & 373 & 32 & 0 \\
\hline 3 & 7 & 15546 & 37808 & 50606 & 45520 & 26316 & 9557 & 2054 \\
\hline 3 & 8 & 4089 & 37242 & $1,2628 \mathrm{E}+05$ & $2,2747 \mathrm{E}+05$ & $2,7083 \mathrm{E}+05$ & 222598 & 124061 \\
\hline 3 & 9 & 0 & 6553 & 79902 & $3,6362 \mathrm{E}+05$ & $8,6380 \mathrm{E}+05$ & $1,3192 \mathrm{E}+06$ & $1,4193 \mathrm{E}+06$ \\
\hline 3 & 10 & 0 & 0 & 9991 & $1,5733 \mathrm{E}+05$ & $9,3011 \mathrm{E}+05$ & $2,8519 \mathrm{E}+06$ & $5,4954 \mathrm{E}+06$ \\
\hline 3 & 11 & 0 & 0 & 0 & 14631 & $2,8924 \mathrm{E}+05$ & $2,1617 \mathrm{E}+06$ & $8,3761 \mathrm{E}+06$ \\
\hline 3 & 12 & 0 & 0 & 0 & 0 & 20725 & $5,0277 \mathrm{E}+05$ & $4,6438 \mathrm{E}+06$ \\
\hline 3 & 13 & 0 & 0 & 0 & 0 & 0 & 28549 & 834110 \\
\hline 3 & 14 & 0 & 0 & 0 & 0 & 0 & 0 & 38403 \\
\hline 4 & 4 & 3152 & 1650 & 412 & 50 & 0 & 0 & 0 \\
\hline 4 & 5 & 29927 & 39374 & 36489 & 22666 & 8959 & 2084 & 271 \\
\hline 4 & 6 & 64452 & 170848 & 308448 & 408903 & 400028 & 285680 & 144682 \\
\hline 4 & 7 & 29952 & 221638 & 783440 & 1829160 & $3,1681 \mathrm{E}+06$ & $4,2021 \mathrm{E}+06$ & $4,3173 \mathrm{E}+06$ \\
\hline 4 & 8 & 0 & 64513 & 652240 & 3019645 & $8,8979 \mathrm{E}+06$ & $1,9252 \mathrm{E}+07$ & $3,2345 \mathrm{E}+07$ \\
\hline 4 & 9 & 0 & 0 & 127295 & 1696355 & $1,0086 \mathrm{E}+07$ & $3,7001 \mathrm{E}+07$ & $9,7743 \mathrm{E}+07$ \\
\hline 4 & 10 & 0 & 0 & 0 & 234298 & 3994145 & $2,9904 \mathrm{E}+07$ & $1,3501 \mathrm{E}+08$ \\
\hline 4 & 11 & 0 & 0 & 0 & 0 & 407527 & $8,6692 \mathrm{E}+06$ & $8,0223 \mathrm{E}+07$ \\
\hline 4 & 12 & 0 & 0 & 0 & 0 & 0 & $6,7634 \mathrm{E}+05$ & $1,7586 \mathrm{E}+07$ \\
\hline 4 & 13 & 0 & 0 & 0 & 0 & 0 & 0 & $1,0789 \mathrm{E}+06$ \\
\hline 5 & 5 & 96520 & 261938 & 505848 & 744732 & 831828 & 696182 & $4,2284 \mathrm{E}+05$ \\
\hline 5 & 6 & 77148 & 473072 & 1658045 & $4,1972 \mathrm{E}+06$ & $8,3096 \mathrm{E}+06$ & $1,3136 \mathrm{E}+07$ & $1,6629 \mathrm{E}+07$ \\
\hline 5 & 7 & 0 & 235247 & 1917815 & $8,4780 \mathrm{E}+06$ & $2,6764 \mathrm{E}+07$ & $6,6311 \mathrm{E}+07$ & $1,3373 \mathrm{E}+08$ \\
\hline 5 & 8 & 0 & 0 & 624495 & $6,6619 \mathrm{E}+06$ & $3,6756 \mathrm{E}+07$ & $1,4135 E+08$ & $4,2322 \mathrm{E}+08$ \\
\hline 5 & 9 & 0 & 0 & 0 & $1,4887 \mathrm{E}+06$ & $2,0366 \mathrm{E}+07$ & $1,3894 \mathrm{E}+08$ & $6,4293 \mathrm{E}+08$ \\
\hline 5 & 10 & 0 & 0 & 0 & 0 & $3,2564 \mathrm{E}+06$ & $5,5976 \mathrm{E}+07$ & $4,6720 \mathrm{E}+08$ \\
\hline 5 & 11 & 0 & 0 & 0 & 0 & 0 & $6,6390 \mathrm{E}+06$ & $1,4070 \mathrm{E}+08$ \\
\hline 5 & 12 & 0 & 0 & $\begin{array}{r}0 \\
-\quad\end{array}$ & 0 & 0 & 0 & $1,2764 \mathrm{E}+07$ \\
\hline 6 & 6 & 0 & 357950 & $2,6590 \mathrm{E}+06$ & $1,1526 \mathrm{E}+07$ & $3,6808 \mathrm{E}+07$ & $9,4467 \mathrm{E}+07$ & $2,0093 \mathrm{E}+08$ \\
\hline 6 & 7 & 0 & 0 & 1345865 & $1,2343 \mathrm{E}+07$ & $6,4670 \mathrm{E}+07$ & $2,4948 \mathrm{E}+08$ & $7,7821 \mathrm{E}+08$ \\
\hline 6 & 8 & 0 & 0 & 0 & 4318015 & $4,9166 \mathrm{E}+07$ & $3,0895 E+08$ & $1,4113 \mathrm{E}+09$ \\
\hline 6 & 9 & 0 & 0 & 0 & 0 & $1,2237 \mathrm{E}+07$ & $1,7228 \mathrm{E}+08$ & $1,2932 \mathrm{E}+09$ \\
\hline 6 & 10 & 0 & 0 & 0 & 0 & 0 & $3,1380 \mathrm{E}+07$ & $5,4127 \mathrm{E}+08$ \\
\hline 6 & 11 & 0 & 0 & 0 & 0 & 0 & 0 & $7,4124 \mathrm{E}+07$ \\
\hline 7 & 7 & 0 & 0 & 0 & $6,1166 \mathrm{E}+06$ & $6,4818 \mathrm{E}+07$ & $3,9560 \mathrm{E}+08$ & $1,7911 \mathrm{E}+09$ \\
\hline 7 & 8 & 0 & 0 & 0 & 0 & $2,3332 \mathrm{E}+07$ & $2,9100 \mathrm{E}+08$ & $2,0590 \mathrm{E}+09$ \\
\hline 7 & 9 & 0 & 0 & 0 & 0 & 0 & $7,7525 \mathrm{E}+07$ & $1,1479 \mathrm{E}+09$ \\
\hline 7 & 10 & 0 & 0 & 0 & 0 & 0 & 0 & $2,3037 \mathrm{E}+08$ \\
\hline 8 & 8 & 0 & 0 & 0 & 0 & 0 & $1,0436 \mathrm{E}+08$ & $1,4598 \mathrm{E}+09$ \\
\hline 8 & 9 & 0 & 0 & 0 & 0 & 0 & 0 & $4,0181 \mathrm{E}+08$ \\
\hline
\end{tabular}




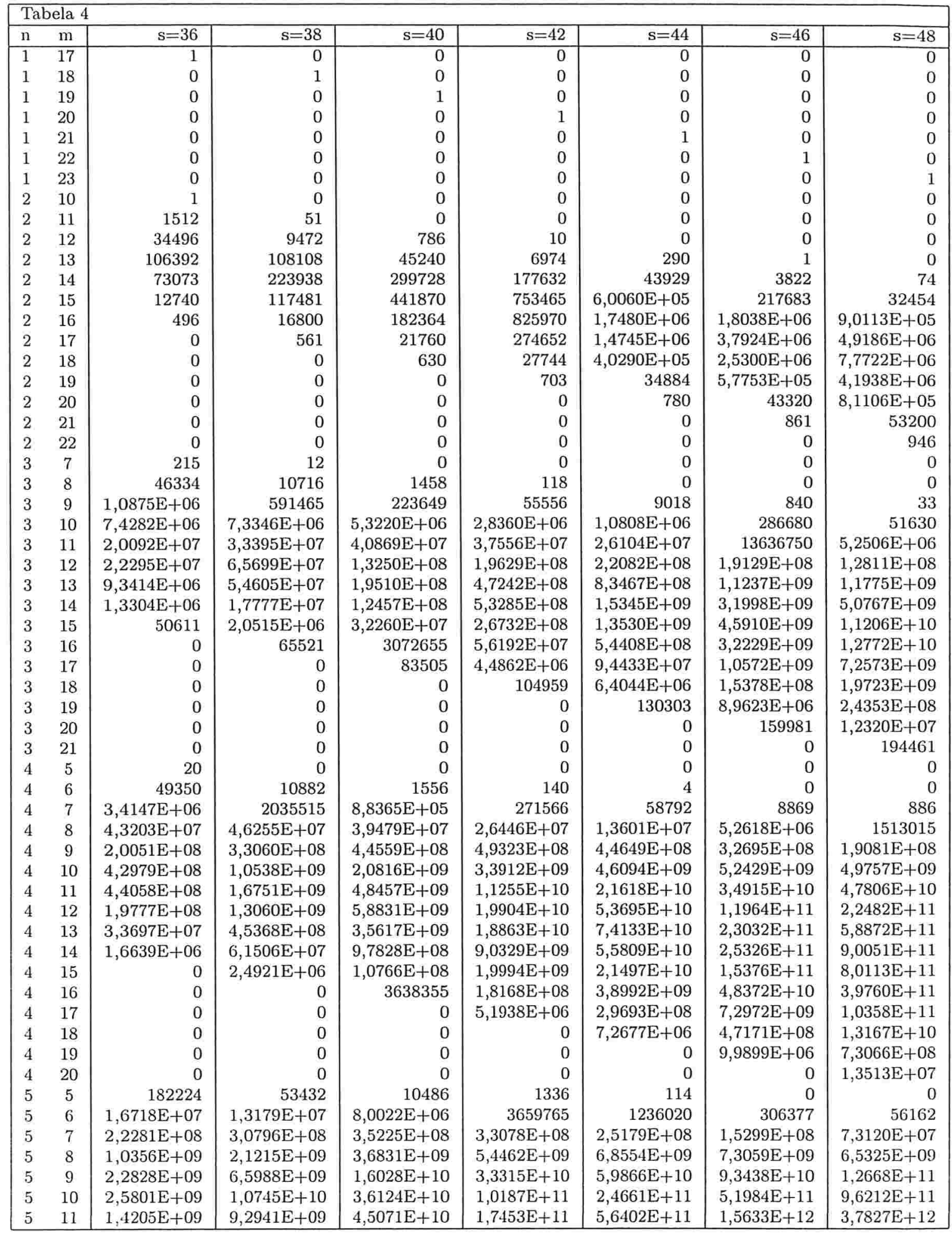




\begin{tabular}{|c|c|c|c|c|c|c|c|c|}
\hline $\mathrm{n}$ & $\mathrm{m}$ & $\mathrm{s}=36$ & $\mathrm{~s}=38$ & $\mathrm{~s}=40$ & $\mathrm{~s}=42$ & $\mathrm{~s}=44$ & $\mathrm{~s}=46$ & $\mathrm{~s}=48$ \\
\hline 5 & 12 & $3,2790 \mathrm{E}+08$ & $3,9580 \mathrm{E}+09$ & $3,0461 \mathrm{E}+10$ & $1,7105 \mathrm{E}+11$ & $7,5793 \mathrm{E}+11$ & $2,7827 \mathrm{E}+12$ & $8,7335 \mathrm{E}+12$ \\
\hline 5 & 13 & $3350 \mathrm{E}+07$ & $7,1630 \mathrm{E}+08$ & $1,0223 \mathrm{E}+10$ & $9,1861 \mathrm{E}+10$ & $5,9423 \mathrm{E}+11$ & $2,9982 \mathrm{E}+12$ & $1,2431 \mathrm{E}+13$ \\
\hline 5 & 14 & 0 & $4,0933 \mathrm{E}+07$ & $1,4799 \mathrm{E}+09$ & $2,4713 \mathrm{E}+10$ & $2,5733 \mathrm{E}+11$ & $1,9078 \mathrm{E}+12$ & $1,0916 \mathrm{E}+13$ \\
\hline 5 & 15 & 0 & 0 & $6,9152 \mathrm{E}+07$ & $2,9125 \mathrm{E}+09$ & $5,6363 \mathrm{E}+10$ & $6,7515 \mathrm{E}+11$ & $5,7072 \mathrm{E}+12$ \\
\hline 5 & 16 & 0 & 0 & 0 & $1,1310 \mathrm{E}+08$ & $5,4931 \mathrm{E}+09$ & $1,2211 \mathrm{E}+11$ & $1,6709 \mathrm{E}+12$ \\
\hline 5 & 17 & 0 & 0 & 0 & 0 & $1,7977 \mathrm{E}+08$ & $9,9778 \mathrm{E}+09$ & $2,5275 \mathrm{E}+11$ \\
\hline 5 & 18 & 0 & 0 & 0 & 0 & 0 & $2,7854 \mathrm{E}+08$ & $1,7528 \mathrm{E}+10$ \\
\hline 5 & 19 & 0 & 0 & 0 & 0 & 0 & 0 & $4,2187 \mathrm{E}+08$ \\
\hline 6 & 6 & $3,5797 \mathrm{E}+08$ & $5,3414 \mathrm{E}+08$ & $6,6439 \mathrm{E}+08$ & $6,8388 \mathrm{E}+08$ & $5,7734 \mathrm{E}+08$ & $3,9512 \mathrm{E}+08$ & $2,1635 \mathrm{E}+08$ \\
\hline 6 & 7 & $2,0423 \mathrm{E}+09$ & $4,5898 \mathrm{E}+09$ & $8,8915 \mathrm{E}+09$ & $1,4862 \mathrm{E}+10$ & $2,1386 \mathrm{E}+10$ & $2,6379 \mathrm{E}+10$ & $2,7728 \mathrm{E}+10$ \\
\hline 6 & 8 & $5,1908 \mathrm{E}+09$ & $1,6108 \mathrm{E}+10$ & $4,3175 \mathrm{E}+10$ & $1,0118 \mathrm{E}+11$ & $2,0852 \mathrm{E}+11$ & $3,7872 \mathrm{E}+11$ & $6,0592 \mathrm{E}+11$ \\
\hline 6 & 9 & $6,9236 \mathrm{E}+09$ & $17 \mathrm{E}+10$ & $1,0600 \mathrm{E}+11$ & $3,2894 \mathrm{E}+11$ & $8,9749 \mathrm{E}+11$ & $2,1741 \mathrm{E}+12$ & $4,7023 \mathrm{E}+12$ \\
\hline 6 & 10 & $4,8326 \mathrm{E}+09$ & $3,0137 \mathrm{E}+10$ & $1,4784 \mathrm{E}+11$ & $6,0526 \mathrm{E}+11$ & $2,1375 \mathrm{E}+12$ & $6,6429 \mathrm{E}+12$ & $1,8402 \mathrm{E}+13$ \\
\hline 6 & 11 & $1,5485 \mathrm{E}+09$ & $1,6354 \mathrm{E}+10$ & $1,1824 \mathrm{E}+11$ & $6,6281 \mathrm{E}+11$ & $3,0716 \mathrm{E}+12$ & $1,2215 \mathrm{E}+13$ & $4,2664 \mathrm{E}+13$ \\
\hline 6 & 12 & $1,6344 \mathrm{E}+08$ & $4,0867 \mathrm{E}+09$ & $5,0706 \mathrm{E}+10$ & $4,2321 \mathrm{E}+11$ & $2,6992 \mathrm{E}+12$ & $1,4085 \mathrm{E}+13$ & $6,2639 \mathrm{E}+13$ \\
\hline 6 & 13 & 0 & $3,3991 \mathrm{E}+08$ & $1,0055 \mathrm{E}+10$ & $1,4551 \mathrm{E}+11$ & $1,3955 \mathrm{E}+12$ & $1,0090 \mathrm{E}+13$ & $5,9059 \mathrm{E}+13$ \\
\hline 6 & 14 & 0 & 0 & $6,7216 \mathrm{E}+08$ & $2,3273 \mathrm{E}+10$ & $3,8985 \mathrm{E}+11$ & $4,2751 \mathrm{E}+12$ & $3,4924 \mathrm{E}+13$ \\
\hline 6 & 15 & 0 & 0 & 0 & $1,2721 \mathrm{E}+09$ & $5,1048 \mathrm{E}+10$ & $9,8259 \mathrm{E}+11$ & $1,2257 \mathrm{E}+13$ \\
\hline 6 & 16 & 0 & 0 & 0 & 0 & $2,3167 \mathrm{E}+09$ & $1,0678 \mathrm{E}+11$ & $2,3450 \mathrm{E}+12$ \\
\hline 6 & 17 & 0 & 0 & 0 & 0 & 0 & $4,0775 \mathrm{E}+09$ & $2,1412 \mathrm{E}+11$ \\
\hline 6 & 18 & 0 & 0 & 0 & 0 & 0 & 0 & $6,9616 \mathrm{E}+09$ \\
\hline 7 & 7 & $6,6263 \mathrm{E}+09$ & $2,0938 \mathrm{E}+10$ & $5,7757 \mathrm{E}+10$ & $1,4050 \mathrm{E}+11$ & $3,0253 \mathrm{E}+11$ & $5,7667 \mathrm{E}+11$ & $9,7147 \mathrm{E}+11$ \\
\hline 7 & 8 & $0760 \mathrm{E}+10$ &, $5941 \mathrm{E}+10$ & $1,6823 \mathrm{E}+11$ & $5,4202 \mathrm{E}+11$ & $1,5577 \mathrm{E}+12$ & $4,0211 \mathrm{E}+12$ & $9,3508 \mathrm{E}+12$ \\
\hline 7 & 9 & $9,4089 \mathrm{E}+09$ & $5,6309 \mathrm{E}+10$ & $2,7371 \mathrm{E}+11$ & $1,1390 \mathrm{E}+12$ & $4,1760 \mathrm{E}+12$ & $1,3716 \mathrm{E}+13$ & $4,0749 \mathrm{E}+13$ \\
\hline 7 & 10 & $4,0541 \mathrm{E}+09$ & $3,8485 \mathrm{E}+10$ & $2,6268 \mathrm{E}+11$ & $1,4426 \mathrm{E}+12$ & $6,7466 \mathrm{E}+12$ & $2,7736 \mathrm{E}+13$ & $8 \mathrm{E}+14$ \\
\hline 7 & 11 & $6,2415 \mathrm{E}+08$ & $1,3009 \mathrm{E}+10$ & $1,4283 \mathrm{E}+11$ & $1,1089 \mathrm{E}+12$ & $6,8490 \mathrm{E}+12$ & $3,5754 \mathrm{E}+13$ & $E+14$ \\
\hline 7 & 12 & 0 & $1,5646 \mathrm{E}+09$ & $3,8387 \mathrm{E}+10$ & $4,8618 \mathrm{E}+11$ & $4,2834 \mathrm{E}+12$ & $2,9660 \mathrm{E}+13$ & $1,7208 \mathrm{E}+14$ \\
\hline 7 & 13 & 0 & 0 & $3,6706 \mathrm{E}+09$ & $1,0523 \mathrm{E}+11$ & $1,5314 \mathrm{E}+12$ & $74 \mathrm{E}+13$ & $1,1828 \mathrm{E}+14$ \\
\hline 7 & 14 & 0 & 0 & 0 & $8,1318 \mathrm{E}+09$ & $2,7030 \mathrm{E}+11$ & $94 \mathrm{E}+12$ & $5,0657 \mathrm{E}+13$ \\
\hline 7 & 15 & 0 & 0 & 0 & 0 & $1,7137 \mathrm{E}+10$ & $6,5543 \mathrm{E}+11$ & $1,2416 \mathrm{E}+13$ \\
\hline 7 & 16 & 0 & 0 & 0 & 0 & 0 & $3,4558 \mathrm{E}+10$ & $1,5097 \mathrm{E}+12$ \\
\hline 7 & 17 & 0 & 0 & 0 & 0 & 0 & 0 & $1 \mathrm{E}+10$ \\
\hline 8 & 8 & $1,1619 \mathrm{E}+10$ & $6,8476 \mathrm{E}+10$ & $3,3099 \mathrm{E}+11$ & $1,3803 \mathrm{E}+12$ & $5,1073 \mathrm{E}+12$ & $1,7038 \mathrm{E}+13$ & $2 \mathrm{E}+13$ \\
\hline 8 & 9 & $4092 \mathrm{E}+09$ & $E+10$ & $06 \mathrm{E}+11$ & $56 \mathrm{E}+12$ & $933 \mathrm{E}+12$ & $15 \mathrm{E}+13$ & $1,4962 \mathrm{E}+14$ \\
\hline 8 & 10 & $1,3696 \mathrm{E}+09$ & $2,5140 \mathrm{E}+10$ & $2,5489 \mathrm{E}+11$ & $1,8851 \mathrm{E}+12$ & $1,1341 \mathrm{E}+13$ & $5,8677 \mathrm{E}+13$ & $2,6965 \mathrm{E}+14$ \\
\hline 8 & 11 & 0 & $4,2186 \mathrm{E}+09$ & $8,9433 \mathrm{E}+10$ & $1,0265 \mathrm{E}+12$ & $8,4863 \mathrm{E}+12$ & $5,6596 \mathrm{E}+13$ & $3,2285 \mathrm{E}+14$ \\
\hline 8 & 12 & 0 & 0 & $1,1930 \mathrm{E}+10$ & $2,9195 \mathrm{E}+11$ & $3,7948 \mathrm{E}+12$ & $49 \mathrm{E}+13$ & $2,5860 \mathrm{E}+14$ \\
\hline 8 & 13 & 0 & 0 & 0 & $3,1356 \mathrm{E}+10$ & $8,8322 \mathrm{E}+11$ & $1,2989 \mathrm{E}+13$ & $1,3391 \mathrm{E}+14$ \\
\hline 8 & 14 & 0 & 0 & 0 & 0 & $7,7350 \mathrm{E}+10$ & $2,4968 \mathrm{E}+12$ & $1 E+13$ \\
\hline 8 & 1 & 0 & 0 & 0 & 0 & 0 & $1,8051 \mathrm{E}+11$ & $6,6430 \mathrm{E}+12$ \\
\hline 8 & 16 & 0 & 0 & 0 & 0 & 0 & 0 & $4,0110 \mathrm{E}+11$ \\
\hline 9 & 9 & $1,7746 \mathrm{E}+09$ & $3,1115 \mathrm{E}+10$ & $3,0701 \mathrm{E}+11$ & $2,2327 \mathrm{E}+12$ & $1,3301 \mathrm{E}+13$ & $6,8517 \mathrm{E}+13$ & $3,1492 \mathrm{E}+14$ \\
\hline 9 & 10 & 0 & $6,8771 \mathrm{E}+09$ & $1,3446 \mathrm{E}+11$ & $1,4662 \mathrm{E}+12$ & $1,1726 \mathrm{E}+13$ & $389 E+13$ & $4,3195 \mathrm{E}+14$ \\
\hline 9 & 11 & 0 & 0 & $2,3897 \mathrm{E}+10$ & $5,2573 \mathrm{E}+11$ & $6,3608 \mathrm{E}+12$ & $5,5965 \mathrm{E}+13$ & $3,9993 \mathrm{E}+14$ \\
\hline 9 & 12 & 0 & 0 & 0 & $7,5715 \mathrm{E}+10$ & $1,8826 \mathrm{E}+12$ & $2,5341 \mathrm{E}+13$ & $2,4548 \mathrm{E}+14$ \\
\hline 9 & 13 & 0 & 0 & 0 & 0 & $2,2159 \mathrm{E}+11$ & $6,2351 \mathrm{E}+12$ & $9,3507 \mathrm{E}+13$ \\
\hline 9 & 14 & 0 & 0 & 0 & 0 & 0 & $6,0532 \mathrm{E}+11$ & $1,9256 \mathrm{E}+13$ \\
\hline 9 & 15 & 0 & 0 & 0 & 0 & 0 & 0 & $\mathrm{E}+12$ \\
\hline 10 & 10 & 0 & 0 & $3,0065 \mathrm{E}+10$ & $6,3690 \mathrm{E}+11$ & $7,5203 \mathrm{E}+12$ & $6,5087 \mathrm{E}+13$ & $4,6000 \mathrm{E}+14$ \\
\hline 10 & 11 & 0 & 0 & 0 & $1,1705 \mathrm{E}+11$ & $2,7204 \mathrm{E}+12$ & $3,4985 \mathrm{E}+13$ & $3,2828 \mathrm{E}+14$ \\
\hline 10 & 12 & 0 & 0 & 0 & 0 & $4,1295 \mathrm{E}+11$ & $1,0617 \mathrm{E}+13$ & $1,4938 \mathrm{E}+14$ \\
\hline 10 & 13 & 0 & 0 & 0 & 0 & 0 & $1,3383 \mathrm{E}+12$ & $3,8250 \mathrm{E}+13$ \\
\hline 10 & 14 & 0 & 0 & 0 & 0 & 0 & 0 & $4,0285 \mathrm{E}+12$ \\
\hline 11 & 11 & 0 & 0 & 0 & 0 & $5,0744 \mathrm{E}+11$ & $1,2641 \mathrm{E}+13$ & $1,7406 \mathrm{E}+14$ \\
\hline 11 & 12 & 0 & 0 & 0 & c & 0 & $1,9825 \mathrm{E}+12$ & $5,3517 \mathrm{E}+13$ \\
\hline 11 & 13 & 0 & 0 & 0 & 0 & 0 & 0 & $7,0798 \mathrm{E}+12$ \\
\hline 12 & 12 & 0 & 0 & 0 & 0 & 0 & 0 & $8,5345 \mathrm{E}+12$ \\
\hline
\end{tabular}




\begin{tabular}{|c|c|c|c|c|c|c|}
\hline \multicolumn{7}{|c|}{ Tabela 5} \\
\hline $\mathrm{n}$ & $\mathrm{m}$ & $\mathrm{s}=50$ & $\mathrm{~s}=52$ & $\mathrm{~s}=54$ & $\mathrm{~s}=56$ & $\mathrm{~s}=58$ \\
\hline 1 & 24 & 1 & 0 & 0 & 0 & 0 \\
\hline 1 & 25 & 0 & 1 & 0 & 0 & 0 \\
\hline 1 & 26 & 0 & 0 & 1 & 0 & 0 \\
\hline 1 & 27 & 0 & 0 & 0 & 1 & 0 \\
\hline 1 & 28 & 0 & 0 & 0 & 0 & 1 \\
\hline 2 & 15 & 1565 & 12 & 0 & 0 & 0 \\
\hline 2 & 16 & 205336 & 18512 & 472 & 1 & 0 \\
\hline 2 & 17 & $3,2399 \mathrm{E}+06$ & $1,0476 \mathrm{E}+06$ & 152108 & 8184 & 101 \\
\hline 2 & 18 & $1,2376 \mathrm{E}+07$ & $1,0394 \mathrm{E}+07$ & 4526760 & $9,6580 \mathrm{E}+05$ & 89496 \\
\hline 2 & 19 & $1,5167 \mathrm{E}+07$ & $2,9091 \mathrm{E}+07$ & 30340700 & $1,7124 \mathrm{E}+07$ & $5,0453 \mathrm{E}+06$ \\
\hline 2 & 20 & $6,7443 \mathrm{E}+06$ & $2,8362 \mathrm{E}+07$ & 64496500 & $8,1788 \mathrm{E}+07$ & $5,8067 \mathrm{E}+07$ \\
\hline 2 & 21 & $1,1184 \mathrm{E}+06$ & $1,0558 \mathrm{E}+07$ & 51088500 & $1,3591 \mathrm{E}+08$ & $2,0594 \mathrm{E}+08$ \\
\hline 2 & 22 & 64680 & $1,5171 \mathrm{E}+06$ & 16137750 & $8,9024 \mathrm{E}+07$ & $2,7392 \mathrm{E}+08$ \\
\hline 2 & 23 & 1035 & 77924 & 2027795 & $2,4141 \mathrm{E}+07$ & $1,5061 \mathrm{E}+08$ \\
\hline 2 & 24 & 0 & 1128 & 93104 & $2,6742 \mathrm{E}+06$ & $3,5418 \mathrm{E}+07$ \\
\hline 2 & 25 & 0 & 0 & 1225 & 110400 & $3,4838 \mathrm{E}+06$ \\
\hline 2 & 26 & 0 & 0 & 0 & 1326 & 130000 \\
\hline 2 & 27 & 0 & 0 & 0 & 0 & 1431 \\
\hline 3 & 10 & 5851 & 374 & 4 & 0 & 0 \\
\hline 3 & 11 & $1,4626 \mathrm{E}+06$ & 286782 & 37910 & 3104 & 106 \\
\hline 3 & 12 & $6,5823 \mathrm{E}+07$ & $2,5592 \mathrm{E}+07$ & $7,4090 \mathrm{E}+06$ & $1,5595 \mathrm{E}+06$ & 232508 \\
\hline 3 & 13 & $9,7020 \mathrm{E}+08$ & $6,2915 \mathrm{E}+08$ & $3,1889 \mathrm{E}+08$ & $1,2503 \mathrm{E}+08$ & $3,7348 \mathrm{E}+07$ \\
\hline 3 & 14 & $6,3031 \mathrm{E}+09$ & $6,2167 \mathrm{E}+09$ & $4,9042 \mathrm{E}+09$ & $3,0923 \mathrm{E}+09$ & $1,5499 \mathrm{E}+09$ \\
\hline 3 & 15 & $2,0725 \mathrm{E}+10$ & $3,0038 \mathrm{E}+10$ & $3,4791 \mathrm{E}+10$ & $3,2560 \mathrm{E}+10$ & $2,4724 \mathrm{E}+10$ \\
\hline 3 & 16 & $3,6220 \mathrm{E}+10$ & $7,7451 \mathrm{E}+10$ & $1,2962 \mathrm{E}+11$ & $1,7385 \mathrm{E}+11$ & $1,8958 \mathrm{E}+11$ \\
\hline 3 & 17 & $3,3305 \mathrm{E}+10$ & $1,0897 \mathrm{E}+11$ & $2,6761 \mathrm{E}+11$ & $5,1292 \mathrm{E}+11$ & $7,8826 \mathrm{E}+11$ \\
\hline 3 & 18 & $1,5549 \mathrm{E}+10$ & $8,1974 \mathrm{E}+10$ & $3,0741 \mathrm{E}+11$ & $8,6181 \mathrm{E}+11$ & $1,8793 \mathrm{E}+12$ \\
\hline 3 & 19 & $3,5486 \mathrm{E}+09$ & $3,1870 \mathrm{E}+10$ & $1,9159 \mathrm{E}+11$ & $8,1822 \mathrm{E}+11$ & $2,6043 \mathrm{E}+12$ \\
\hline 3 & 20 & $3,7618 \mathrm{E}+08$ & $6,1821 \mathrm{E}+09$ & $6,2789 \mathrm{E}+10$ & $4,2744 \mathrm{E}+11$ & $2,0662 \mathrm{E}+12$ \\
\hline 3 & 21 & $1,6666 \mathrm{E}+07$ & $5,6822 \mathrm{E}+08$ & $1,0462 \mathrm{E}+10$ & $1,1938 \mathrm{E}+11$ & $9,1445 \mathrm{E}+11$ \\
\hline 3 & 22 & 234235 & $2,2222 \mathrm{E}+07$ & $8,4116 \mathrm{E}+08$ & $1,7250 \mathrm{E}+10$ & $2,1979 \mathrm{E}+11$ \\
\hline 3 & 23 & 0 & 279819 & $2,9241 \mathrm{E}+07$ & $1,2226 \mathrm{E}+09$ & $2,7776 \mathrm{E}+10$ \\
\hline 3 & 24 & 0 & 0 & 331753 & $3,8017 \mathrm{E}+07$ & $1,7476 \mathrm{E}+09$ \\
\hline 3 & 25 & 0 & 0 & 0 & 390601 & $4,8887 \mathrm{E}+07$ \\
\hline 3 & 26 & 0 & 0 & 0 & 0 & 456951 \\
\hline 4 & 7 & 56 & 0 & 0 & 0 & 0 \\
\hline 4 & 8 & 321558 & 50320 & 5652 & 413 & 12 \\
\hline 4 & 9 & $8,7364 \mathrm{E}+07$ & $3,0999 \mathrm{E}+07$ & $8,4738 \mathrm{E}+06$ & $1,7823 \mathrm{E}+06$ & 286842 \\
\hline 4 & 10 & $3,9100 \mathrm{E}+09$ & $2,5170 \mathrm{E}+09$ & $1,3113 \mathrm{E}+09$ & $5,4698 \mathrm{E}+08$ & $1,8147 \mathrm{E}+08$ \\
\hline 4 & 11 & $5,5625 \mathrm{E}+10$ & $5,4887 \mathrm{E}+10$ & $4,5678 \mathrm{E}+10$ & $3,1805 \mathrm{E}+10$ & $1,8357 \mathrm{E}+10$ \\
\hline 4 & 12 & $3,6066 \mathrm{E}+11$ & $4,9702 \mathrm{E}+11$ & $5,8952 \mathrm{E}+11$ & $6,0102 \mathrm{E}+11$ & $5,2456 \mathrm{E}+11$ \\
\hline 4 & 13 & $1,2689 \mathrm{E}+12$ & $2,3422 \mathrm{E}+12$ & $3,7367 \mathrm{E}+12$ & $5,1785 \mathrm{E}+12$ & $6,2443 \mathrm{E}+12$ \\
\hline 4 & 14 & $2,6194 \mathrm{E}+12$ & $6,4109 \mathrm{E}+12$ & $1,3444 \mathrm{E}+13$ & $2,4444 \mathrm{E}+13$ & $3,8819 \mathrm{E}+13$ \\
\hline 4 & 15 & $3,2429 \mathrm{E}+12$ & $1,0671 \mathrm{E}+13$ & $2,9435 \mathrm{E}+13$ & $6,9491 \mathrm{E}+13$ & $1,4238 \mathrm{E}+14$ \\
\hline 4 & 16 & $2,3650 \mathrm{E}+12$ & $1,0848 \mathrm{E}+13$ & $4,0187 \mathrm{E}+13$ & $1,2424 \mathrm{E}+14$ & $3,2792 \mathrm{E}+14$ \\
\hline 4 & 17 & $9,7150 \mathrm{E}+11$ & $6,5608 \mathrm{E}+12$ & $3,3951 \mathrm{E}+13$ & $1,4101 \mathrm{E}+14$ & $4,8634 \mathrm{E}+14$ \\
\hline 4 & 18 & $2,1223 \mathrm{E}+11$ & $2,2562 \mathrm{E}+12$ & $1,7205 \mathrm{E}+13$ & $1,0001 \mathrm{E}+14$ & $4,6396 \mathrm{E}+14$ \\
\hline 4 & 19 & $2,2996 \mathrm{E}+10$ & $4,1798 \mathrm{E}+11$ & $5,0055 \mathrm{E}+12$ & $4,2877 \mathrm{E}+13$ & $2,7878 \mathrm{E}+14$ \\
\hline 4 & 20 & $1,1064 \mathrm{E}+09$ & $3,9006 \mathrm{E}+10$ & $7,9452 \mathrm{E}+11$ & $1,0656 \mathrm{E}+13$ & $1,0202 \mathrm{E}+14$ \\
\hline 4 & 21 & $1,8016 \mathrm{E}+07$ & $1,6414 \mathrm{E}+09$ & $6,4443 \mathrm{E}+10$ & $1,4626 \mathrm{E}+12$ & $2,1851 \mathrm{E}+13$ \\
\hline 4 & 22 & 0 & $2,3705 \mathrm{E}+07$ & $2,3905 \mathrm{E}+09$ & $1,0396 \mathrm{E}+11$ & $2,6152 \mathrm{E}+12$ \\
\hline 4 & 23 & 0 & 0 & $3,0818 \mathrm{E}+07$ & $3,4231 \mathrm{E}+09$ & $1,6410 \mathrm{E}+11$ \\
\hline 4 & 24 & 0 & 0 & 0 & $3,9627 \mathrm{E}+07$ & $4,8268 \mathrm{E}+09$ \\
\hline 4 & 25 & 0 & 0 & 0 & 0 & $5,0442 \mathrm{E}+07$ \\
\hline 5 & 6 & 7591 & 726 & 41 & 0 & 0 \\
\hline 5 & 7 & $2,7210 \mathrm{E}+07$ & $7,8699 \mathrm{E}+06$ & $1,7736 \mathrm{E}+06$ & 311294 & 42388 \\
\hline 5 & 8 & $4,8463 \mathrm{E}+09$ & $2,9496 \mathrm{E}+09$ & $1,4588 \mathrm{E}+09$ & $5,8269 \mathrm{E}+08$ & $1,8766 \mathrm{E}+08$ \\
\hline 5 & 9 & $1,4863 \mathrm{E}+11$ & $1,4996 \mathrm{E}+11$ & $1,2905 \mathrm{E}+11$ & $9,3889 \mathrm{E}+10$ & $5,7276 \mathrm{E}+10$ \\
\hline
\end{tabular}




\begin{tabular}{|c|c|c|c|c|c|c|}
\hline $\mathrm{n}$ & $\mathrm{m}$ & $\mathrm{s}=50$ & $\mathrm{~s}=52$ & $\mathrm{~s}=54$ & $\mathrm{~s}=56$ & $\mathrm{~s}=58$ \\
\hline 5 & 10 & $1,5697 \mathrm{E}+12$ & $2,2585 \mathrm{E}+12$ & $2,8589 \mathrm{E}+12$ & $3,1696 \mathrm{E}+12$ & $3,0592 \mathrm{E}+12$ \\
\hline 5 & 11 & $8,0802 \mathrm{E}+12$ & $1,5341 \mathrm{E}+13$ & $2,5974 \mathrm{E}+13$ & $3,9245 \mathrm{E}+13$ & $5,2840 \mathrm{E}+13$ \\
\hline 5 & 12 & $2,3918 \mathrm{E}+13$ & $5,7945 \mathrm{E}+13$ & $1,2531 \mathrm{E}+14$ & $2,4323 \mathrm{E}+14$ & $4,2500 \mathrm{E}+14$ \\
\hline 5 & 13 & $4,3840 \mathrm{E}+13$ & $1,3459 \mathrm{E}+14$ & $3,6547 \mathrm{E}+14$ & $8,8736 \mathrm{E}+14$ & $1,9406 \mathrm{E}+15$ \\
\hline 5 & 14 & $5,0882 \mathrm{E}+13$ & $2,0053 \mathrm{E}+14$ & $6,8546 \mathrm{E}+14$ & $2,0689 \mathrm{E}+15$ & $5,5836 \mathrm{E}+15$ \\
\hline 5 & 15 & $3,6884 \mathrm{E}+13$ & $1,9258 \mathrm{E}+14$ & $8,4466 \mathrm{E}+14$ & $3,1988 \mathrm{E}+15$ & $1,0667 \mathrm{E}+16$ \\
\hline 5 & 16 & $1,6020 \mathrm{E}+13$ & $1,1649 \mathrm{E}+14$ & $6,7911 \mathrm{E}+14$ & $3,3038 \mathrm{E}+15$ & $1,3808 \mathrm{E}+16$ \\
\hline 5 & 17 & $3,9243 \mathrm{E}+12$ & $4,2455 \mathrm{E}+13$ & $3,4603 \mathrm{E}+14$ & $2,2453 \mathrm{E}+15$ & $1,2081 \mathrm{E}+16$ \\
\hline 5 & 18 & $5,0228 \mathrm{E}+11$ & $8,7939 \mathrm{E}+12$ & $1,0681 \mathrm{E}+14$ & $9,7192 \mathrm{E}+14$ & $6,9983 \mathrm{E}+15$ \\
\hline 5 & 19 & $2,9882 \mathrm{E}+10$ & $9,6234 \mathrm{E}+11$ & $1,8888 \mathrm{E}+13$ & $2,5629 \mathrm{E}+14$ & $2,5938 \mathrm{E}+15$ \\
\hline 5 & 20 & $6,2597 \mathrm{E}+08$ & $4,9590 \mathrm{E}+10$ & $1,7840 \mathrm{E}+12$ & $3,9044 \mathrm{E}+13$ & $5,8910 \mathrm{E}+14$ \\
\hline 5 & 21 & 0 & $9,1169 \mathrm{E}+08$ & $8,0316 \mathrm{E}+10$ & $3,2102 \mathrm{E}+12$ & $7,7942 \mathrm{E}+13$ \\
\hline 5 & 22 & 0 & 0 & $1,3056 \mathrm{E}+09$ & $1,2723 \mathrm{E}+11$ & $5,6217 \mathrm{E}+12$ \\
\hline 5 & 23 & 0 & 0 & 0 & $1,8409 \mathrm{E}+09$ & $1,9752 \mathrm{E}+11$ \\
\hline 5 & 24 & 0 & 0 & 0 & 0 & $2,5593 \mathrm{E}+09$ \\
\hline 6 & 6 & $9,3633 \mathrm{E}+07$ & $3,1871 \mathrm{E}+07$ & $8,5341 \mathrm{E}+06$ & 1802140 & 299752 \\
\hline 6 & 7 & $2,4655 \mathrm{E}+10$ & $1,8385 \mathrm{E}+10$ & $1,1392 \mathrm{E}+10$ & $5,8207 \mathrm{E}+09$ & $2,4397 \mathrm{E}+09$ \\
\hline 6 & 8 & $8,5173 \mathrm{E}+11$ & $1,0476 \mathrm{E}+12$ & $1,1215 \mathrm{E}+12$ & $1,0383 \mathrm{E}+12$ & $8,2587 \mathrm{E}+11$ \\
\hline 6 & 9 & $9,1064 \mathrm{E}+12$ & $1,5797 \mathrm{E}+13$ & $2,4513 \mathrm{E}+13$ & $3,3928 \mathrm{E}+13$ & $4,1718 \mathrm{E}+13$ \\
\hline 6 & 10 & $4,5822 \mathrm{E}+13$ & $1,0310 \mathrm{E}+14$ & $2,1023 \mathrm{E}+14$ & $3,8887 \mathrm{E}+14$ & $6,5211 \mathrm{E}+14$ \\
\hline 6 & 11 & $1,3291 \mathrm{E}+14$ & $3,7325 \mathrm{E}+14$ & $9,5169 \mathrm{E}+14$ & $2,2138 \mathrm{E}+15$ & $4,7114 \mathrm{E}+15$ \\
\hline 6 & 12 & $2,4374 \mathrm{E}+14$ & $8,4475 \mathrm{E}+14$ & $2,6402 \mathrm{E}+15$ & $7,5079 \mathrm{E}+15$ & $1,9546 \mathrm{E}+16$ \\
\hline 6 & 13 & $2,9237 \mathrm{E}+14$ & $1,2600 \mathrm{E}+15$ & $4,8227 \mathrm{E}+15$ & $1,6627 \mathrm{E}+16$ & $5,2167 \mathrm{E}+16$ \\
\hline 6 & 14 & $2,2859 \mathrm{E}+14$ & $1,2553 \mathrm{E}+15$ & $5,9672 \mathrm{E}+15$ & $2,5093 \mathrm{E}+16$ & $9,4834 \mathrm{E}+16$ \\
\hline 6 & 15 & $1,1274 \mathrm{E}+14$ & $8,2288 \mathrm{E}+14$ & $4,9996 \mathrm{E}+15$ & $2,6131 \mathrm{E}+16$ & $1,2029 \mathrm{E}+17$ \\
\hline 6 & 16 & $3,3105 \mathrm{E}+13$ & $3,4156 \mathrm{E}+14$ & $2,7729 \mathrm{E}+15$ & $1,8595 \mathrm{E}+16$ & $1,0661 \mathrm{E}+17$ \\
\hline 6 & 17 & $5,3291 \mathrm{E}+12$ & $8,4704 \mathrm{E}+13$ & $9,7672 \mathrm{E}+14$ & $8,7950 \mathrm{E}+15$ & $6,4960 \mathrm{E}+16$ \\
\hline 6 & 18 & $4,1344 \mathrm{E}+11$ & $1,1589 \mathrm{E}+13$ & $2,0636 \mathrm{E}+14$ & $2,6493 \mathrm{E}+15$ & $2,6387 \mathrm{E}+16$ \\
\hline 6 & 19 & $1,1566 \mathrm{E}+10$ & $7,7169 \mathrm{E}+11$ & $2,4221 \mathrm{E}+13$ & $4,8083 \mathrm{E}+14$ & $6,8471 \mathrm{E}+15$ \\
\hline 6 & 20 & 0 & $1,8748 \mathrm{E}+10$ & $1,3968 \mathrm{E}+12$ & $4,8828 \mathrm{E}+13$ & $1,0758 \mathrm{E}+15$ \\
\hline 6 & 21 & 0 & 0 & $2,9717 \mathrm{E}+10$ & $2,4591 \mathrm{E}+12$ & $9,5258 \mathrm{E}+13$ \\
\hline 6 & 22 & 0 & 0 & 0 & $4,6156 \mathrm{E}+10$ & $4,2206 \mathrm{E}+12$ \\
\hline 6 & 23 & 0 & 0 & 0 & 0 & $7,0366 \mathrm{E}+10$ \\
\hline 7 & 7 & $1,4424 \mathrm{E}+12$ & $1,8811 \mathrm{E}+12$ & $2,1455 \mathrm{E}+12$ & $2,1295 \mathrm{E}+12$ & $1,8286 \mathrm{E}+12$ \\
\hline 7 & 8 & $1,9600 \mathrm{E}+13$ & $3,7000 \mathrm{E}+13$ & $6,2800 \mathrm{E}+13$ & $9,5608 \mathrm{E}+13$ & $1,3018 \mathrm{E}+14$ \\
\hline 7 & 9 & $1,1012 \mathrm{E}+14$ & $2,7145 \mathrm{E}+14$ & $6,1120 \mathrm{E}+14$ & $1,2570 \mathrm{E}+15$ & $2,3591 \mathrm{E}+15$ \\
\hline 7 & 10 & $3,4131 \mathrm{E}+14$ & $1,0418 \mathrm{E}+15$ & $2,9200 E+15$ & $7,5381 \mathrm{E}+15$ & $1,7954 \mathrm{E}+16$ \\
\hline 7 & 11 & $6,6721 \mathrm{E}+14$ & $2,4709 \mathrm{E}+15$ & $8,3745 \mathrm{E}+15$ & $2,6145 \mathrm{E}+16$ & $7,5526 \mathrm{E}+16$ \\
\hline 7 & 12 & $8,6856 \mathrm{E}+14$ & $3,9053 \mathrm{E}+15$ & $1,5890 \mathrm{E}+16$ & $5,9149 \mathrm{E}+16$ & $2,0302 \mathrm{E}+17$ \\
\hline 7 & 13 & $7,6041 \mathrm{E}+14$ & $4,2240 \mathrm{E}+15$ & $2,0803 \mathrm{E}+16$ & $9,2439 \mathrm{E}+16$ & $3,7519 \mathrm{E}+17$ \\
\hline 7 & 14 & $4,3776 \mathrm{E}+14$ & $3,1112 \mathrm{E}+15$ & $1,8968 \mathrm{E}+16$ & $1,0198 \mathrm{E}+17$ & $4,9283 \mathrm{E}+17$ \\
\hline 7 & 15 & $1,5728 \mathrm{E}+14$ & $1,5133 \mathrm{E}+15$ & $1,1867 \mathrm{E}+16$ & $7,9245 \mathrm{E}+16$ & $4,6398 \mathrm{E}+17$ \\
\hline 7 & 16 & $3,2373 \mathrm{E}+13$ & $4,5983 \mathrm{E}+14$ & $4,9144 \mathrm{E}+15$ & $4,2443 \mathrm{E}+16$ & $3,0989 \mathrm{E}+17$ \\
\hline 7 & 17 & $3,3210 \mathrm{E}+12$ & $8,0196 \mathrm{E}+13$ & $1,2725 \mathrm{E}+15$ & $1,5067 \mathrm{E}+16$ & $1,4305 \mathrm{E}+17$ \\
\hline 7 & 18 & $1,2552 \mathrm{E}+11$ & $7,0095 \mathrm{E}+12$ & $1,8965 \mathrm{E}+14$ & $3,3487 \mathrm{E}+15$ & $4,3812 \mathrm{E}+16$ \\
\hline 7 & 19 & 0 & $2,2781 \mathrm{E}+11$ & $1,4252 \mathrm{E}+13$ & $4,2992 \mathrm{E}+14$ & $8,4161 \mathrm{E}+15$ \\
\hline 7 & 20 & 0 & 0 & $4,0189 \mathrm{E}+11$ & $2,8013 \mathrm{E}+13$ & $9,3775 \mathrm{E}+14$ \\
\hline 7 & 21 & 0 & 0 & 0 & $6,9094 \mathrm{E}+11$ & $5,3387 \mathrm{E}+13$ \\
\hline 7 & 22 & 0 & 0 & 0 & 0 & $1,1603 \mathrm{E}+12$ \\
\hline 8 & 8 & $1,4344 \mathrm{E}+14$ & $3,6431 \mathrm{E}+14$ & $8,4739 \mathrm{E}+14$ & $1,8038 \mathrm{E}+15$ & $3,5094 \mathrm{E}+15$ \\
\hline 8 & 9 & $5,1472 \mathrm{E}+14$ & $1,6314 \mathrm{E}+15$ & $4,7808 \mathrm{E}+15$ & $1,2974 \mathrm{E}+16$ & $3,2623 \mathrm{E}+16$ \\
\hline 8 & 10 & $1,1227 \mathrm{E}+15$ & $4,2880 \mathrm{E}+15$ & $1,5145 \mathrm{E}+16$ & $4,9712 \mathrm{E}+16$ & $1,5211 \mathrm{E}+17$ \\
\hline 8 & 11 & $1,6303 \mathrm{E}+15$ & $7,4461 \mathrm{E}+15$ & $3,1190 \mathrm{E}+16$ & $1,2093 \mathrm{E}+17$ & $4,3675 \mathrm{E}+17$ \\
\hline 8 & 12 & $1,6209 \mathrm{E}+15$ & $8,9508 \mathrm{E}+15$ & $4,4564 \mathrm{E}+16$ & $2,0312 \mathrm{E}+17$ & $8,5645 \mathrm{E}+17$ \\
\hline 8 & 13 & $1,0915 \mathrm{E}+15$ & $7,5007 \mathrm{E}+15$ & $4,5150 \mathrm{E}+16$ & $2,4403 \mathrm{E}+17$ & $1,2041 \mathrm{E}+18$ \\
\hline 8 & 14 & $4,7655 \mathrm{E}+14$ & $4,2865 \mathrm{E}+15$ & $3,2239 \mathrm{E}+16$ & $2,1108 \mathrm{E}+17$ & $1,2351 \mathrm{E}+18$ \\
\hline 8 & 15 & $1,2421 \mathrm{E}+14$ & $1,5891 \mathrm{E}+15$ & $1,5752 \mathrm{E}+16$ & $1,2951 \mathrm{E}+17$ & $9,2087 \mathrm{E}+17$ \\
\hline 8 & 16 & $1,6738 \mathrm{E}+13$ & $3,5120 \mathrm{E}+14$ & $4,9908 \mathrm{E}+15$ & $5,4449 \mathrm{E}+16$ & $4,8878 \mathrm{E}+17$ \\
\hline
\end{tabular}




\begin{tabular}{|c|c|c|c|c|c|c|}
\hline $\mathrm{n}$ & $\mathrm{m}$ & $\mathrm{s}=50$ & $\mathrm{~s}=52$ & $\mathrm{~s}=54$ & $\mathrm{~s}=56$ & $\mathrm{~s}=58$ \\
\hline 8 & 17 & $8,5328 \mathrm{E}+11$ & $4,0158 \mathrm{E}+13$ & $9,4200 \mathrm{E}+14$ & $1,4834 \mathrm{E}+16$ & $1,7783 \mathrm{E}+17$ \\
\hline 8 & 18 & 0 & $1,7457 \mathrm{E}+12$ & $9,2169 \mathrm{E}+13$ & $2,4078 \mathrm{E}+15$ & $4,1904 \mathrm{E}+16$ \\
\hline 8 & 19 & 0 & 0 & $3,4483 \mathrm{E}+12$ & $2,0320 \mathrm{E}+14$ & $5,8888 \mathrm{E}+15$ \\
\hline 8 & 20 & 0 & 0 & 0 & $6,5979 \mathrm{E}+12$ & $4,3185 \mathrm{E}+14$ \\
\hline 8 & 21 & 0 & 0 & 0 & 0 & $1,2264 \mathrm{E}+13$ \\
\hline 9 & 9 & $1,3168 \mathrm{E}+15$ & $5,0718 \mathrm{E}+15$ & $1,8132 \mathrm{E}+16$ & $6,0452 \mathrm{E}+16$ & $1,8845 \mathrm{E}+17$ \\
\hline 9 & 10 & $2,1736 \mathrm{E}+15$ & $9,9624 \mathrm{E}+15$ & $4,2155 \mathrm{E}+16$ & $1,6614 \mathrm{E}+17$ & $6,1349 \mathrm{E}+17$ \\
\hline 9 & 11 & $2,4588 \mathrm{E}+15$ & $1,3458 \mathrm{E}+16$ & $6,7027 \mathrm{E}+16$ & $3,0821 \mathrm{E}+17$ & $1,3214 \mathrm{E}+18$ \\
\hline 9 & 12 & $1,9173 \mathrm{E}+15$ & $1,2817 \mathrm{E}+16$ & $7,6009 \mathrm{E}+16$ & $4,0917 \mathrm{E}+17$ & $2,0308 \mathrm{E}+18$ \\
\hline 9 & 13 & $9,9781 \mathrm{E}+14$ & $8,5137 \mathrm{E}+15$ & $6,1792 \mathrm{E}+16$ & $3,9602 \mathrm{E}+17$ & $2,2963 \mathrm{E}+18$ \\
\hline 9 & 14 & $3,2179 \mathrm{E}+14$ & $3,7831 \mathrm{E}+15$ & $3,5250 \mathrm{E}+16$ & $2,7750 \mathrm{E}+17$ & $1,9189 \mathrm{E}+18$ \\
\hline 9 & 15 & $5,5845 \mathrm{E}+13$ & $1,0390 \mathrm{E}+15$ & $1,3453 \mathrm{E}+16$ & $1,3684 \mathrm{E}+17$ & $1,1676 \mathrm{E}+18$ \\
\hline 9 & 16 & $3,7940 \mathrm{E}+12$ & $1,5302 \mathrm{E}+14$ & $3,1646 \mathrm{E}+15$ & $4,5089 \mathrm{E}+16$ & $5,0036 \mathrm{E}+17$ \\
\hline 9 & 17 & 0 & $8,8171 \mathrm{E}+12$ & $3,9824 \mathrm{E}+14$ & $9,1348 \mathrm{E}+15$ & $1,4305 \mathrm{E}+17$ \\
\hline 9 & 18 & 0 & 0 & $1,9633 \mathrm{E}+13$ & $9,8911 \mathrm{E}+14$ & $2,5098 \mathrm{E}+16$ \\
\hline 9 & 19 & 0 & 0 & 0 & $4,2060 \mathrm{E}+13$ & $2,3541 \mathrm{E}+15$ \\
\hline 9 & 20 & 0 & 0 & 0 & 0 & $8,7009 \mathrm{E}+13$ \\
\hline 10 & 10 & $2,8082 \mathrm{E}+15$ & $1,5313 \mathrm{E}+16$ & $7,6194 \mathrm{E}+16$ & $3,5096 \mathrm{E}+17$ & $1,5112 \mathrm{E}+18$ \\
\hline 10 & 11 & $2,5076 \mathrm{E}+15$ & $1,6514 \mathrm{E}+16$ & $9,7033 \mathrm{E}+16$ & $5,2015 \mathrm{E}+17$ & $2,5824 \mathrm{E}+18$ \\
\hline 10 & 12 & $1,5226 \mathrm{E}+15$ & $1,2570 \mathrm{E}+16$ & $8,9142 \mathrm{E}+16$ & $5,6264 \mathrm{E}+17$ & $3,2345 \mathrm{E}+18$ \\
\hline 10 & 13 & $5,9070 \mathrm{E}+14$ & $6,5506 \mathrm{E}+15$ & $5,8464 \mathrm{E}+16$ & $4,4611 \mathrm{E}+17$ & $3,0190 \mathrm{E}+18$ \\
\hline 10 & 14 & $1,2826 \mathrm{E}+14$ & $2,1783 \mathrm{E}+15$ & $2,6315 \mathrm{E}+16$ & $2,5400 \mathrm{E}+17$ & $2,0846 \mathrm{E}+18$ \\
\hline 10 & 15 & $1,1363 \mathrm{E}+13$ & $4,0312 \mathrm{E}+14$ & $7,5358 \mathrm{E}+15$ & $9,9238 \mathrm{E}+16$ & $1,0363 \mathrm{E}+18$ \\
\hline 10 & 16 & 0 & $3,0257 \mathrm{E}+13$ & $1,1947 \mathrm{E}+15$ & $2,4582 \mathrm{E}+16$ & $3,5296 \mathrm{E}+17$ \\
\hline 10 & 17 & 0 & 0 & $7,6529 \mathrm{E}+13$ & $3,3567 \mathrm{E}+15$ & $7,5951 \mathrm{E}+16$ \\
\hline 10 & 18 & 0 & 0 & 0 & $1,8482 \mathrm{E}+14$ & $8,9817 \mathrm{E}+15$ \\
\hline 10 & 19 & 0 & 0 & 0 & 0 & $4,2808 \mathrm{E}+14$ \\
\hline 11 & 11 & $1,7469 \mathrm{E}+15$ & $1,4261 \mathrm{E}+16$ & $1,0033 \mathrm{E}+17$ & $6,2983 \mathrm{E}+17$ & $3,6087 \mathrm{E}+18$ \\
\hline 11 & 12 & $7,9368 \mathrm{E}+14$ & $8,5447 \mathrm{E}+15$ & $7,4607 \mathrm{E}+16$ & $5,6017 \mathrm{E}+17$ & $3,7473 \mathrm{E}+18$ \\
\hline 11 & 13 & $2,0867 \mathrm{E}+14$ & $3,3488 \mathrm{E}+15$ & $3,8774 \mathrm{E}+16$ & $3,6246 \mathrm{E}+17$ & $2,9038 \mathrm{E}+18$ \\
\hline 11 & 14 & $2,3376 \mathrm{E}+13$ & $7,5591 \mathrm{E}+14$ & $1,3172 \mathrm{E}+16$ & $1,6437 \mathrm{E}+17$ & $1,6468 \mathrm{E}+18$ \\
\hline 11 & 15 & 0 & $7,2032 \mathrm{E}+13$ & $2,5622 \mathrm{E}+15$ & $4,8588 \mathrm{E}+16$ & $6,5453 \mathrm{E}+17$ \\
\hline 11 & 16 & 0 & 0 & $2,0875 \mathrm{E}+14$ & $8,1757 \mathrm{E}+15$ & $1,6894 \mathrm{E}+17$ \\
\hline 11 & 17 & 0 & 0 & 0 & $5,7265 \mathrm{E}+14$ & $2,4689 \mathrm{E}+16$ \\
\hline 11 & 18 & 0 & 0 & 0 & 0 & $1,4952 \mathrm{E}+15$ \\
\hline 12 & 12 & $2,4491 \mathrm{E}+14$ & $3,8558 \mathrm{E}+15$ & $4,4013 \mathrm{E}+16$ & $4,0703 \mathrm{E}+17$ & $3,2343 \mathrm{E}+18$ \\
\hline 12 & 13 & $3,3433 \mathrm{E}+13$ & $1,0296 \mathrm{E}+15$ & $1,7308 \mathrm{E}+16$ & $2,1019 \mathrm{E}+17$ & $2,0623 \mathrm{E}+18$ \\
\hline 12 & 14 & 0 & $1,2059 \mathrm{E}+14$ & $4,0130 \mathrm{E}+15$ & $7,2363 \mathrm{E}+16$ & $9,3764 \mathrm{E}+17$ \\
\hline 12 & 15 & 0 & 0 & $4,0443 \mathrm{E}+14$ & $1,4610 \mathrm{E}+16$ & $2,8356 \mathrm{E}+17$ \\
\hline 12 & 16 & 0 & 0 & 0 & $1,2712 \mathrm{E}+15$ & $4,9995 \mathrm{E}+16$ \\
\hline 12 & 17 & 0 & 0 & 0 & 0 & $3,7702 \mathrm{E}+15$ \\
\hline 13 & 13 & 0 & $1,4308 \mathrm{E}+14$ & $4,6531 \mathrm{E}+15$ & $8,2490 \mathrm{E}+16$ & $1,0550 \mathrm{E}+18$ \\
\hline 13 & 14 & 0 & 0 & $5,6168 \mathrm{E}+14$ & $1,9453 \mathrm{E}+16$ & $3,6567 \mathrm{E}+17$ \\
\hline 13 & 15 & 0 & 0 & 0 & $2,0430 \mathrm{E}+15$ & $7,5819 \mathrm{E}+16$ \\
\hline 13 & 16 & 0 & 0 & 0 & 0 & $6,9428 \mathrm{E}+15$ \\
\hline 14 & 14 & 0 & 0 & 0 & $2,3916 \mathrm{E}+15$ & $8,7005 \mathrm{E}+16$ \\
\hline 14 & 15 & 0 & 0 & 0 & 0 & $9,4050 \mathrm{E}+15$ \\
\hline
\end{tabular}




\section{Referências Bibliográficas}

[1] Fernández R., Ferrari P. A. and Garcia N. L. Measures on contour, polymer or animal models. A probabilistic approach. Markov Processes and Related Fields, 4:479-497, 1998.

[2] Fernández R., Ferrari P. A. and Garcia N. L. Loss network representation of Peierls contours. Ann. Probab., 29(2):902-937, 2001.

[3] Fernández R., Ferrari P. A and Garcia N. L. Perfect simulation for interacting point processes, loss networks and Ising models. Stoch. Process. Appl., 102(1):63-68, 2002.

[4] Fill J. A. An interruptible algorithm for exact sampling via Markov Chains. The Annals of Applied Probability, 8:131-162, 1998.

[5] Guttmann A. Enumerations in statistical mechanics and combinatorics. Computing in Science and Emgineering, pages 42-47, 2001.

[6] Kloczkowski A. and Jernigan R.L. Transfer matrix method for enumeration and generation of compact self-avoiding walks. I. Square lattices. Journal of Chemical Physics, 109(12):5134-5146, 1998.

[7] Derrida B. J. Phys. A, 14:L5, 1981.

[8] Gaunt D.S. Guttmann A.J. Leask J.L. Owczarek A. L. Whittington S.G. Bennett-Wood D., Enting I. G. Exact enumeration study of free energies of interacting polygons and walks in two dimensions. J. Phys. A: Math. Gen., 31:4725-4741, 1998.

[9] M. Bousquet-Mélou and Guttmann A. Three-dimensional convex polygons. Phys. Rev. E Rapid Communications, 55:R6323-R6326, 1997. 
[10] Borgs C. Polymers, contours, and their applications in discrete mathematics Preliminary version. February 2004.

[11] Poulalhon D. and Schaeffer G. Counting, coding and sampling with words. 2003. Preliminary version of a chapter for Lothaire's third volume, Applied Combinatorics on Words, in preparation.

[12] Rechnitzer A. D. Some problems in the counting of lattice animals, polyominoes, polygons and walks. PhD thesis, Department of Mathematics and Statistics The University of Melbourne, Parkville Victoria 3010 Australia, 2000.

[13] Sokal A. D. Monte Carlo Methods for the Self-Avoiding Walk. Monte Carlo and Molecular Dynamics Simulations in Polymer Science. Oxford University Press, 1995. (hep-lat/9405016).

[14] Zeilberger D. The umbral transfer-matrix method - IV counting self-avoiding polygons and walks. Elec. J. Comb., 8(1):R28, 2001.

[15] Knuth D. E. Polynum and polyslave. Program avaiable from knuth's homepage http://www-cs-faculty.stanford.edu/ knuth/. 2001.

[16] Enting I. G. Generating functions for self-avoiding rings. J. Phys. A: Math. Gen., 13:3713-3722, 1980.

[17] Propp J. G. and Wilson D. B. Exact sampling with coupled Markov chains and applications to statistical mechanics. Proceedings of the Seventh International Conference on Random Structures and Algorithms (Atlanta,GA), 9:223-252, 1995.

[18] Swendsen R. H. and Wang J. S. Non-universal critical dynamics in Monte-Carlo simulations. Physical Review Letters, 58:86-88, 1987.

[19] Thorisson H. Coupling, Stationarity, and Regeneration. Probability and its Applications. Springer-Verlag New York NY, 2000.

[20] Jensen I. Enumerations of lattice animals and trees. J. Stat. Phys., 102(3/4):865-881, 2001.

[21] Jensen I. A parallel algorithm for the enumeration of self-avoiding polygons on the square lattice. Phys. A, 34:5731-45, 2003. 
[22] Jensen I. and Guttmann A.J. Self-avoiding polygons on the square lattice. $J$. Phys. A: Math. Gen., 32:4867-4876, 1999.

[23] Jensen I. and Guttmann A. J. Self-avoiding polygon on the square, 1 and manhattan lattices. Phys. A: Math. Gen., 18:1007-17, 1985.

[24] Gessel I.M. On the number of convex polyominoes. Ann. Sci. Math. Québec., 24(1):63-66, 2000.

[25] Klein D. J. J. Stat. Phys., 23:561, 1980.

[26] Dobrushin R. L. Perturbation methods of the theory of Gibbsian fields. In P. Bernard, editor, Lectures on Probability Theory and Statistics - Ecole d'Eté de Probabilités de Saint-Flour XXIV-1994, Lectures Notes in Mathematics 1648, pages 1-66. Springer-Verlag Berlin Heidelberg, 1996.

[27] Onsager L. Crystal statistics I. a two-dimensional model with an order-disorder transition. Phys. Rev., 65:117-149, 1944.

[28] Jerrum M. and Sinclair A. Polynomial-time approximation algorithms for the Ising model. SIAM Journal on Computing, 22:1087-1116, 1993.

[29] Lal M. Monte Carlo computer simulations of chains molecules i. Molec. Phys., 17:57-64, 1996.

[30] N., Rosenbluth A.W., Rosenbluth M.N., Teller A. H. Metropolis and Teller E. Equation of state calculation by fast computing machines. Journal of Chemical Physics., 21:1087-1092, 1953.

[31] Madras N. and Sokal A. D. The pivot algorithm: a highly efficient Monte Carlo method for the self-avoiding walk. J. Stat. Phys., 50:109-186, 1988.

[32] Kelly F. P. Loss networks. Ann. Appl. Probab., 1(3):319-378, 1991.

[33] Fernández R. Contour ensembles and the description of Gibbsian probability distributions at low temperature. 1997. Notes for a minicourse given at the 21 Colóquio Brasileiro de Matemática, IMPA, Rio de Janeiro, July 21-25.

[34] Hite G. E. Schmalz T. G. and Klein D. J. Compact self-avoiding circuits on two-dimensional lattices. J. Phys. A: Math. Gen., 17:445-453, 1984. 
[35] Gore V. and Jerum M. R. The Swendsen-Wang process does not always mix rapidly. Proceedings of the 29th Annual ACM Symposium on Theory of Computing, pages 674-681, 1997.

[36] Li S. Z. Markov Random Field - Modeling in Computer Vision. Springer-Verlag, november 1995. 